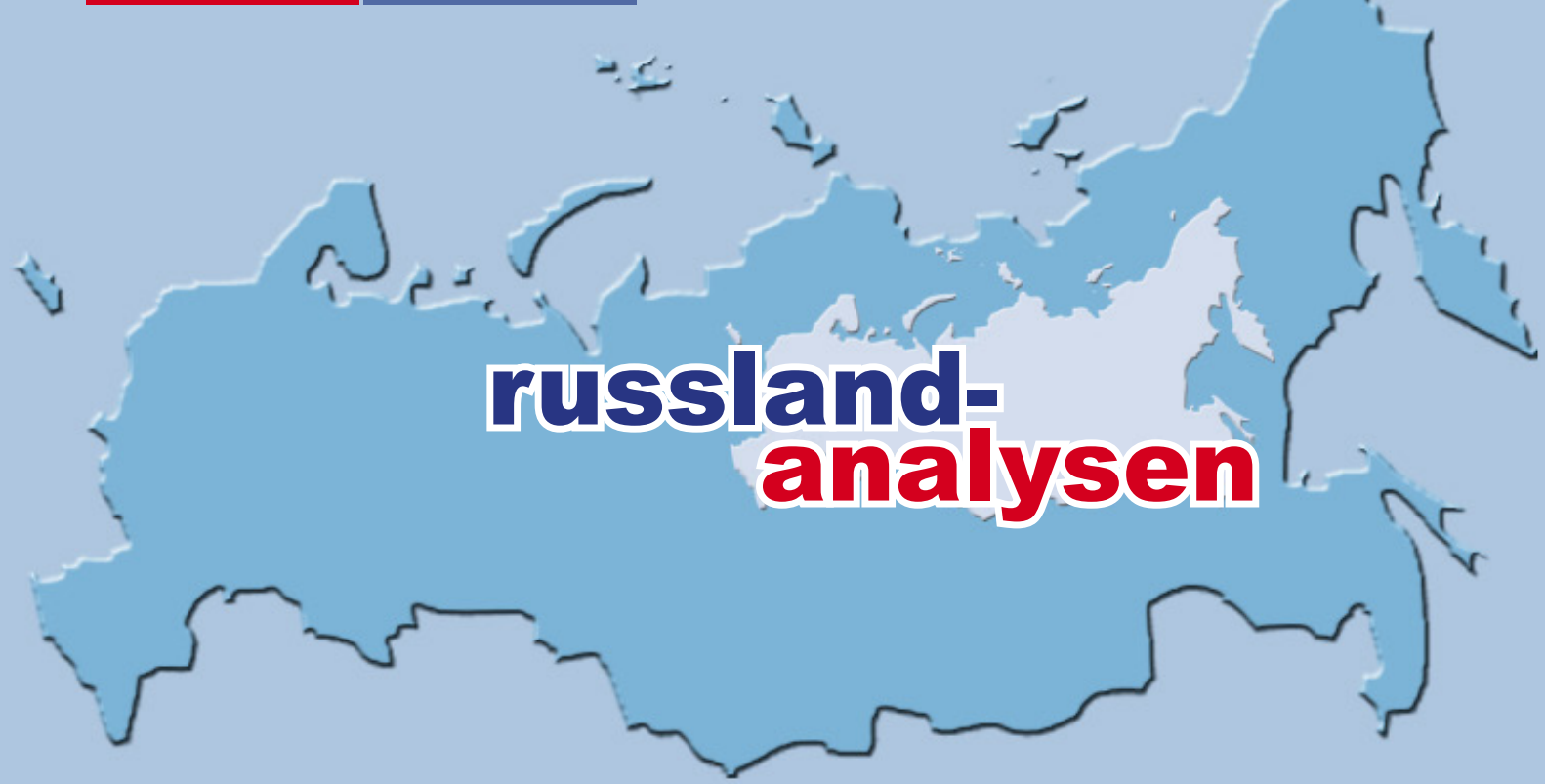

\title{
http://www.laender-analysen.de/russland/
}

\section{RUSSLANDS WIRTSCHAFT}

ANALYSE

Zwei Jahre Wirtschaftskrise: Zögerliche Erholung, alte Rezepte und "Stagnationsmarketing"

Gunter Deuber und Andreas Schwabe, Wien

STATISTIK

Russland: Wichtige Wirtschaftsindikatoren und Prognosen

- ANALYSE

Anzeichen für positive Veränderungen

Andrei Yakovlev, Moskau

aNALYSE

Unmittelbare und mittelbare Folgen der Wirtschaftssanktionen zwischen der EU und Russland auf Produktion und Beschäftigung in Deutschland

Jutta Günther, Bremen, Maria Kristalova, Bremen, Udo Ludwig, Leipzig

UMFRAGE

Wahrnehmung der Wirtschaftskrise und ihrer Auswirkungen

Einschätzung des Einflusses der Sanktionen auf die Wirtschaftskrise

\section{AUS RUSSISCHEN BLOGS}

Ein Trumpolin für neue Beziehungen zwischen den USA und Russland?

Sergey Medvedev, Berlin/Moskau

\section{NOTIZEN AUS MOSKAU}

Lebt in Russland ein »russländisches Volk»?

Jens Siegert, Moskau

\section{CHRONIK}

3. - 17. November 2016 


\section{Zwei Jahre Wirtschaftskrise: Zögerliche Erholung, alte Rezepte und "Stagnationsmarketing"}

Gunter Deuber und Andreas Schwabe, Wien

\section{Zusammenfassung}

Russlands Wirtschaft erholt sich bedächtig und auf vertrauten Grundlagen, also vor allem auf den Rohstoffsektor gestützt. Die Wirtschaftspolitik folgt langen Entwicklungslinien: orthodoxe Budget- und Geldpolitik zur Wahrung staatlicher Handlungsspielräume, Konzentration von Wirtschaftsmacht bei Beibehaltung einer ansehnlichen internationalen Einbettung und Orientierung nach Asien. Insgesamt gibt es wenig Anzeichen, dass wirtschaftspolitische Neuerungen oder eine umfassende Wirtschaftsstimulierung anstehen. Der jetzige Politikmix mündet wohl in einer Stagnation. Die sich abzeichnende Gesamtkonstellation kann länger bestimmend sein und muss nicht per se radikale (wirtschafts-)politische Gegenbewegungen auslösen. Angesichts negativer Einkommenserwartungen der Haushalte liegt es indes nahe, durch "Stagnationsmarketing« die Stimmung nicht abgleiten zu lassen bzw. Anzeichen des wirtschaftlichen Niedergangs zu kaschieren.

\section{Die Vorkrisen-Niveaus von BIP und Einkommen sind erst wieder 2019 bis 2020 erreichbar}

Russland kommt nach und nach aus der Wirtschaftskrise. Der Konsum stabilisiert sich bzw. hat bei leicht steigenden Reallöhnen wohl die Talsohle durchschritten. Stimmungsumfragen deuten eine moderate Besserung an, die Industrie schwächelt aber, abgesehen vom Rohstoffsektor. Trotz Rubelabwertung und Importsubstitutionsstrategie weisen nur wenige Industriebranchen Zuwachs auf. Die chemische Industrie, die Nahrungsmittelindustrie und einige Branchen der Leichtindustrie können auch im aktuellen Umfeld zulegen, während vor allem der Transportmittel- und Maschinenbau, die Elektronikbranche und die Metallurgie heftige Rückgänge verzeichnen. Das Bruttoinlandsprodukt (BIP) wird - trotz Stabilisierung im zweiten Halbjahr 2016 heuer das zweite Jahr in Folge sinken. Die Rezession verflacht aber heuer mit einem BIP-Rückgang um ca. 0,5 Prozent (BIP Rückgang 2015 - 3,7 Prozent). Der rechnerische Abschwächungseffekt impliziert aber keinen dynamischen Zuwachs. Anlageinvestitionen und private Haushaltsnachfrage werden 2016 abermals spürbar um ca. 3-4 Prozent fallen. Das Vorjahr dazugerechnet, liegt der Nachfrageeinbruch russischer Haushalte bei 12-13 Prozent.

Relevante Prognostiker gehen nach 2016 nur von einer verhaltenen Besserung aus. BIP-Zuwachsraten um 1 Prozent sind offenbar die "neue alte Realität«. Solche "Zuwachsraten« prägten schon die Jahre 2013/2014 oder die ökonomisch erlahmende Sowjetunion der 1980er Jahre, mit einem aufgrund historischer Quellen geschätzten jährlichen BIP-Wachstum von ca. 1,2 Prozent. Es wird Jahre dauern, bis Konsumausgaben oder Einkommen mutmaßlich wieder Vorkrisenniveaus erreichen. Gemäß plausiblen Annahmen könnte das reale BIP bis 2019 wieder auf dem Niveau von 2014 liegen. In Fremdwährung bemessen, könnte das Wiedererlangen von Vorkrisenniveaus beim BIP und beim Pro-Kopf-BIP (mit den Gipfelpunkten 2012 bzw. 2013) gar bis 2020 bzw. 2021 auf sich warten lassen - ohne tiefe Krise. Angesichts des jüngsten Einbruchs haben vor allem private Haushalte sehr negative Erwartungen zur zukünftigen Einkommensentwicklung, noch negativere als Firmen. Letztere haben sich rascher der "Stagnationsrealität« angepasst. Für ein Wachstum deutlich über 1-2 Prozent bräuchte es gemäß einer ÖkonomenUmfrage - bei gleichbleibenden Rahmenbedingungen einen derzeit kaum vorstellbar hohen Ölpreis von rund 70 US-Dollar. Es fehlt eine ölpreisunabhängige Wachstumsperspektive und angesichts des Stagnationsausblicks wird sich die Tendenz des sinkenden weltwirtschaftlichen Gewichts Russlands fortsetzten, mit einem Rückgang von fast 4 Prozent Anteil am Welt-BIP (2008) auf knapp unter 3 Prozent am Ende dieser Dekade; das ist ein niedrigerer Wert als 1998.

Die aktuelle Erholung verläuft - trotz Rubelabwertung - schleppender, als es empirische Ländervergleiche nahelegen. Eine Studie des Internationalen Währungsfonds (IWF) zeigt, dass vor allem Exporteure außerhalb des Rohstoffsektors kaum von der realen Abwertung profitieren, und sie sieht die Gründe hierfür in institutionellen Mängeln im Geschäftsumfeld bzw. in starren Wirtschaftsstrukturen. Trotz schwacher Wirtschaftsdynamik gibt sich die politische Elite derzeit aber einem "Erholungsmantra" hin und betont: Die härteste Zeit ist (vorerst) überwunden. Oft wird der Bezug zu einer vermeintlichen Weltwirtschaftskrise hergestellt. Weltwirtschaft und -handel entwickeln sich historisch schwach, doch ist das massiv schlechtere Abschneiden Russlands, vor allem gegenüber Vergleichsländern, dennoch eklatant. Zudem sind über 
die prominente und durchaus öffentlichkeitswirksame Betonung der aktuellen Stabilisierung hinaus keine Reformansätze erkennbar. An ausgearbeiteten (teils liberal-marktwirtschaftlich orientierten) Entwürfen, etwa der "Strategie 2020«, an der 1000 führende Experten arbeiteten, mangelt es nicht. Es hakt an der Implementierung bzw. Reform- und Veränderungsbereitschaft in der praktischen Wirtschaftspolitik. Daher dürften auch von wahrscheinlich in 2017 oder 2018 vorgestellten weiteren Modernisierungspapieren nicht zu viele Impulse ausgehen. Die Stabilisierung der Rohstoffpreise hat die Planbarkeit wieder erhöht; Reformdebatten unter Entscheidungsträgern finden in Russland vor allem bei hoher Ölpreisunsicherheit statt. Andererseits verwehrt man sich klar einer Rückwärtsgewandtheit. Radikale Politikideen etlicher heimischer Ökonomen, etwa des selbsternannten "Stolypin-Klubs«, wie aggressiv-expansive Geldpolitik, mehr Staatsschulden, Abschottung vom Ausland beim Handel und bei Finanztranskationen, radikal-prohibitive Besteuerung Vermögender oder mehr Subventionierung finden keinen Eingang in die Praxis.

\section{Geld- und Währungspolitik: Orthodoxie überwiegt}

Die russische Notenbank hat bis dato mit einer restriktiven Geldpolitik und der strikten Konzentration auf Inflationsbekämpfung überrascht. Jüngste Ausführungen zur weiter angedachten Geldpolitik bestätigen, dass dieser Kurs fortbestehen wird bzw. ein nachdrücklich positiver Realzins (ein Leitzins deutlich über der Inflationsrate) von 2-3 Prozent angepeilt wird. Die Notenbank will keine Stimulierung durch Schulden bzw. massive Kreditvergabe oder (Überraschungs-)Inflation. Sie sieht Russlands Wirtschaft in einem neuen »Niedrigwachstumsgleichgewicht« angelangt. Im Gegensatz zur Periode von 2001 bis etwa 2014 wird "nur" einstelliges Kreditwachstum, leicht aber nicht deutlich über dem nominalen BIP-Wachstum, erstrebt. Für ihren eher restriktiven Kurs bekommt die Notenbank prinzipiell politischen Beistand. Teure Stabilisierungsmaßnahmen bei staatlichen Großbanken und Aufräummaßnahmen im Bankensektor haben vorgeführt, dass ein heftiger und spekulativer Schuldenanstieg (wie in der letzten Dekade) mit Nachteilen verbunden ist und staatliche Ressourcen auffressen kann. Daher gibt es auch politischen Beistand für aktuelle Aufräummaßnahmen im Bankensektor. Zumal dadurch Agenden wie De-Offshoring (bzw. weniger Kapitalfluss ins Ausland) oder Kontrolle von Finanz- bzw. Eigentumsverhältnissen flankiert werden und staatliche bzw. staatsnahe Banken Marktanteile gewinnen. Obendrein gilt Russlands Finanzsektor dadurch weniger als Risikofaktor, auch bei internationalen Akteuren. Gerne wird öffentlichkeitswirksam vor allem auf die abfallende Inflation verwiesen, und auf die Aussicht auf historisch niedrige Preissteigerungsraten als wirtschaftspolitische Errungenschaft - auch mit Blick auf die breite Bevölkerung. Eine nachhaltig niedrige und wenig volatile Inflation ist zwar gesamtwirtschaftlich positiv, aber im Kontext einer eher restriktiven Geldpolitik (alleine) nicht hinreichend, um Wachstumsimpulse zu generieren. Zudem sind in einer de facto stagnierenden Ökonomie Preissteigerungsraten um 4-5 Prozent noch beträchtlich, und es ist unklar, wieviel realer Wohlstandsgewinn in einem Stagnationsumfeld mit solchen Preissteigerungsraten möglich ist.

Der Wechselkurs erholte sich, zum Teil gestützt durch die Geldpolitik, die Rubel-Veranlagungen interessant macht, und stieg auf fundamental gerechtfertigte Niveaus. Dieser Trend deutet aber im Lichte analoger Preisentwicklungen bei anderen Rohstoffwährungen bzw. dem Ölpreistrend nicht per se auf eine intrinsische Rubelstärke hin. Dennoch ist unverkennbar: Bis dato wird keine Politik des »schwachen Rubels«, die etwa gewisse exportorientierte Branchen oder das föderale Budget unterstützen könnte, verfolgt. Auch der rubelschwächende (Notenbank-)Plan, die Devisenreserven eine zentrale Komponente im Politikkalkül - in Phasen der Währungsstärke über Rubelverkäufe (also Dollarkäufe) aufzustocken, wird bis dato nicht konsequent umgesetzt. Jüngste moderate Anstiege der Devisenreserven sind auf die Rückführung von Devisen-Swaps mit Banken und auf Bewertungseffekte zurückzuführen. Die marktgetriebene Rubel-Aufwertung wurde toleriert, weil die Notenbank das Versprechen eines frei schwankenden Rubels glaubhaft machen will und so zugleich breitenwirksam Stabilisierung signalisiert wird. Dennoch könnte eine weiterhin schleppende Erholung bei starkem Rubel und bei nachhaltiger Stabilität am Ölmarkt - eine moderate Währungsschwächung wieder (politisch) attraktiver erscheinen lassen. Die Notenbank selber sieht die substanziellen gesamtwirtschaftlichen Risiken eines zu starken Rubels auch, und die Politik hat sich in den letzten Monaten durchaus aktiv in die Geld- und Währungspolitik eingemischt. Letztendlich könnte ein schwächerer Rubel opportun sein, da so ein zu schnelles Importwachstum verhindert bzw. die Importsubstitution unterstützt wird. Dies wäre jedoch zum Vorteil einzelner Produzenten und zum Nachteil der meisten russischen Verbraucher. Wobei vom aktuellen Niveau aus ein moderat schwächerer RubelAußenwert selbst keine Wachstumsimpulse liefern kann. Die gilt vor allem angesichts schwacher gesamtwirtschaftlicher Effekte durch die reale Abwertung der letzten Jahre. 


\section{Fiskalpolitik, orthodoxer Politikmix und Besinnung auf »alte Stärken"}

Wie in der Geldpolitik überwiegt in der Fiskalpolitik eine restriktive Einstellung. Teils war die Fiskalpolitik in Vorwahlzeiten - auch wenn es die eher unbedeutenden Duma-Wahlen waren - restriktiver als erwartet. Mittelfristig gibt es ambitionierte Ziele zur Rückführung des (föderalen) Haushaltsdefizits in den Jahren 2017 bis 2019. Das "föderale« Defizit, also das des Zentralstaates ohne Regionen, soll von ca. 3,7 Prozent des BIP (2016) sukzessive auf 1,2 Prozent in 2019 reduziert werden. Schon 2017 soll es nur noch 3,2 Prozent betragen. Die Konsolidierung soll durch ein nominales Einfrieren der Ausgaben (auch der Einkommen Staatsbediensteter) erreicht werden, was in den kommenden Jahren real Ausgabenkürzungen (unter Berücksichtigung der Inflation) von ca. 4 Prozentpunkten des BIP entspricht. Dennoch versucht die Budgetplanung die "soziale Ausrichtung" des Haushalts aufrechtzuerhalten. Im Jahre 2016 ging die reale Kaufkraft der Pensionen bei einer Rentenerhöhung von nur 4 Prozent (d. h. unterhalb der Inflationsrate) zurück. Auch eine Einmalzahlung von 5000 RUB (etwa 70 Euro) zu Beginn 2017 ändert dies nicht. Falls die Inflation jedoch niedrig bleiben sollte und dies ist offenbar ein politisches Oberziel, könnte im Haushalt genug Spielraum sein, um reale Kaufkraftverluste der Renten in den kommenden Jahren weitgehend zu verhindern. Die Haushaltsplanung der kommenden Jahre basiert auf konservativen Ölpreisannahmen, das heißt: Steuereinahmen aus dem Öl- und Gasbereich werden mit einem mittleren Ölpreis von 40 US-Dollar kalkuliert. Die Rückkehr zu einer dreijährigen Budgetplanung - die in der aktuellen Krise ausgesetzt wurde - soll in den kommenden Jahren wieder erhöhte Handlungsfähigkeit und Stabilitätsorientierung anzeigen. Die Defizitfinanzierung wird nach dem Aufbrauchen des Reservefonds ab 2017 stärker auf die Aufnahme von Inlands- und partiell Auslandsschulden umgestellt. Diese Kapitalmarktfinanzierung sollte angesichts aktueller Finanzmarkttrends und einer stabilitätsorientierten Wirtschaftspolitik (die Zahlungsfähigkeit und -willigkeit signalisiert) reibungslos verlaufen.

Wie viel Mittel durch Privatisierungen und aus dem zweiten Regierungsfonds aufgebracht werden müssen, ist noch unklar. Bislang spielen Privatisierungen (über die 2016 intendierte Rosneft-Teilprivatisierung hinaus) eine untergeordnete Rolle in der Finanzplanung. Bis dato sieht die Haushaltsplanung begrenzte Einnahmesteigerungen (v. a. höhere Steuerzahlungen im Nicht-Rohstoffsektors, aber auch steuerliche Adjustierungen im Rohstoffsektor, Privatisierungserlöse und höhere Dividenden von Staatsfirmen) vor. Die fiskalische Ausrichtung impliziert, dass die Staatschuldenquote mittelfristig eher stabil bleiben oder nur leicht ansteigen soll. Diese Zielsetzung erfordert angesichts schrumpfender Spielräume einen weiteren Rückbau staatlicher Leistungen bzw. der Zielkonflikt aus niedriger Besteuerung und in Relation dazu hohen Ausgaben wird eher durch sinkende Staatsausgaben gelöst. Gemäß plausiblen Mittelfrist-Projektionen wird der Anteil der Staatseinnahmen und -ausgaben graduell in Richtung 30 Prozent des BIP absinken. So wird sich Russland von einer Staatsaktivität in Relation zum BIP, die über dem Niveau anderer größerer (aufstrebender) Länder liegt, auf ein Niveau ähnlich dem in vergleichbaren aufstrebenden außereuropäischen Ökonomien (wie China, weiteren aufstrebenden asiatischen Ländern oder Südafrika) annähern. Für den Sparkurs bestehen Risiken, etwa, wenn im Vorfeld der Präsidentenwahl 2018 eine (temporär) weichere Konsolidierung erfolgt. Prinzipiell scheint die Bewahrung staatlicher Handlungsspielräume aber ein wirtschaftspolitisches Oberziel zu sein.

Eine restriktive Fiskalpolitik ohne Reformen wirkt im aktuellen Umfeld nicht wachstumsfördernd; relevanten Akteuren in Zentralbank, Finanz- und Wirtschaftsministerium ist klar, dass dadurch das (Potential-)Wachstum unter 2 Prozent liegt. In anderen Teilen der politischen Elite besteht aber durchaus die Hoffnung, dass Faktoren wie Stabilität bei Staatsschulden oder Wechselkurs, (wirtschafts-)politische Kontinuität sowie das "Reformtuning" der letzten Jahre (z. B. Verbesserung in Wettbewerbsrankings wie dem »Doing Business Index« der Weltbank) in höherem Wachstum münden. Allerdings sollte nicht zu viel Rückenwind erwartet werden. Es handelt sich um weniger deutliche (Stabilitäts-)Verbesserungen als in früheren Phasen der Präsidentschaft Putins. Auch im »Standortmarketing" gegenüber internationalen Investoren werden derzeit vor allem traditionelle Aspekte (z. B. wirtschaftspolitische Kontinuität, absolute Marktgröße) bewusst betont, aber kaum neue Ansätze angeführt.

\section{Rückgang der internationalen Integration bei pragmatischer und selektiver Fortsetzung}

Außenwirtschaftlich ist Russland in einem neuen Gleichgewicht angekommen. Die Währungsreserven haben sich dank des frei schwankenden Rubels und Sondereffekten moderat erhöht. Die Abdeckungsquote der Außenschulden durch Devisenreserven ist damit auch in Kombination mit der Rückführung der Auslandsschulden vom Tief bei 65 Prozent auf 75 Prozent gestiegen - den höchsten Wert seit drei Jahren. Der Private Nettokapitalabfluss bzw. die sogenannte »Kapitalflucht « sind fast gestoppt: In den ersten drei Quartalen 2016 flossen nur 10 Milliarden Dollar ab, im Vorjahres- 
zeitraum waren es 50 Milliarden (im Gesamtjahr 2014: ca. 150 Milliarden USD). Russische Marktakteure bringen weniger Kapital ins Ausland bzw. halten weniger Fremdwährung, während sich der Auslandsschuldenabbau verlangsamt. Zudem gibt es erste positive Signale im Warenhandel. Im Gleichklang mit Ölpreis und Rubel erholen sich Importe und Exporte. Der Importwert (in US-Dollar) des dritten Quartals 2016 überstieg den Wert des Vorjahres um 5 Prozent. Der Exportwert hinkt noch hinterher bzw. schrumpfte unlängst noch um 10 Prozent gegenüber dem Vorjahr. Doch auch hier wurde der Tiefpunkt überwunden. Allerdings liegen die Außenhandelswerte insgesamt drastisch unter denen der Jahre 2011 bis 2014. Die jährlichen Exporte halbierten sich auf 270-280 Milliarden Dollar, die Importe fielen um 45 Prozent auf unter 200 Milliarden US-Dollar ab. Eine Rückkehr auf Vorkrisen-Niveaus ist angesichts des Wirtschaftsausblicks unrealistisch. Zudem hat sich die Rohstoff-Abhängigkeit nur leicht reduziert - der Exportanteil von Öl und Gas fiel von 67 Prozent in 2013 auf zuletzt 55 Prozent. Ferner ist der traditionell hohe Handels- und Leistungsbilanzüberschuss gesunken. Dies könnte sich im Falle neuerlicher starker Kapitalabflüsse als problematisch erweisen, nämlich eine weitere Rubelschwächung oder Notenbankeingriffe erfordern - damit besteht ein Anreiz für eine weiter stabilitätsorientierte Wirtschaftspolitik.

Die propagierte außenwirtschaftliche Ausrichtung gen Osten - insbesondere nach China - macht unter den Parametern niedrigerer Ölpreis und verschlechterte Wirtschaftsbeziehungen mit dem Westen graduelle Fortschritte. Dieser Prozess ist zwar schon längerer angelegt, hat sich zuletzt aber beschleunigt. So erhöhte sich der China-Anteil im Export in den letzten zehn Jahren um 4,5 Prozentpunkte (auf ca. 10 Prozent), während sich der China-Anteil bei den russischen Importen im gleichen Zeitraum auf ca. 20 Prozent verdoppelte. Damit liegt China zwar weit hinter der EU, welche in den ersten acht Monaten 2016 mit 46 Prozent der Exporte und knapp 40 Prozent der Importe der zentrale Handelspartner ist. Jedoch sind die EU-Außenhandelsanteile in den letzten 10 Jahren merklich gesunken, im Export um 12, bei den Importen um 6 Prozentpunkte. Zudem konzentrierten sich rund die Hälfte der relativen Abnahme mit der EU sowie die Hälfte der Zunahme im ChinaHandel auf die letzten drei Jahre. Allerdings entfallen noch immer 60 Prozent des Handelsüberschusses auf den EU-Handel, während mit China moderate Handelsdefizite eingefahren werden und insgesamt von der graduellen Handelsumlenkung selbst - bei eher schwachen Ausländischen Direktinvestitionen (ADI) - kaum Wachstumsimpulse ausgehen. Die Verflechtung Russlands mit der EU über ADI bleibt im Vergleich zu China hoch, während der ADI-Zufluss aus China sehr zögerlich ist. Trotz eines Rückgangs des ADI-Bestandes der EU (v. a. durch Positionsveränderungen an Standorten wie Zypern) beträgt das ADI-Volumen der EU in Russland immer noch ca. 150 Milliarden US-Dollar (gegenüber zuvor 250-270 Milliarden), während die ADI aus China (je nach Quelle und Zurechnungsmethode) im Bereich von 2-3 bis maximal 30 Milliarden US-Dollar liegen (genauso viel hat China in Kasachstan investiert).

Importe, Auslandsinvestitionen und Auslandsschulden sind aufgrund der Wirtschaftskrise, der limitierten Investitionsoptionen (vor Ort und international) sowie der beidseitigen Sanktionen gesunken. Der damit einhergehende Rückgang an internationaler Vernetzung ist durchaus breit angelegt; es haben sich dadurch seit Jahren bestehende Trends verstärkt. Laut internationalen Statistiken ist der Wert der ADI in Russland bzw. die Zahl von ADI-Neuprojekten mit Russlandbezug deutlich abgefallen. Der Rückgang ist stärker als der globale Trend. Bei teils noch verfolgten ADI-Projekten (aus Russland heraus bzw. russischer Firmen) ist eine Fokussierung auf traditionelle oder neue "Verbündete» erkennbar (etwa Indien, China), wobei der Rückgang der Absolutsummen hier insgesamt auch mit De-Offshoring-Agenden in Verbindung steht. Bei der Integration in das globale Finanzsystem sind Rückgänge erkennbar, teils stärker als bei globalen Trends bzw. in Vergleichsländern. Grenzüberschreitende Bankfinanzierungen nach Russland sind stärker gefallen, als es Trends bei Kenngrößen wie Handelsvolumina oder Außenschulden oder Entwicklungen in Vergleichsländern nahelegen. Auch auf dem russischen Bankenmarkt hat sich der Auslandsanteil an den Gesamtaktiva merklich verringert (von knapp über 10 Prozent in 2008 auf ca. 6 Prozent in 2016), auf dem russischen Interbankenmarkt hat sich der Anteil westlicher Auslandsbanken auf etwas höheren Niveaus halbiert (von 42 Prozent auf 23 Prozent). Auch bei internationalen Kapitalmarktfinanzierungen haben russische Firmen und Banken weniger Volumina platziert als Vergleichsländer und weniger auf Fremdwährungsfinanzierung gesetzt. Der Rückgang an internationaler Integration bzw. Verknüpfung ist eine schwierig zu bewertende Entwicklung. Es scheint, dass durch weniger Konnektivität bzw. geringere Wirtschafts- und Finanzmarktintegration geopolitischen Spielraum geschaffen wird. Allerdings sind gewisse Rückgänge bereits länger angelegt, liegen in Teilbereichen partiell auch noch im Bereich internationaler Trends (wie zum Teil bei grenzüberschreitenden Bankfinanzierungen) und erscheinen angesichts von Wirtschaftslage, Sanktionen und Stagnationsausblick ökonomisch rational. Das gilt insbesondere angesichts von früher (v. a. bis 2008/2009) sehr viel spekulativer Schuldenaufnahme in Russland, wobei jetzt 
andere aufstrebende Ökonomien in den letzten Jahren frühere Verfehlungen Russlands wiederholt haben. Insofern spielt Russland bei einigen Kenngrößen der Integration in das globale Finanzsystem derzeit eher "nur" auf dem Niveau seiner "wirklichen" wirtschaftlichen Größe und nicht unverkennbar darüber, wie zum Teil in der Vergangenheit. Zudem ist der Integrationsgrad von Russlands Wirtschaft gemäß einem breiten Indikatoren-Set (Handelsoffenheit, ADI, internationale Bankenund Finanzmarktintegration) noch substanziell und hat sich noch nicht dramatisch reduziert. Zwar wird von einigen Akteuren die völlige Kapitalverkehrsliberalisierung vor rund zehn Jahren kritischer bewertet. Es wird aber anerkannt, dass es kein einfaches Zurück zum Status quo ante gibt. Zudem sind die absoluten Wertsummen der Auslandsverflechtungen immer noch substanziell; die Integration der Vergangenheit impliziert viel an zukünftiger Schuldenrückzahlung und (Re-)Finanzierung. Erst nach 2020 würden die Rückzahlungspositionen russischer Firmen und Banken gegenüber dem Ausland (unter der Annahme keiner Schuldenneuaufnahme) deutlich sinken. Angesichts steigender Finanzierungserfordernisse des Staates auf dem lokalen Markt erscheint damit ein Offenhalten des internationalen Marktzugangs pragmatisch rational.

Zudem hat sich angesichts der aktuellen ökonomischen Stabilisierung die internationale Kapitalmarktfähigkeit russischer (Groß-)Firmen verbessert. Es finden derzeit wieder mehr nicht unter die Sanktionen fallende Transaktionen mit Russlandbezug statt. Hier sind neben russischen Banken und selektiv chinesischen Banken auch globale Investmentbanken (darunter USGroßbanken) sowie in Russland verwurzelte europäische Auslandsbanken involviert. Zur Marktbelebung bzw. Preisfindung bei internationalen Russlandfinanzierungen hat der Staat aktiv beigetragen. Er platzierte 2016 wieder zwei großvolumige internationale Staatsanleihen, im geplanten Umfang von 3 Milliarden Dollar. Zum Teil wurden hierbei aktiv internationale Netzwerke bzw. Infrastrukturen übergangen, zum Teil wurde nach gewissen Schwierigkeiten pragmatisch auf internationale Infrastruktur zurückgegriffen. Nachdem die erste staatliche Emission ohne unmittelbare Berechtigung zum internationalen Zahlungs- bzw. Abwicklungssystem "Euroclear « zögerlich verlief, wurde in der zweiten Transaktion die für internationale Investoren wichtige Euroclear-Fähigkeit sichergestellt. So wurde auch signalisiert: Eine Komplettisolation Russlands ist trotz westlicher Sanktionen - nicht einfach durchsetzbar. Auch für 2017 sind internationale Transaktionen angekündigt. Der russische Staat könnte ausstehende Fremdwährungsanleihen zurückkaufen bzw. prolongieren und zugleich neue Wertpapiere begeben (mit einem
Gesamttransaktionswert von 7 Milliarden Dollar). Solche Summen staatlicher Emissionsvolumina gab es 2012 und 2013; unter normalen Marktbedingungen.

Angesichts der Stabilisierung in Kombination mit einer orthodoxen Wirtschaftspolitik engagieren sich zunehmend wieder mehr ausländische Akteure in russischen Staatspapieren in Rubeln. Der Auslandsanteil am OFZ-Markt (»Obligazii Federalnogo Saima«, Staatsanleihen der Zentralregierung) ist in den letzten Monaten von unter 20 Prozent auf fast 30 Prozent geklettert; ein eher hoher Wert unter relevanten Vergleichsländern bzw. in den globalen Finanzmarkt integrierten aufstrebenden Ländern (wie etwa der Türkei, Mexiko, Südafrika). Es wird deutlich, dass Russland am Finanzmarkt auf gewisse internationale Einbindung setzt und diese angenommen wird. Im Energiesektor verfolgt Russland ebenfalls weiterhin langfristig angelegte Kooperationen mit westlichen bzw. europäischen Firmen, z. B. über »NordStream II "und den möglichen Tausch von Vermögenswerten mit der österreichischen "OMV (Tausch von Gazprom-Vermögenswerten in Russland gegen OMVVermögenswerte in Westeuropa, ggfs. in Norwegen) und verweist bei Verzögerungen gerne auf politisch motivierte Blockaden von westlicher Seite.

Bei den beidseitigen Wirtschaftssanktionen (zwischen Russland und vor allem den G7-Ländern) gibt es indes keine deutlichen Entspannungssignale. Auch wenn Russland offenbar an keiner weiteren Sanktionseskalation interessiert ist und die Sanktionspolitik als Sackgasse bezeichnet, ist mit einem Sanktionsfortbestand im kommenden Jahr oder auch darüber hinaus zu rechnen. Derzeit am internationalen Finanzmarkt und teils auch in Russland selbst gehegte Hoffnungen auf ein eher rasches Ende der Sanktionspolitik unter einem neuen US-Präsident Donald Trump könnten sich als zu optimistisch erweisen. Offizielle russische Planungen gehen bis dato mehr oder weniger explizit von einem Fortbestand aus. Ein längerer Fortbestand würde Erfahrungen mit wirtschaftlichen Sanktionsregimen in anderen Kontexten entsprechen, und von russischer Seite wird gerne betont, dass die Sanktionen keinen unmittelbaren materiellen Einfluss haben oder etwa im »Foreign Investment Advisory Council« (FIAC) kein fassbares Thema seien. In der Sanktionsfrage setzt man auf russischer Seite auf Gewöhnungseffekte. Wobei die Argumentation in Bezug auf geringe unmittelbare Effekte gleichzeitig mittelbare Effekte unterschätzt und es gewisse kommunikative Widersprüche zu Ausführungen in anderen Kontexten gibt, wo den Sanktionen eine Mitverantwortung an der aktuell schwierigen Wirtschaftslage zugeschrieben wird. Insgesamt ist für ausländische Investoren nicht erkennbar, dass sich - abgesehen vom zunehmend positiven Finanzmarktsentiment - die 
Reputation Russlands als internationaler Kooperationspartner absehbar merklich erhöht. Dies führt soweit, dass in (Risiko-)Wirtschaftsszenarien des IWF (weitere) geopolitische Friktionen als plausibles Szenario mit gewisser bzw. mittlerer Eintrittswahrscheinlichkeit versehen sind.

\section{Zunehmende Konzentration, steigender Staatseinfluss, schrumpfende Mittelklasse}

Die jüngste Wirtschaftskrise führt zu steigender Konzentration. Große Firmen sind besser durch die Krise gekommen bzw. weisen bessere Finanzkennzahlen auf als kleinere Unternehmen. In der Tendenz haben Großfirmen stärker unmittelbar oder mittelbar von staatlichen Stützungsmaßnahmen profitiert. Damit zeigt sich in Schlüsselbranchen wie dem Energie- oder Bankensektor ein weiter steigender Marktanteil großer staatlicher bzw. staatsnaher Akteure. Auch bei "Privatisierungsvorhaben" spielen staatsnahe Firmen eine wichtige Rolle bzw. bedeutet Privatisierung staatsnahe Konsolidierung.

Die Effekte der gesamtwirtschaftlichen Situation auf einzelne gesellschaftliche Schichten sind ebenso zu beachten. Unter den massiven Einkommensrückgängen und der Stagnation leidet vor allem die nicht auf Transferleistungen angewiesene Mittelschicht in den Wirtschaftszentren bzw. größeren Städten. Laut repräsentativen Erhebungen (Selbsteinschätzung) und weiteren Berechnungen können derzeit nur noch 40-50 Prozent der Bevölkerung in den größeren Städten (über 100.000 Einwohner) als sogenannte Mittelschicht bezeichnet werden. Noch vor Jahren waren hier Werte knapp über 60 Prozent zu veranschlagen. Auf die Gesamtzahl der Bevölkerung bezogen ist der Mittelschichtanteil natürlich niedriger. Wobei auch hier gilt, dass die Wirtschaftskrise der letzten Jahre überwiegend Empfänger von Lohneinkommen getroffen hat. Zu letzteren gehören auch die Staatsbediensteten, die deutliche reale Einkommensverluste (noch über denen von Einkommensbeziehern in der Privatwirtschaft) hinnehmen mussten. Derzeit ist nicht absehbar inwiefern im korruptionsanfälligen Kontext Russlands eine anderweitige Kompensation für erlittene Einkommensverluste ansteht. Wobei interessanterweise in den letzten Jahren teils Regulierungen bewusst in international bzw. von der Weltbank (im "Doing Business Index") nicht beachteten Bereichen intensiviert wurden; während sie für in Weltbank-Index relevanten Bereichen reduziert wurden. Insgesamt ist die Kombination der skizzierten Markt- und Einkommenstrends für das Investitionsklima und die Stimmung unter ausländischen Investoren nicht förderlich. Letztere wollten in den letzten Jahren mehr oder weniger bewusst, mit Nischenspieler-Ansätzen, vor allem die
Kaufkraft der Mittelschicht in den Wirtschaftszentren abschöpfen. Wobei der wirtschaftliche Druck auf die Mittelschicht nicht per se (gesellschafts-)politische Veränderung impliziert; ganz wie das Entstehen oder der Aufstieg der Mittelklasse das politische System nicht wirklich und nachhaltig beeinflusste.

\section{"Stagnationsmarketing" als nachhaltige Strategie?}

Es gibt in Russland eine oberflächliche Modernisierungsbzw. Umgestaltungsrhetorik, doch solche Absichtserklärungen gibt es seit Jahren. Prinzipiell scheint das Verwalten des Bestehenden die dominante wirtschaftspolitische Strategie zu sein; in der Praxis deutet alles auf Systemstabilisierung bzw. ein Festigen des aktuellen (Wirtschafts-)Systems hin. Personelle Signale für neue wirtschaftspolitische Prioritäten gibt es nicht. Zwar findet partiell eine Erneuerung der Eliten statt, doch sind damit keine neuen (Denk-)Ansätze verbunden, es werden jetzt technokratische Verwalter etabliert. Personen, die als auffallend reformorientiert gelten, haben es schwer, weiter oder wieder an Einfluss zu gewinnen (etwa die Vorsitzende der Notenbank, Ex-Finanzminister Kudrin oder der Ministerpräsident). Unter Entscheidungsträgern wird teils auch auf wenig greifbare ökonomische Fortschritte durch die Umgestaltungen in der Endphase der Sowjetunion sowie Systemunterschiede im Vergleich zur Sowjetzeit verwiesen (etwa mehr Marktsteuerung, flexibler Wechselkurs, liberale Außenhandelsgesetzte, stabile außenwirtschaftliche Position). Es herrscht also ein gewisses Vertrauen in die Anpassungsfähigkeit bei flexiblem Rubelkurs vor, und zwar bei (wirklichen oder vermeintlich) privatwirtschaftlichen Akteuren im Umfeld des staatlich-gesteuerten Wettbewerbs. Zudem gibt es eine "Stagnationstoleranz«. Russland wird als zu weit weg von jenen kritischen Einkommensschwellen gesehen, die soziale Unruhen auslösen könnten. Damit erscheint ein Systemkollaps aus ökonomischen Gründen unwahrscheinlich bzw. man geht davon aus, die Stimmung hinreichend im Griff zu haben. Zumal in dieser Denkweise eine (erwartete) verhaltende Wirtschaftsentwicklung als einfach kontrollierbares Szenario erscheint, im Unterschied zu raschen krisenhaften (Finanzmarkt-)Entwicklungen (wie zum Jahresende 2014/2015).

Im Kontext der wirtschaftspolitischen Ausrichtung Russlands könnte auch die überraschende Verhaftung des Wirtschafsministers Uljukajew - obwohl Finanzministerium und Notenbank de facto wichtigere Akteure der Wirtschaftspolitik sind - ein nicht folgenloses Ereignis sein. Die Verhaftung könnte noch weitere Kreise ziehen und Uljukajew repräsentierte immerhin gemäßigt liberale Positionen und bewertete aktuelle Entwicklun- 
gen, inklusive des steigenden Staatseinflusses, skeptisch. Teils stellte er sich als Wirtschaftsminister gegen letzteren Trend, auch im Rahmen der Privatisierung von »Baschneft" an »Rosneft", der er jedoch schlussendlich seine Zustimmung gab. Andererseits forderte er in seiner Rolle als Wirtschaftsminister eine expansivere Geldund Fiskalpolitik, was ihn in Konflikt mit dem eigenen wirtschaftsliberalen Lager brachte. Dennoch könnte ein Abstieg Uljukajews aus den Machtzirkeln (abseits der Interpretation von zunehmenden Umverteilungskonflikten in der Elite) auch als inhaltliches Signal verstanden werden, dass nämlich liberale Ansätze und Kritiker am aktuellen wirtschaftspolitischen Kurs an Unterstützung verlieren bzw. die aktuelle wirtschaftspolitische Ausrichtung noch stärker von schwierig einschätzbaren (Eigen-) Interessen wichtiger Vetoakteure dominiert wird.

Abseits des öffentlichen Hervorstreichens der momentanen Erholung wird aber auch deutlich: Teile der (wirtschafts-)politischen Elite bereiten sich und das Land auf eine umfassendere Stagnation vor. Die Gretchenfrage ist dann: Wie können stagnierende Wirtschaftskraft und Einkommen der Bevölkerung erklärt bzw. im Kontext eines "Stagnationsmarketings" politisch verkauft werden. Ein öffentlichkeitswirksames "Stagnationsmarketing« scheint im Hinblick auf die Präsidentschafts- wahlen 2018 durchaus angezeigt. Bis dahin kann ein "Stagnationsmarketing" gewiss mit sichtbaren Themen wie Inflationsrückgang, Stabilisierung unter herausfordernden Bedingungen (inklusive Sanktionen), einem noch hohen Wohlstand - historisch und im Vergleich $\mathrm{zu}$ anderen aufstrebenden Ländern - und mit ersten Erfolgen bei der Umorientierung nach Asien befüllt werden. Im Sinne von Pfadabhängigkeiten erscheint es aber wenig wahrscheinlich, dass nach 2018 aktiv eine ökonomische Transformation angegangen wird. Langfristig, nach empirischer Erfahrung etwa 3-5 Jahre nach der ersten Stabilisierung in 2017 und 2018, könnte ein fortdauernder Wirtschaftsstillstand schroffe und womöglich irrationale (wirtschafts-)politische Änderungen begünstigen (z. B. Abschottung, weniger stabilitätsorientierte Wirtschaftspolitik mit desaströsen Folgen auf das Banken- und Finanzsystem). Wobei für eine unter gewissen (meist ausländischen) Betrachtern befürchtete radikalere Änderung zunächst die internationale Einbettung der staatlich gelenkten Wirtschaft, welche vor allem auf international agierenden Großunternehmen basiert, wohl weiter reduziert werden müsste, um das Risiko eines Systemkollaps zu verhindern. Dafür gibt es - trotz eines gewissen Rückgangs beim Integrationsgrad - aber noch keine eindeutigen Hinweise.

\section{Über die Autoren}

Gunter Deuber leitet die Abteilung Volkswirtschaft, Zinsen, Währungen bei der Raiffeisen Bank International (RBI) AG, eine der größten in Russland tätigen Auslandsbanken, in Wien.

Andreas Schwabe ist Senior Economist mit Russland- und Ukraine-Fokus bei der der RBI in Wien. Der vorliegende Beitrag gibt die Auffassung der Autoren und nicht notwendigerweise die Ansicht der RBI AG wieder.

\section{Russland: Wichtige Wirtschaftsindikatoren und Prognosen}

Tabelle 1: Russland: Wichtige Wirtschaftsindikatoren und Prognosen

\begin{tabular}{|l|c|c|c|c|c|c|c|}
\hline & 2012 & 2013 & 2014 & 2015 & $2016^{*}$ & 2017 ** & 2018** \\
$\begin{array}{l}\text { Nominelles BIP } \\
\text { (Mrd. EUR) }\end{array}$ & $1.677,1$ & $1.678,8$ & $1.526,1$ & $1.182,4$ & $1.124,8$ & $1.360,2$ & $1.444,5$ \\
$\begin{array}{l}\text { Reales BIP (\% p.a.) } \\
\begin{array}{l}\text { Industrieproduktion } \\
\text { (\% p.a.) }\end{array}\end{array}$ & 3,5 & 1,3 & 0,7 & $-3,7$ & $-0,5$ & 1,0 & 1,5 \\
$\begin{array}{l}\text { Arbeitslosenquote } \\
\text { (Durchsch., \%) }\end{array}$ & 5,5 & 0,4 & 1,7 & $-3,4$ & 0,5 & 1,0 & 2,0 \\
\hline
\end{tabular}


Tabelle 1: Russland: Wichtige Wirtschaftsindikatoren und Prognosen (Prognosen)

\begin{tabular}{|l|c|c|c|c|c|c|c|}
\hline $\begin{array}{l}\text { Durchschn. Bruttolöhne } \\
\text { (\% p.a.) }\end{array}$ & $\mathbf{2 0 1 2}$ & $\mathbf{2 0 1 3}$ & $\mathbf{2 0 1 4}$ & $\mathbf{2 0 1 5}$ & $\mathbf{2 0 1 \mathbf { 6 } ^ { * }}$ & $\mathbf{2 0 1 7 ^ { * * }}$ & $\mathbf{2 0 1 \mathbf { 8 } ^ { * * }}$ \\
$\begin{array}{l}\text { Produzentenpreise } \\
\text { (Durchschn., \% p.a.) }\end{array}$ & 5,1 & 3,7 & 5,9 & 13,0 & 9,0 & 7,5 & 6,5 \\
$\begin{array}{l}\text { Verbraucherpreise } \\
\text { (Durchschn., \% p.a.) }\end{array}$ & 5,1 & 6,8 & 7,8 & 15,6 & 7,2 & 6,1 & 5,3 \\
$\begin{array}{l}\text { Verbraucherpreise } \\
\text { (Dez., \% p.a.) }\end{array}$ & 6,6 & 6,5 & 11,4 & 12,9 & 6,0 & 5,5 & 5,5 \\
$\begin{array}{l}\text { Konsol. Budgetsaldo } \\
\text { (\% des BIP) }\end{array}$ & 0,4 & $-1,0$ & $-1,0$ & $-3,6$ & $-4,4$ & $-3,3$ & $-2,4$ \\
$\begin{array}{l}\text { Öffentliche } \\
\begin{array}{l}\text { Verschuldung } \\
\text { (\% des BIP) }\end{array}\end{array}$ & 10,5 & 11,3 & 11,5 & 12,7 & 13,5 & 14,0 & 14,5 \\
$\begin{array}{l}\text { Leistungsbilanz } \\
\text { (\% des BIP) }\end{array}$ & 3,3 & 1,5 & 3,2 & 5,0 & 2,0 & 3,9 & 4,3 \\
$\begin{array}{l}\text { Offizielle } \\
\text { Devisenreserven } \\
\text { (Mrd. EUR) }\end{array}$ & 408 & 370 & 319 & 339 & 373 & 391 & 374 \\
$\begin{array}{l}\text { Bruttoauslandsverschul- } \\
\text { dung (\% des BIP) }\end{array}$ & 29,5 & 32,7 & 29,5 & 39,3 & 39,7 & 32,2 & 26,0 \\
$\begin{array}{l}\text { EUR/RUB } \\
\text { (Jahresdurchschnitt) }\end{array}$ & 39,9 & 42,3 & 51,0 & 68,0 & 74,7 & 65,5 & 66,4 \\
$\begin{array}{l}\text { USD/RUB } \\
\text { (Jahresdurchschnitt) }\end{array}$ & 31,1 & 31,9 & 38,6 & 61,3 & 67,3 & 62,4 & 60,9 \\
\hline
\end{tabular}

* Schätzung, ** Prognose

Quelle: Nationale Quellen, Thomson Reuters, RBI/Raiffeisen RESEARCH

Grafik 1: Russland: Reales BIP (Index, 2008=100)

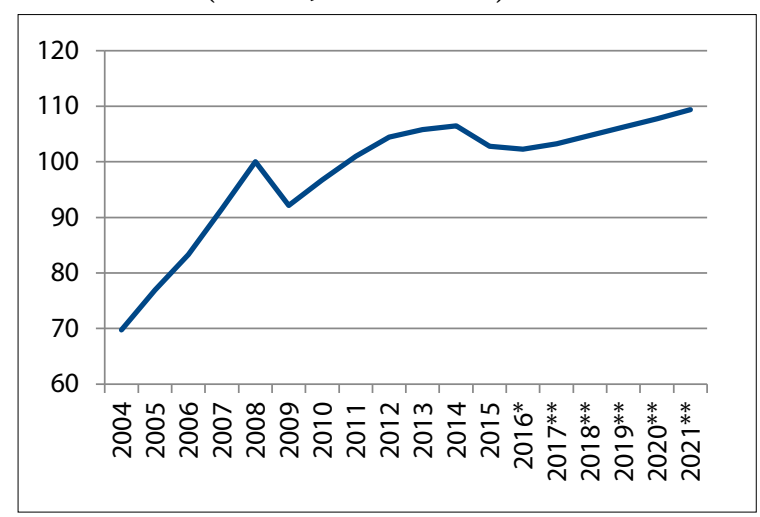

* Schätzung, ** Prognose

Quelle: nationale Quellen, IWF, RBI/Raiffeisen RESEARCH
Grafik 2: Anteil am Welt-BIP (\%)

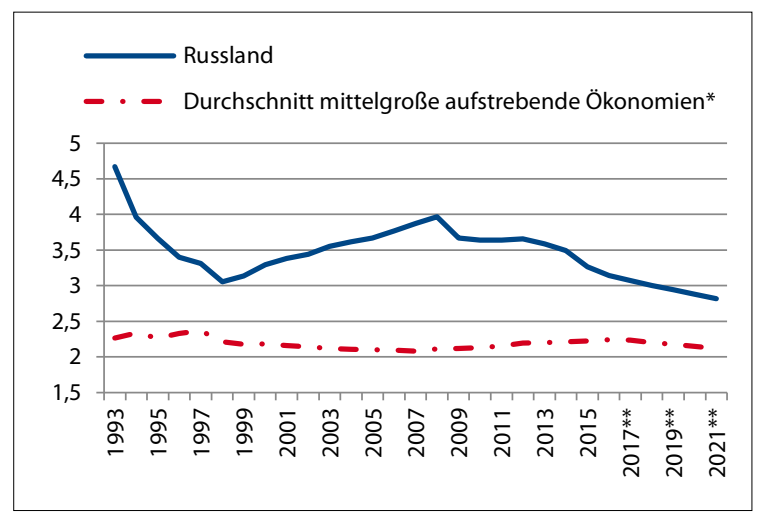

* Durchschnitt Brasilien, Mexiko, Indonesien, Türkei ** Prognose Quelle: IWF, RBI/Raiffeisen RESEARCH 
Grafik 3: Russland: Relative Anteile grenzüberschreitende Bankfinanzierungen

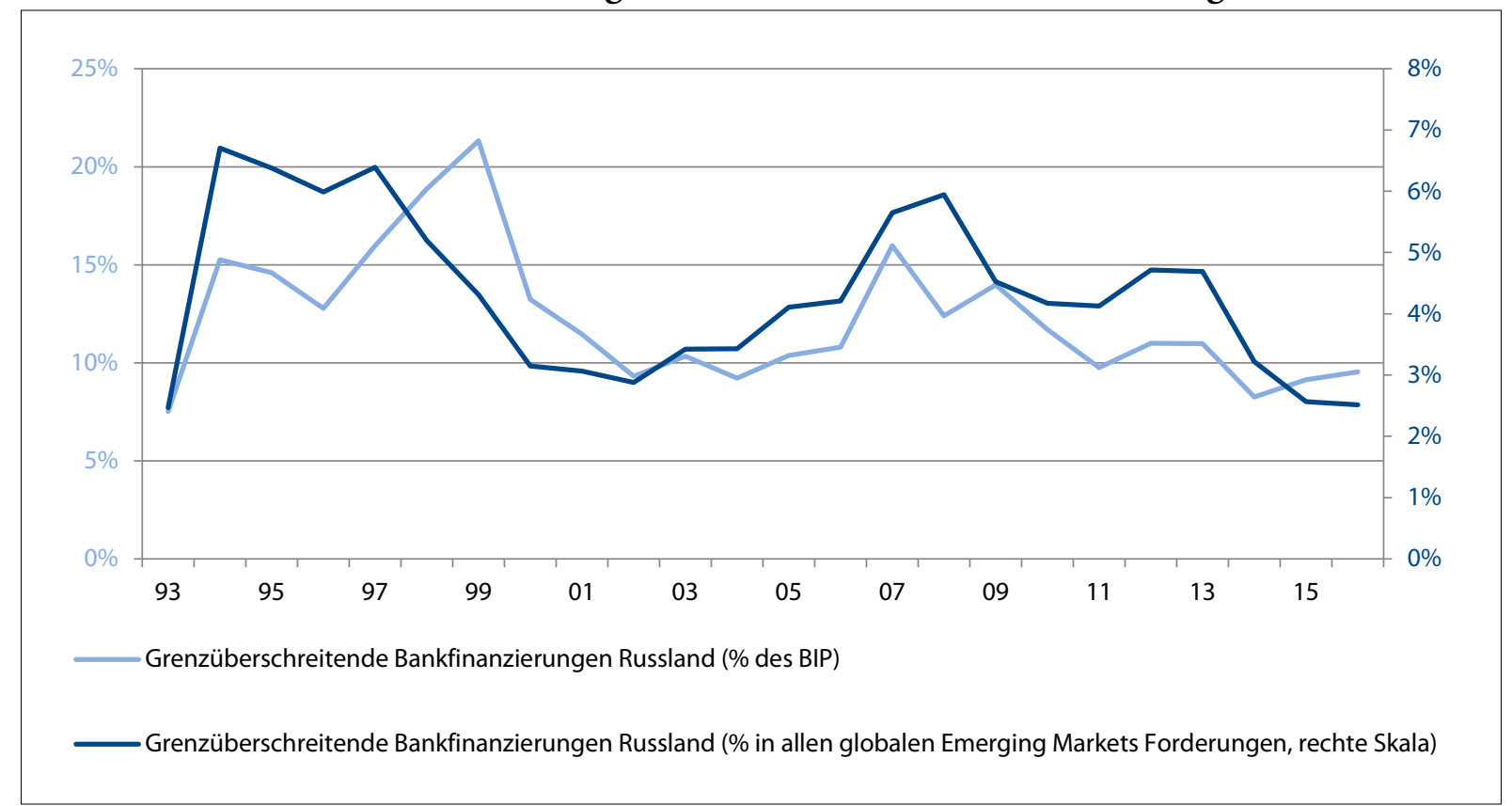

Quelle: Bank für Internationalen Zahlungsausgleich (BIZ), RBI/Raiffeisen RESEARCH

Grafik 4: Russland: Grenzüberschreitende Bankfinanzierungen (Milliarden USD)

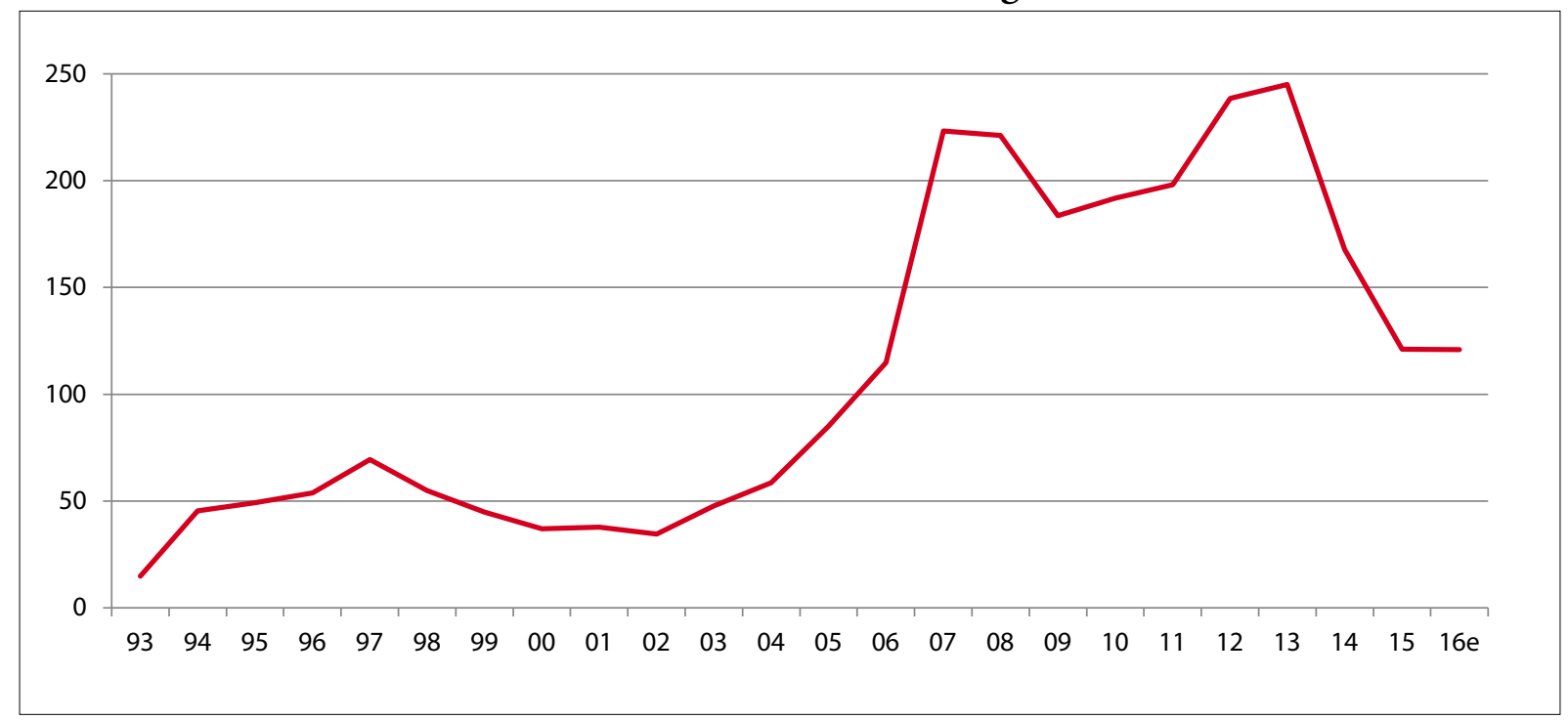

Quelle: Bank für Internationalen Zahlungsausgleich (BIZ), RBI/Raiffeisen RESEARCH 
Grafik 5: Russland: Auslandsschulden

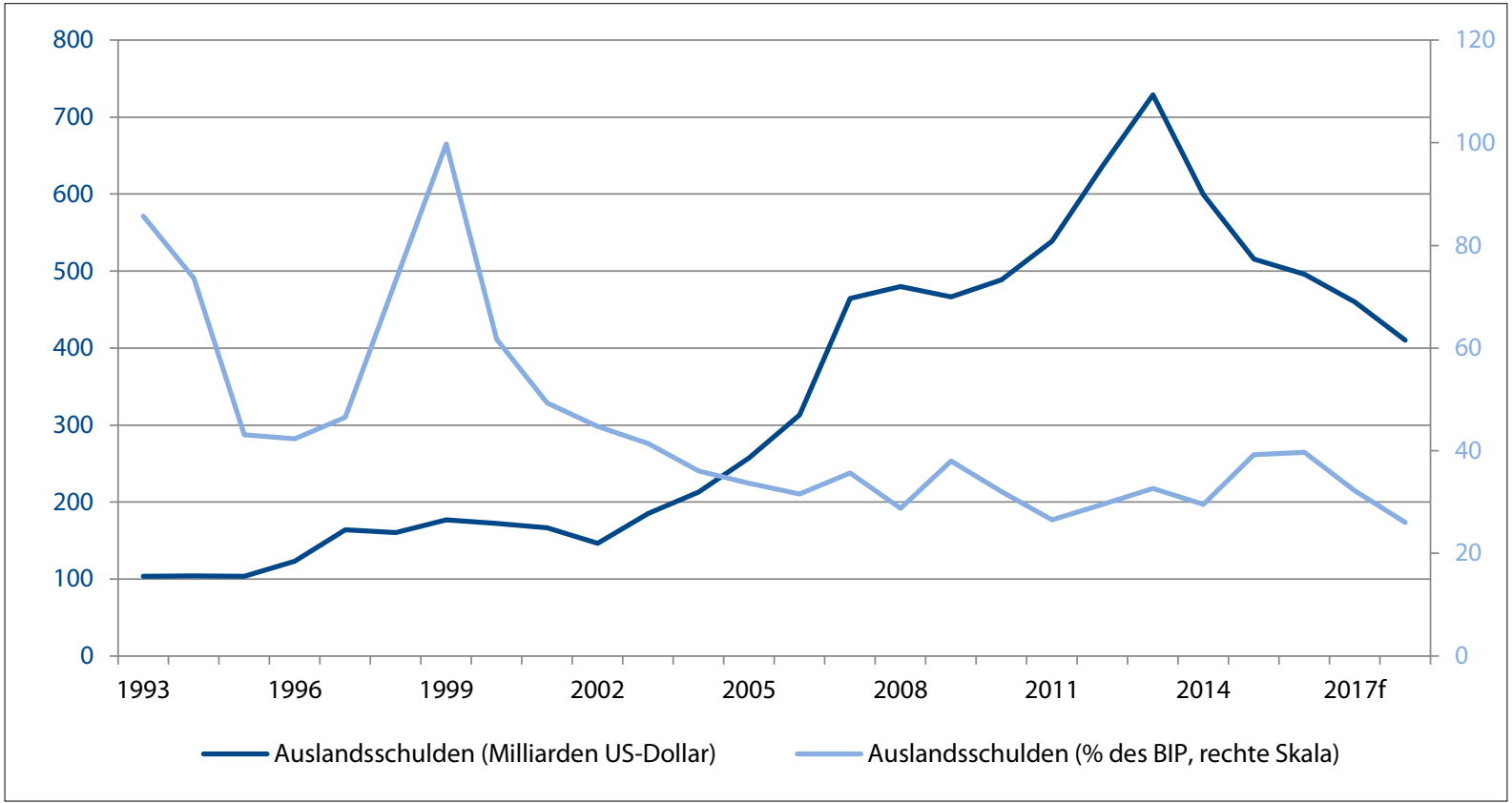

Quelle: nationale Quellen, BIZ, RBI/Raiffeisen RESEARCH

Grafik 6: Ausländische Direktinvestitionen in Russland (\% des BIP)

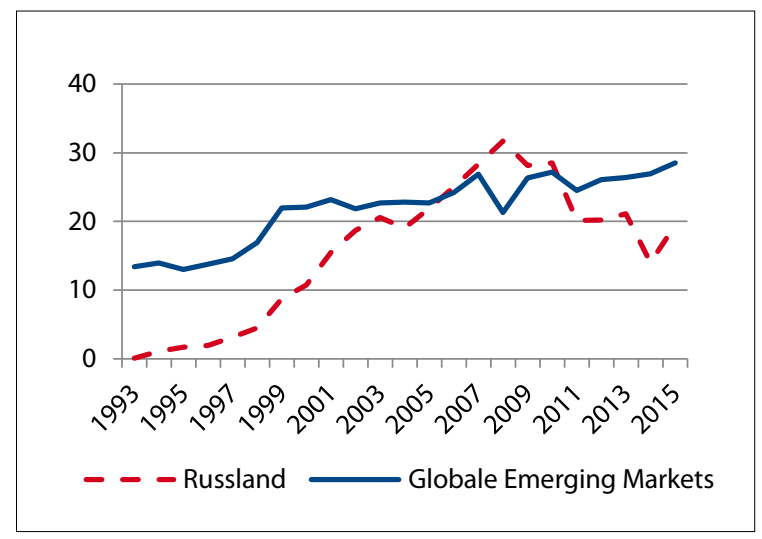

Quelle:nationale Quellen, Weltbank, RBI/Raiffeisen RESEARCH
Grafik 7: Direktinvestitionen Russland im Ausland (\% des BIP)

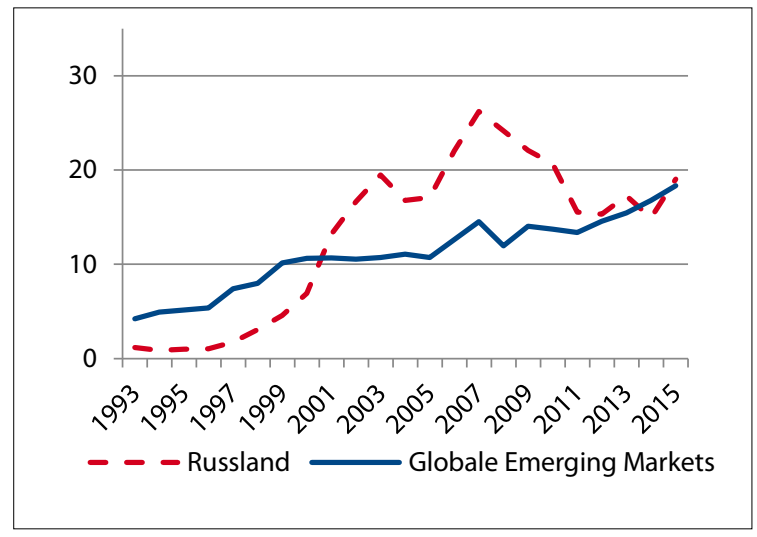

Quelle: nationale Quellen, Weltbank, RBI/Raiffeisen RESEARCH 


\section{Grafik 8: Russland: Internationale Kapitalmarktfinanzierungen}

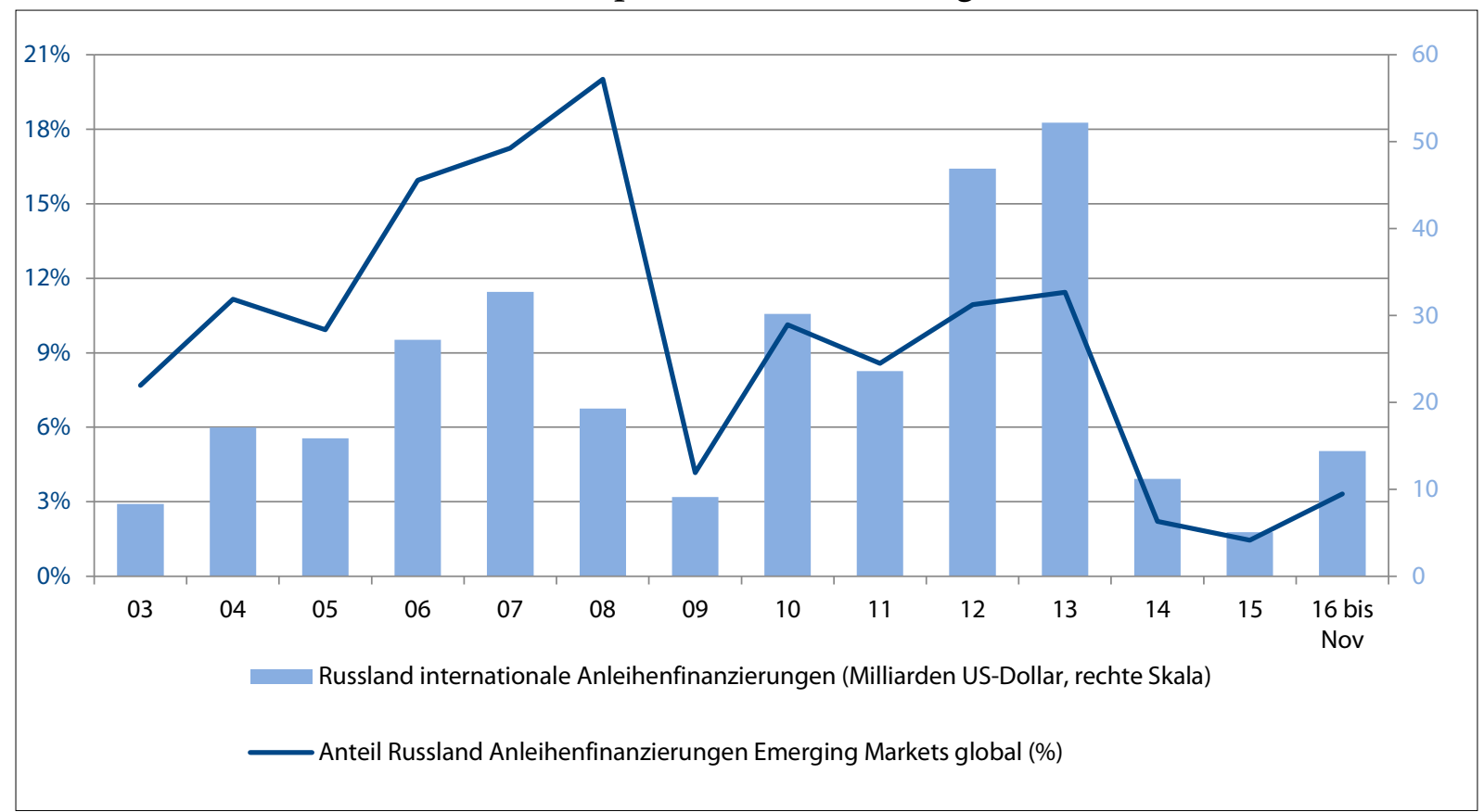

Quelle: Bloomberg, RBI/Raiffeisen RESEARCH

\section{Grafik 9: Russland: Rückzahlungen internationaler Finanzierungen*}

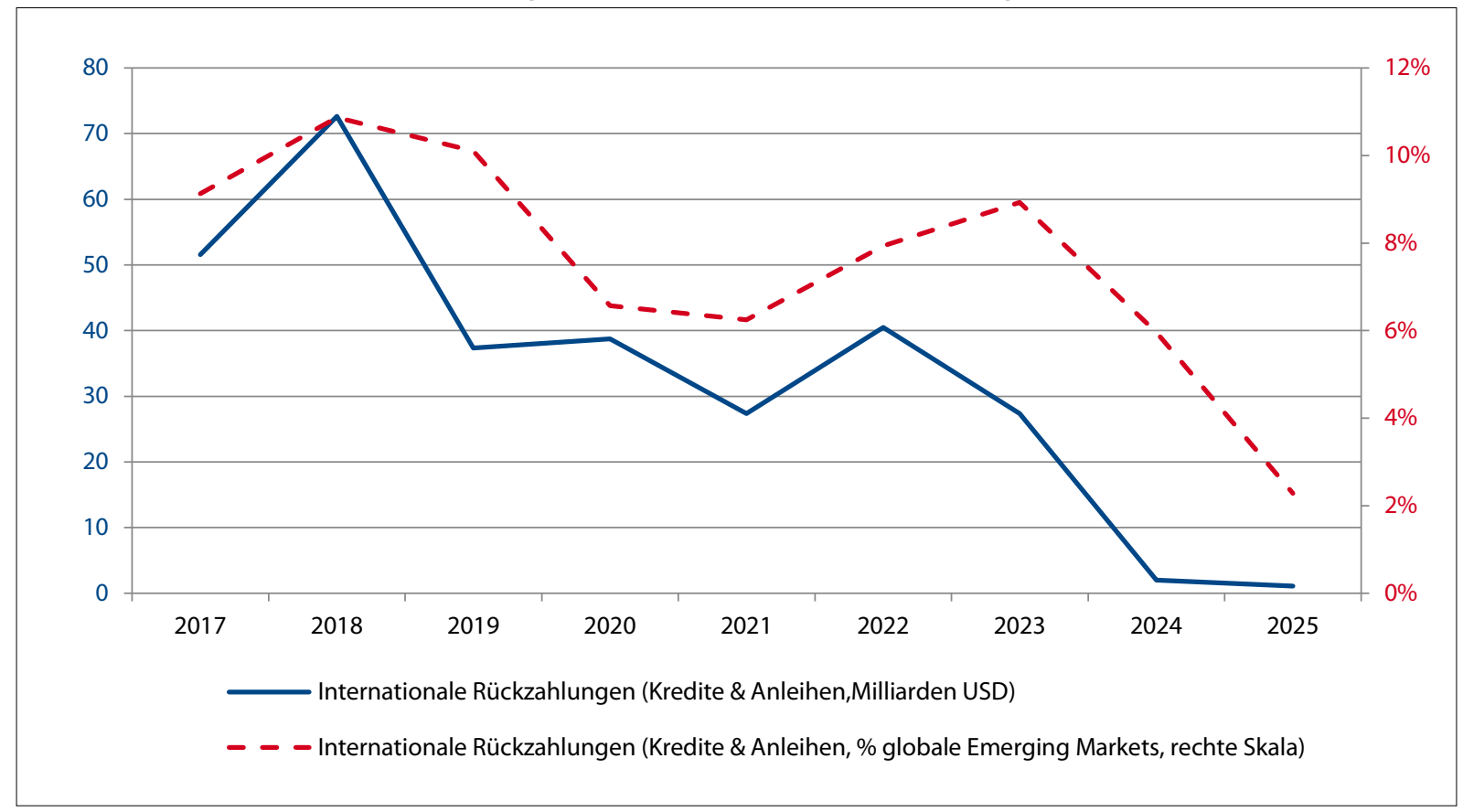

* Alle Sektoren (Staat, Firmen, Banken); über den Gesamtzeitraum ca. 150 Milliarden US-Dollar Quelle: Bloomberg, Institute of International Finance, RBI/Raiffeisen RESEARCH 
Grafik 10: Russland: Grad der internationalen Wirtschafts- und Finanzmarktintegration (2010 und 2015)

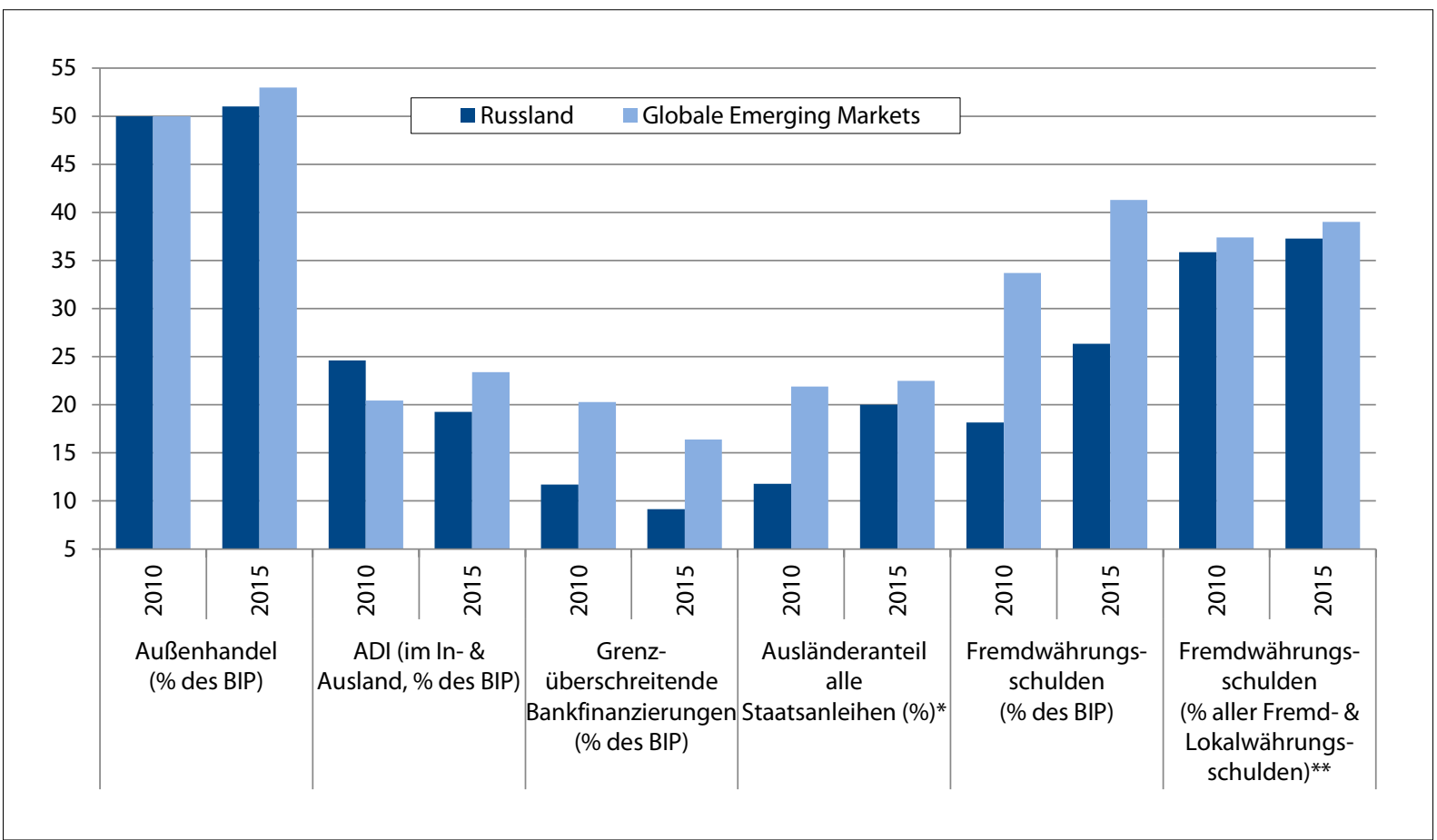

* Fremdwährungs- und Lokalwährungsanleihen

** Alle Sektoren (Staat, Firmen, Banken); über den Gesamtzeitraum ca. 150 Milliarden US-Dollar

Quelle: BIZ, Weltbank, nationale Quellen, IWF, Institute of International Finance, RBI/Raiffeisen RESEARCH

\section{Grafik 11: Wachstumsbeiträge zum realen BIP-Wachstum (in Prozentpunkten)}

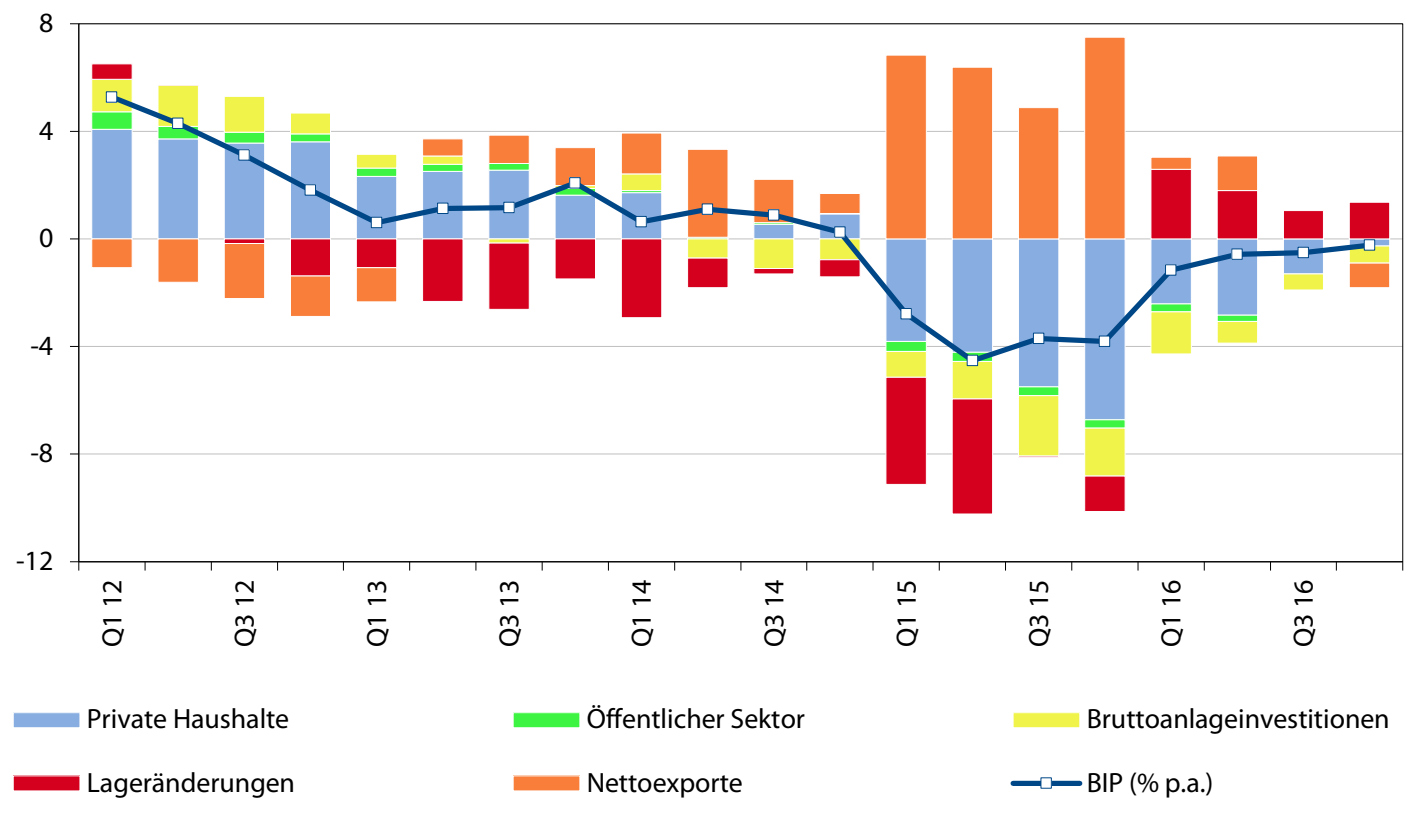

Quelle: Thomson Reuters, RBI/Raiffeisen RESEARCH 
Grafik 12: Nominales und reales Zinsniveau (\%)

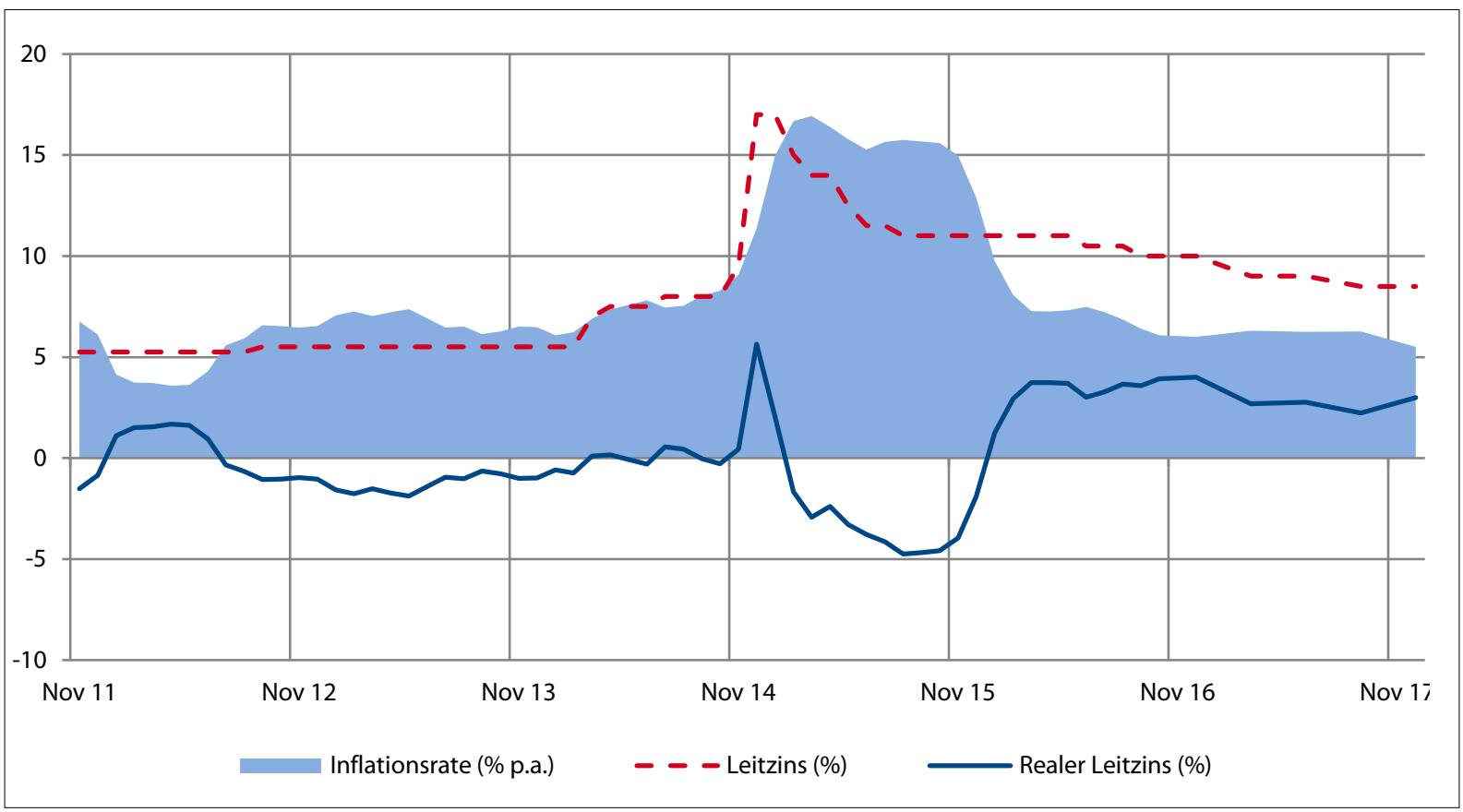

Realer Leitzins: Nominaler Leitzins minus Konsumentenpreisinflation (Rate zum Vorjahresmonat, rückblickend) Quelle: Thomson Reuters, RBI/Raiffeisen RESEARCH

Grafik 13: Föderaler Haushalt und Haushaltsplanung 2017-2019 (in \% des BIP)

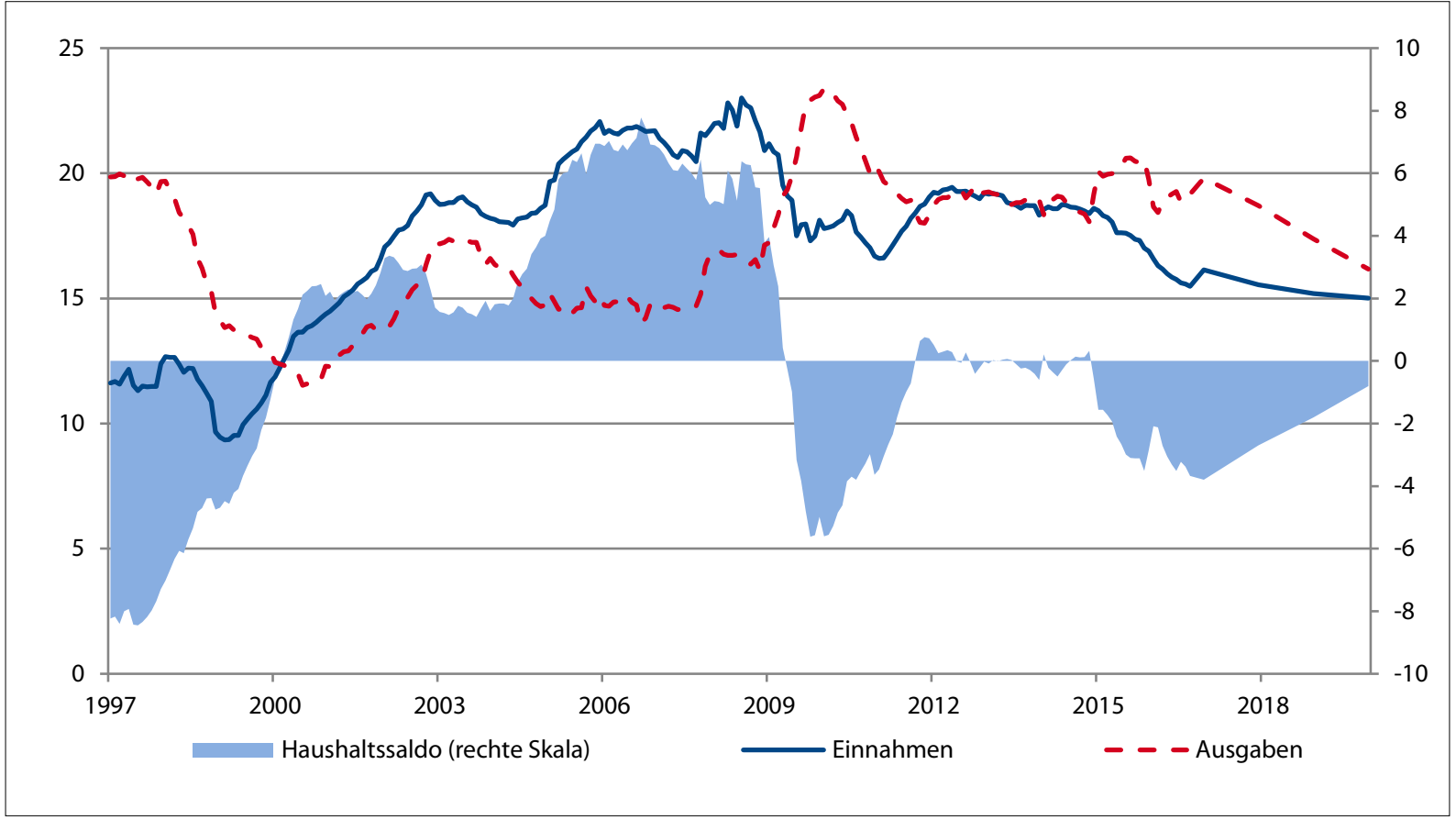

Quelle: Thomson Reuters, RBI/Raiffeisen RESEARCH 
Grafik 14: Handelsbilanz (USD Milliarden, annualisiert, dreimonats gleitender Durchschnitt)

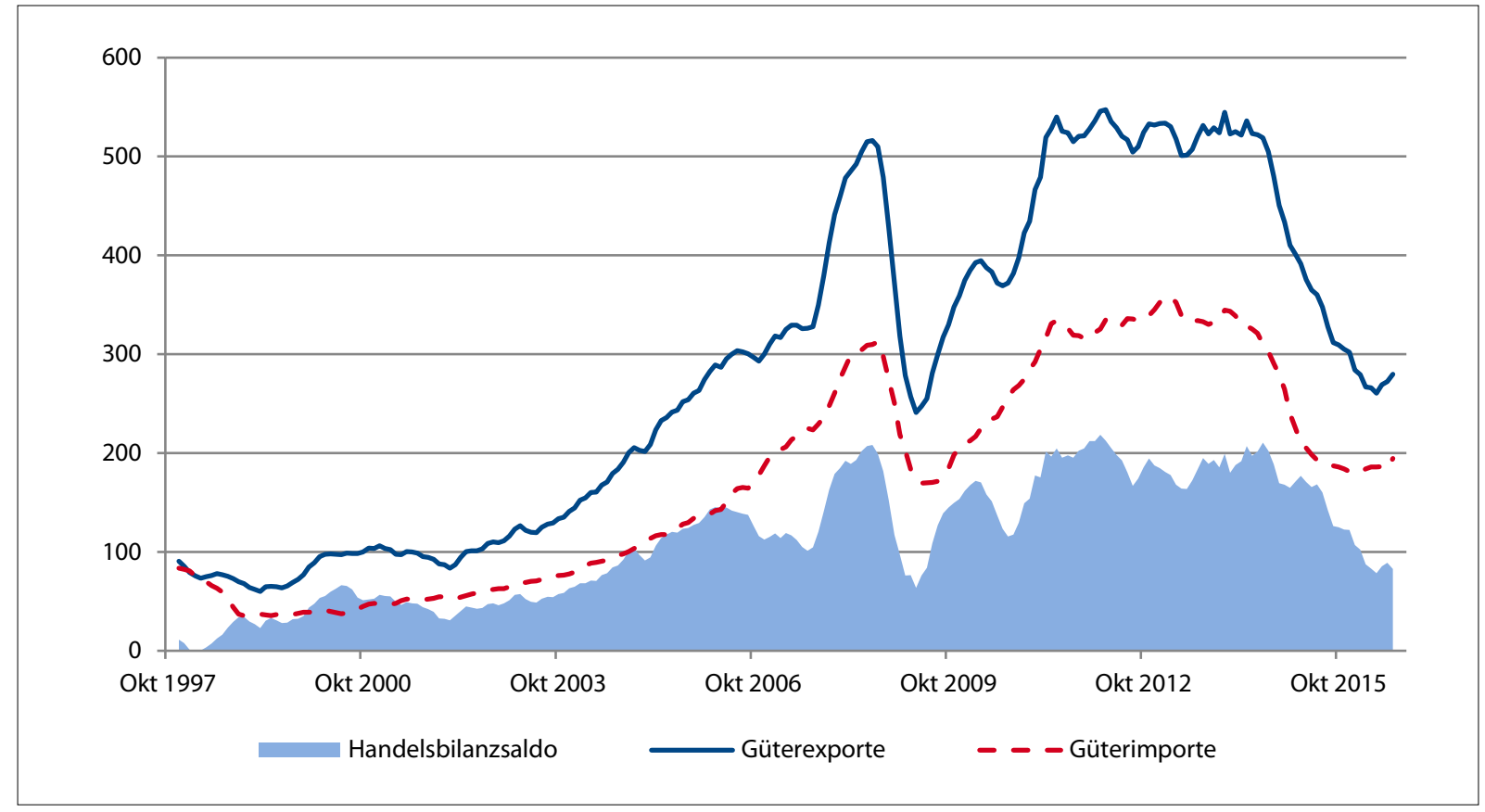

Quelle: Thomson Reuters, RBI/Raiffeisen RESEARCH

Grafik 15: Russland: Marktanteile Bankenmarkt (\% der Gesamtaktiva)

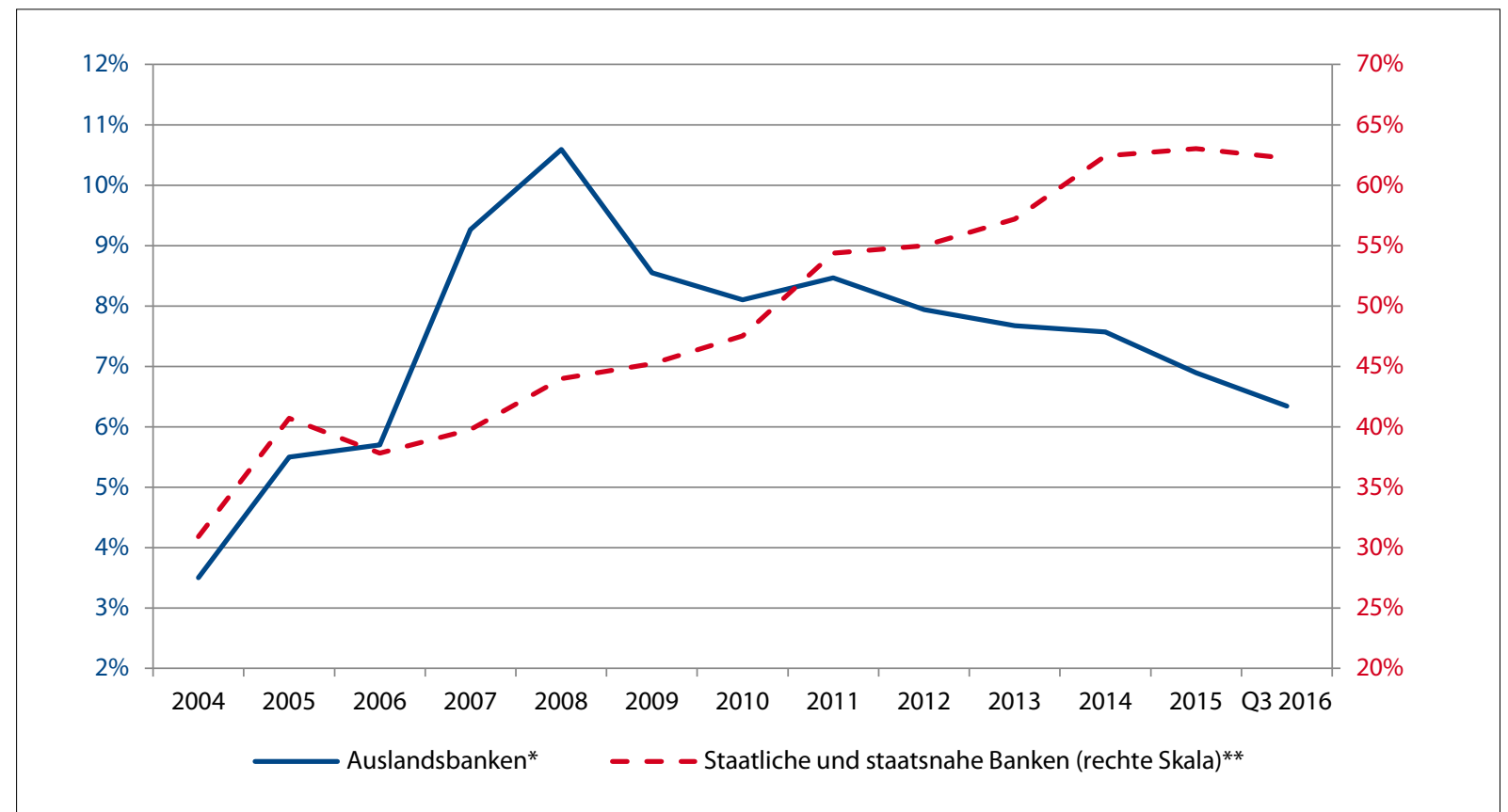

* Mit klar ausländischer Mehrheitseigentümerschaft im Aktionärskreis

** De-jure staatliche Banken plus Otkrytie FC, Rossiya KB, Bank Sankt-Petersburg

Quelle: Firmendaten, Russische Zentralbank, RBI/Raiffeisen RESEARCH 


\title{
Anzeichen für positive Veränderungen
}

\author{
Andrei Yakovlev, Moskau
}

\section{Zusammenfassung}

Der bislang noch sehr schwache positive Trend in der Wirtschaft ist sehr empfindlich gegenüber unterschiedlichen "Signalen", die aus der Regierung kommen und die Erwartungen der Wirtschaftsakteure zum Schlechteren wenden können.

\section{Stimmungswechsel in der Wirtschaft}

In der Wirtschaft Russlands gibt es Anzeichen für Veränderungen. Sie lassen sich in den Stimmungen der Wirtschaftsakteure feststellen. Diese Veränderungen an sich sind noch keine Garantie für eine radikale wirtschaftliche Verbesserung, aber sie können zur Grundlage für ein Wachstum werden, wenn sie von positiven Signalen in der Politik gestützt werden. Zur Begründung dieser Schlussfolgerung möchte ich drei Fallbeispiele aus dem August und dem September 2016 anführen, und Ergebnisse von Studien, die das Zentrum für makroökonomische Analysen und kurzfristige Prognosen (russ. Abk.: "ZMAKP«) vorgenommen hat.

\section{Der Blick auf die Mikroebene}

Fallbeispiel 1: Ein Topmanager aus der Finanzsparte einer großen russischen Holding gab nach der Analyse der Rechnungslegung für das erste Halbjahr 2016 folgenden Kommentar: „Bei uns laufen die Dinge besser, als man erwarten konnte«. Eine der möglichen Erklärungen wäre eine Strategieänderung angesichts der verschärften Konkurrenz. Insbesondere die Branchengruppe der Holding, die für den Einzelhandel außerhalb des Lebensmittelbereichs zuständig ist, hat die Gewinnmargen gesenkt, wodurch eine Erhöhung ihres Marktanteils erreicht werden konnte und sie für die gesamte Holding das Gewinnvolumen in ihrer Branche erhöhte.

Fallbeispiel 2: Im Jahr 2014 ging der Manager eines großen russischen Unternehmens zum Studium ins Ausland und hatte den Plan, im Herbst 2016 nach Russland zurückzukehren. Im Frühjahr 2016 nahm er an, dass es wegen der verschlechterten Wirtschaftslage weniger Einstellungsmöglichkeiten geben werde und er mit einem niedrigeren Einkommen zu rechnen habe, als er vor seiner Abreise hatte. Allerdings erhielt er im Juli und August in Moskau einige Angebote mit vergleichbarer oder höherer Entlohnung. Seine Einschätzung nach informellen Gesprächen mit ehemaligen Kollegen lautet: »Für das gleiche Geld laufen die Leute nun flinker«.

Fallbeispiel 3: Ende August wurden an einer der führenden Hochschulen des Landes der neue Jahrgang analysiert. Bei einem gewissen Rückgang von neuen Studenten mit staatlichen Stipendien ist der Anteil der "zahlenden Studenten« um 60 Prozent gestiegen. Die letzten drei Jahre hatte diese Hochschule die Studiengebühren nicht mehr an die Inflation angepasst (wie das früher geschehen war), und die Aufnahme öffentlich finanzierter Studenten etwas reduziert. Diese Faktoren können jedoch nicht die nach drei Jahren Stagnation explosionsartig gestiegene Nachfrage nach den Studienprogrammen dieser Hochschule erklären - insbesondere, wenn man die damit verbundene langfristige Belastung der Familien in Betracht zieht. Durch demographische Veränderungen lässt sich dieser Effekt auch nicht erklären: 1999 hat es keinerlei Sprung bei der Geburtenrate gegeben. Nun ist die Frage, woher in diesen Familien das Geld für solche Investitionen kommt. Oder: Warum entschieden sie sich gerade jetzt, ihre Ersparnisse für diese Zwecke auszugeben?

\section{Der Blick auf die Mesoebene}

Das ZMAKP hat nach einer Analyse der Ergebnisse des ersten Halbjahres 2016 unterschiedliche Tendenzen in diversen Industriezweigen festgestellt - ohne ein eindeutiges allgemeines Wachstum. Gleichzeitig ist eine gewisse Belebung der Investitionstätigkeit zu beobachten. Wenn im Jahr 2015 gegenüber 2013 in den allermeisten Branchen ein heftiger Rückgang der Investitionen festzustellen war, so gab es 2016 eine Reihe von Branchen, in denen ein merklicher Anstieg der Investitionen einsetzte (s. Grafik 16 auf S. 18). Dabei handelte es sich um die Bereiche Metallurgie, Chemie, Landwirtschaft, Holzverarbeitung und die Papierindustrie sowie eine Reihe von Infrastruktur- und Dienstleistungsbranchen.

Die Daten des ZMAKP belegen auch einen einsetzenden Anstieg der Industrielöhne, und zwar um rund 2-3 Prozent (nach einem Rückgang von 8-9 Prozent in der Zeit von Mitte 2014 bis Ende 2015). Andererseits heben die Experten des ZMAKP hervor, dass dieser Prozess praktisch kaum von einem Anstieg des Anteils der Lohnkosten am Umsatz begleitet war, was ein indirekter Hinweis auf eine erhöhte Effizienz der Unternehmen sein könnte.

Diese Einschätzung deckt sich mit den Kommentaren des Mitbesitzers eines mittelgroßen Unternehmens aus der Elektrotechnikbranche: Die erhöhte Effizienz der 
Unternehmen ist auf eine Konsolidierung der Branche durch Verdrängung der weniger erfolgreichen Unternehmen vom Markt zurückzuführen. Dabei gewinnen diejenigen, die in der vorherigen Periode in die technische Weiterentwicklung investiert hatten.

Auch die Einschätzungen eines Spitzenmanagers einer großen staatlichen Bank verweisen darauf, dass es in einigen Branchen ein Wachstum gibt. Unter anderem geht aus dem Kreditportfolio seiner Bank für mittelgroße Unternehmen (mit einem Jahresumsatz von bis zu 10 Milliarden Rubel) hervor, dass sich im vergangenen Jahr der Anteil von Unternehmen der Agrarindustrie verdoppelt hat, obwohl, so der Befragte, "wir überhaupt nicht die ,Rosselchosbank « [,Russische Agrarbank"] sind und das auch nicht werden wollen«. Auch Unternehmen der Chemie- und Leichtindustrie nehmen Kredite auf, allerdings sind es hier die größeren Unternehmen.

Nach Ansicht dieses Bankmanagers bleibt das Problem der Finanzausstattung ein ernsthaftes Hindernis für den realwirtschaftlichen Bereich. Hier spielen jene Instrumente eine wichtige Rolle, mit denen die Unternehmen den Preis für Finanzmittel reduzieren können. Die Anwendung dieser Instrumente liegt aber oft im Schnittbereich der Zuständigkeiten verschiedener Behörden und Agenturen. Und hier entsteht eine mächtige "Blockade«, die auf die omnipräsente Furcht vor dem »Anmarsch des Staatsanwalts« zurückzuführen ist. Jede notwendige Handlung, die über ein Verlegen von Papieren aus einem Bürozimmer ins andere hinausgeht, bringt automatisch die Frage mit sich: „Und wie erkläre ich das, wenn die Staatsanwälte kommen? (Hier ist der Moduswechsel bezeichnend: Statt des früher üblichen "falls" sagt man heute "wenn«.) Diese Logik der Beziehungen hemmt drastisch die Lösung aller komplexen Fragen und schränkt dementsprechend den Zugang der Unternehmen zu Finanzmitteln ein. Auf das reale Ausmaß der Korruption hat die "totale Kontrolle« durch die Staatsanwaltschaft keine Auswirkung.

\section{Blick auf die Makroebene}

Auf einer allgemeineren Ebene ist es zur Erklärung der aktuellen Entwicklung hilfreich, die Situation der Jahre 2008/2009 zum Vergleich heranzuziehen. Angesichts der Krise damals war die Wahrung sozialer Stabilität eine der zentralen Prioritäten der Regierung. Der Staat griff daher zu einer Erhöhung der Renten, der Gehälter für öffentliche Angestellte und der Arbeitslosenhilfe. In der Folge sind im Jahr 2009 die Realeinkommen der Bevölkerung um 2 Prozent gestiegen - bei einem gleichzeitigen Rückgang des BIP um fast 8 Prozent.

Teil dieser Politik war auch ein informeller Druck auf die Unternehmen, der von den Regionalregierungen mit dem Ziel ausgeübt wurde, Entlassungen zu ver- hindern. Diese Politik setzte natürlich einen "Tauschhandel« zwischen Regierung und Unternehmen voraus, doch wurde dabei in Wirklichkeit den ineffizientesten Unternehmen beträchtliche Hilfe gewährt. Gleichzeitig hat die zentralisierte Erhöhung der Arbeitslosenhilfe und der Gehälter im öffentlichen Sektor dazu geführt, dass sich für die Unternehmen die Opportunitätskosten auf dem Arbeitsmarkt erhöhten und die Möglichkeiten zur Umstrukturierung schrumpften.

In der jetzigen Krise haben die Regionalregierungen aufgrund der getätigten Ausgaben zur Umsetzung von Putins "Maierlassen" aus dem Jahr 2012 praktisch keine Ressourcen mehr, um ineffiziente Unternehmen zu unterstützen. Gleichzeitig führte 2014-2015 eine Kürzung der Sozialausgaben im Haushalt dazu, dass die Opportunitätskosten auf dem Arbeitsmarkt sanken.

Unter diesen Bedingungen wurde der Wettbewerb stärker und es begannen dabei diejenigen Unternehmen zu gewinnen, die zuvor in ihre Entwicklung investiert hatten. Sie gewannen jetzt deshalb, weil der Staat sie jetzt weniger stört. Gleichzeitig zwingt der weiterhin bestehende Fachkräftemangel florierende Unternehmen dazu, die Entlohnung zu erhöhen, während der Wettbewerb sie zu neuen Investitionen drängt.

$\mathrm{Zu}$ all diesen Faktoren kommen natürlich die Auswirkungen der außenpolitischen Schocks, der innenpolitischen Maßnahmen sowie jener Formen hinzu, in denen der Staat mit Unternehmen zusammenarbeitet. In diesem Kontext erfolgte meiner Ansicht nach im Frühjahr und Sommer 2016 eine psychologische Anpassung der Wirtschaftsakteure an die "neue Realität«, indem man sich bewusst wurde, dass es in den Beziehungen zum Westen langfristig Spannungen gibt und der Zugang zu den Kapital- und Technologiemärkten beschränkt ist. Gleichzeitig verstand man auch, dass sich für bestimmte Wirtschaftsbereiche neue Möglichkeiten eröffnen. Hiermit lassen sich auch die Ergebnisse einer jüngsten Konjunkturumfrage des Gajdar-Instituts erklären, bei der ein hoher Anteil der Firmenchefs (74 Prozent) die gegenwärtige Situation als »normal» bezeichnete (<http://www.rbc.ru/economics/08/09/ 2016/57d1837e9a7947127b6bclce?from=main>).

Ein wichtiger Faktor war hier die relative außenpolitische Stabilisierung. Das Einfrieren des Konfliktes in der Ukraine, der schnelle Rückzug der Russischen Föderation aus einer direkten Beteiligung an den Kampfhandlungen in Syrien, die Begrenzung des Konfliktes mit der Türkei, all das sind Beispiele für eine Situation, in der das Ausbleiben schlechter Nachrichten bereits eine gute Nachricht sein kann.

In dieser Situation begannen die Leute zu verstehen, dass man weiterleben und durchhalten muss. Also müssen die Möglichkeiten genutzt werden, die auf dem 
Markt entstehen, es müssen starke Mitarbeiter eingestellt werden, in gute Bildung für die Kinder investiert werden usw. Zur Aufrechterhaltung dieses Trends müssen die Initiativen gewissenhafter Akteure -sowohl in den Unternehmen, als auch im Staatsapparat (besonders auf regionaler Ebene) - unterstützt werden.

Zur Vorbeugung gegen eine Zunahme sozialer Spannungen ist es sehr wichtig, über die Schaffung von Arbeitsplätzen für diejenigen nachzudenken, die entlassen werden. Im Unterschied zu einer Konzeption der »25 Millionen High-Tech-Arbeitsplätze«, wie sie vor fünf Jahren vorgeschlagen wurde, sollte es hier eher um Arbeitsplätze im Dienstleistungsbereich gehen, damit auch die Geringerqualifizierten, die jetzt in der Industrie entlassen werden, wieder in Arbeit gebracht werden.

Der jetzt festzustellende und noch äußerst schwache positive Trend ist sehr empfindlich gegenüber unterschiedlichen "Signalen", die aus der Regierung kommen. Daher ist es äußerst wichtig, "abrupte Bewegungen" zu vermeiden, die die Erwartungen der Wirtschaftsakteure ins Negative wenden könnten.

Dieser Kommentar basiert auf den Ergebnissen von Studien, die 2016 mit Unterstützung des Programms für Grundlagenforschung der "Higher School of Economics» durchgeführt wurden.

\section{Über den Autor}

Andrei Yakovlev ist Direktor des Instituts Unternehmens- und Märkteanalysen der Higher School of Economics Moskau und Präsident des Verbandes unabhängiger Zentren für Wirtschaftsanalyse (ARETT).

\section{Grafik 16: Investitionen ins Grundkapital nach Industriezweigen 2015/2013 und 1. Halbjahr}

\section{6/1. Halbjahr 2015 im Vergleich}

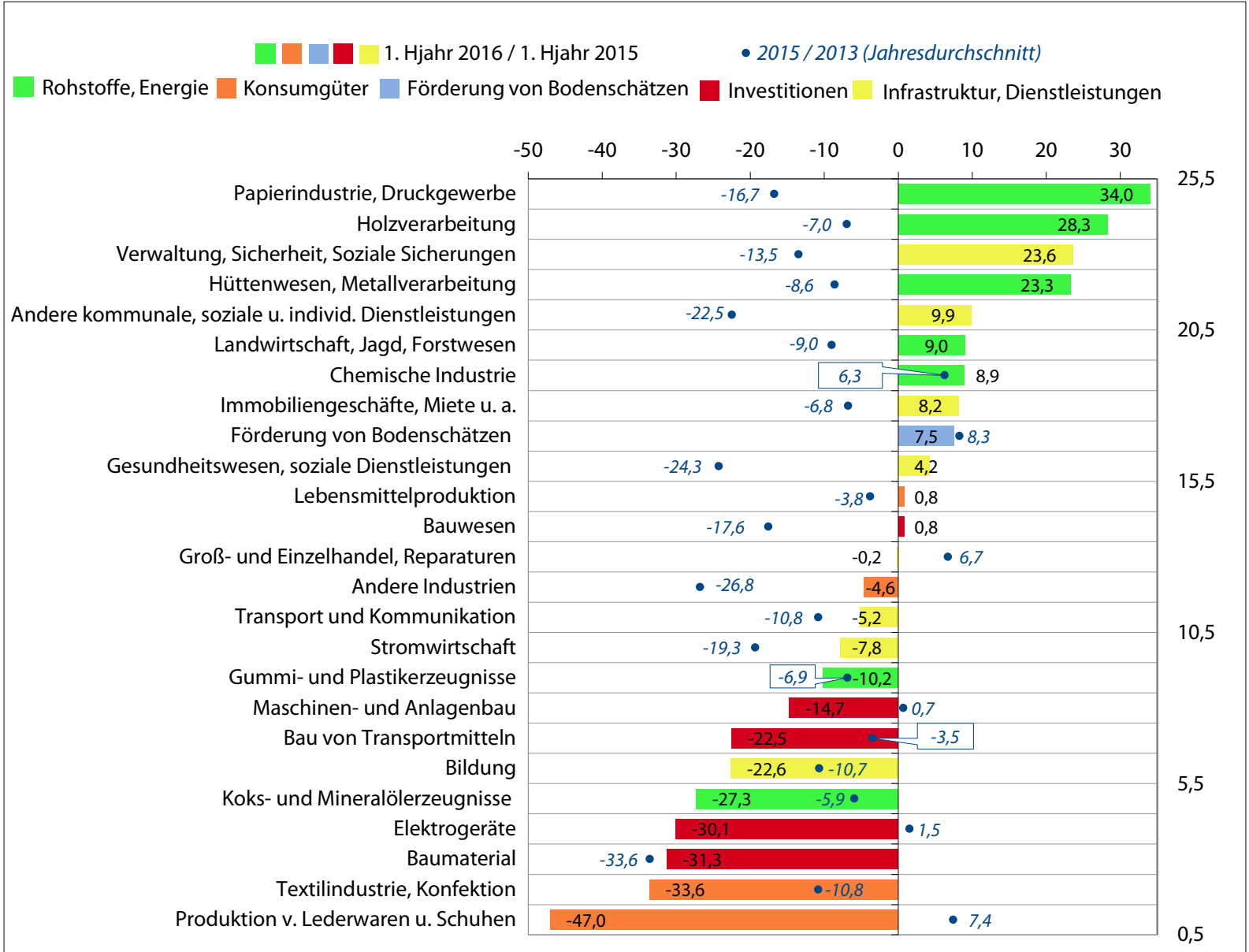

Quelle: Tendenzii raswitija promyschlennosti, ZMAKP (PDF-Datei), 4 September 2016, S. 21 
Grafik 17: Reallohn (3. Quartal $2008=100)$

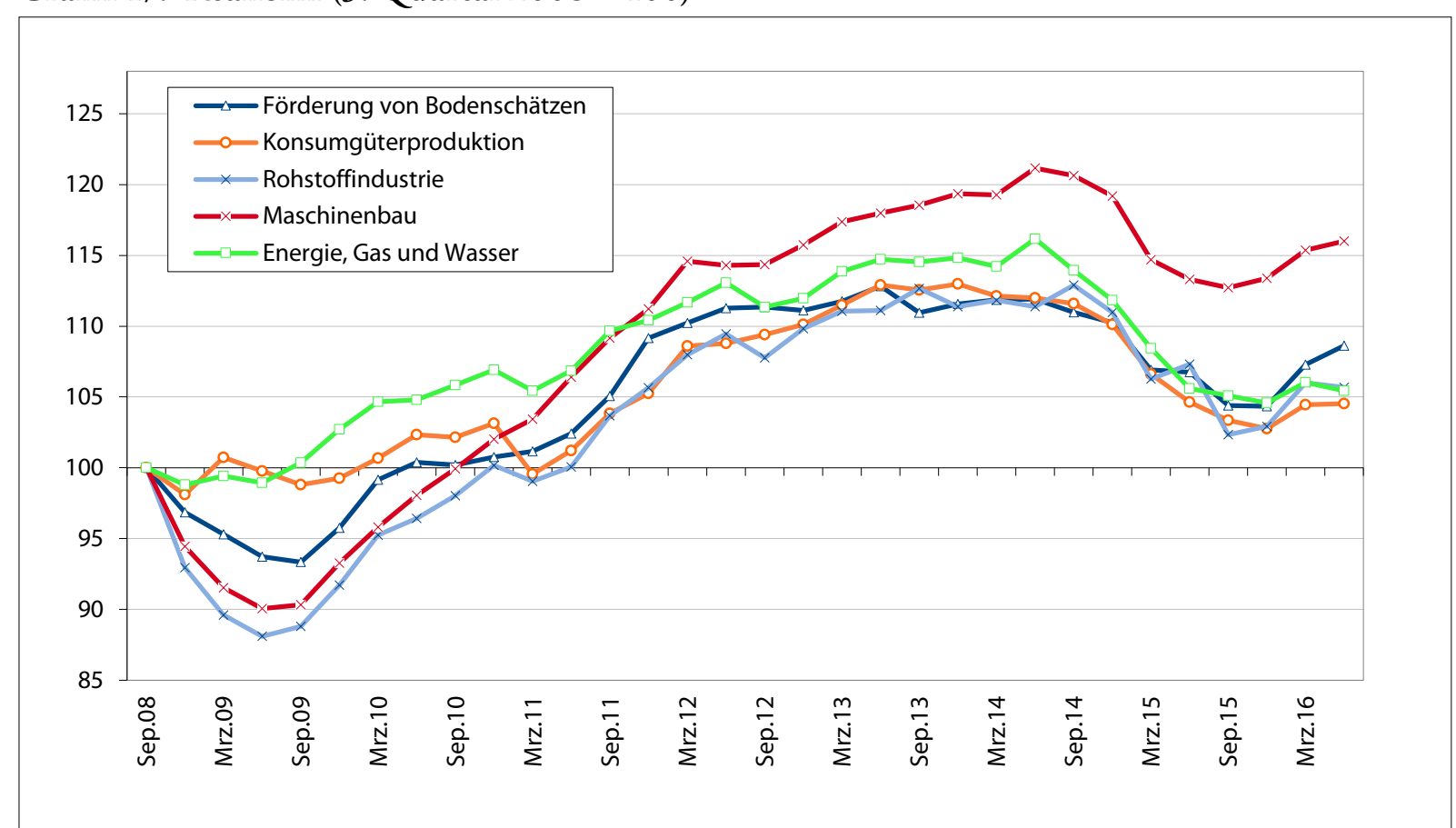

Quelle: Tendenzii raswitija promyschlennosti, ZMAKP (PDF-Datei), 4 September 2016, S. 22

\section{Grafik 18: Anteil des Arbeitslohns im Ertrag (\%)}

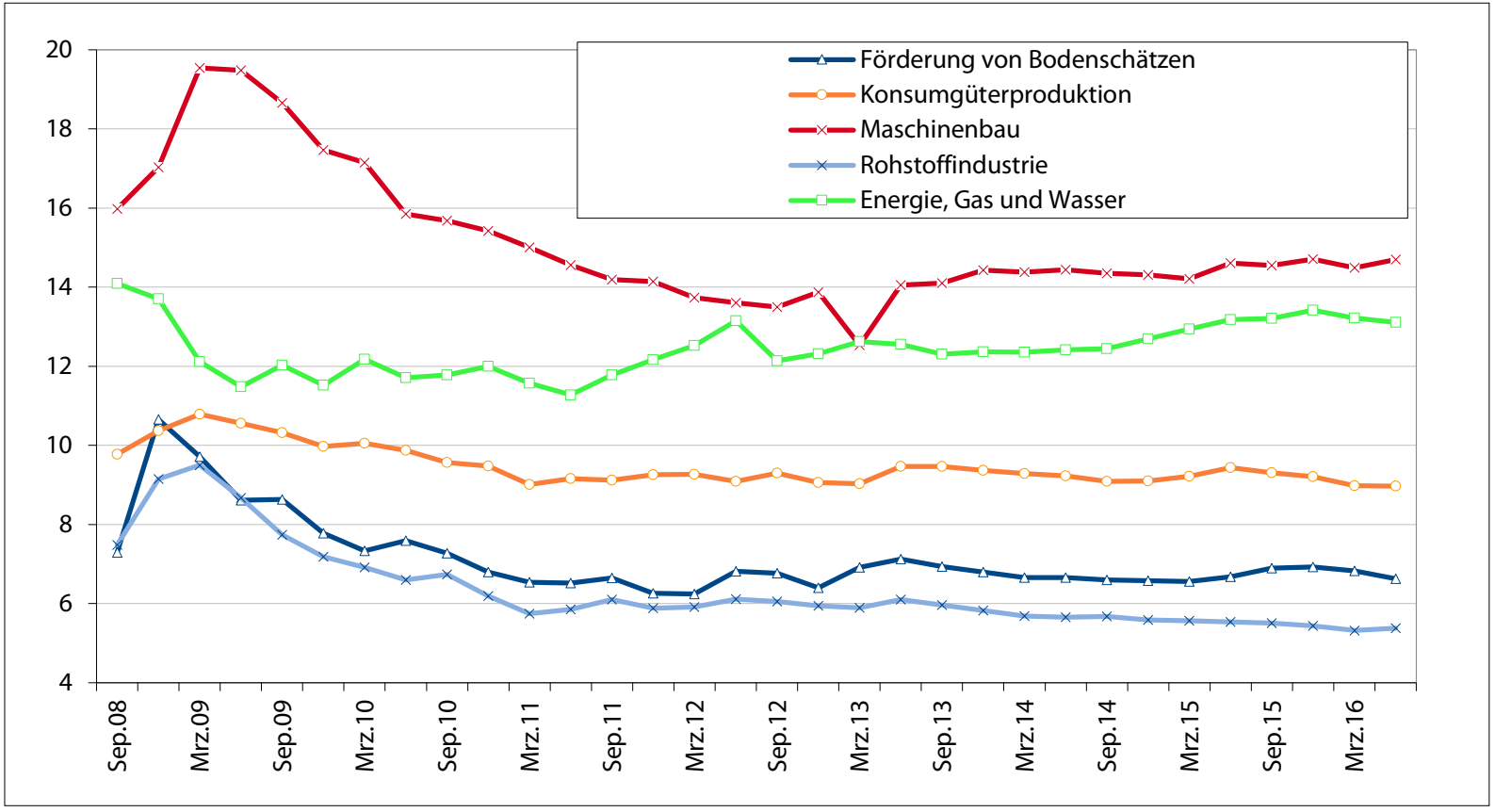

Quelle: Tendenzii raswitija promyschlennosti, ZMAKP (PDF-Datei), 4 September 2016, S. 22 
Grafik 19: Zahl der Mitarbeiter (3. Quartal $2008=100$ )

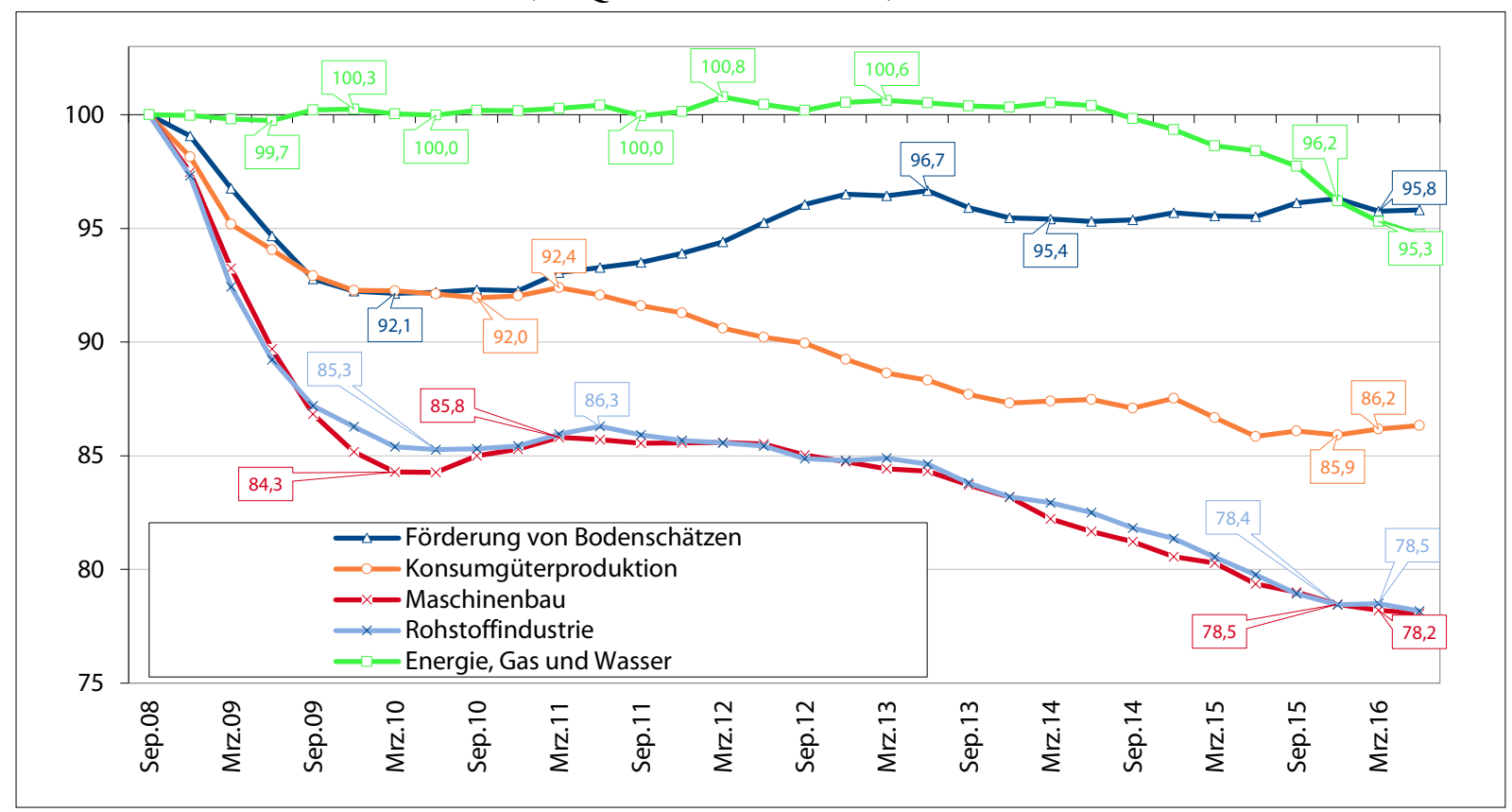

Quelle: Tendenzii raswitija promyschlennosti, ZMAKP (PDF-Datei), 4 September 2016, S. 22

\section{ANALYSE}

\section{Unmittelbare und mittelbare Folgen der Wirtschaftssanktionen zwischen der EU und Russland auf Produktion und Beschäftigung in Deutschland}

Jutta Günther, Bremen, Maria Kristalova, Bremen, Udo Ludwig, Leipzig

\section{Zusammenfassung}

In der Mitte des Jahres 2014 verhängten die EU und Russland infolge des Ukrainekonfliktes gegenseitige Sanktionen. Die bereits seit 2013 abnehmenden Warenexporte Deutschlands nach Russland brachen danach noch tiefer ein. Dieser Beitrag schätzt unter Verwendung der kürzlich vom Statistischen Bundesamt veröffentlichten Input-Output Tabellen für das Jahr 2012 die ökonomischen Folgen der Sanktionen für die Produktion und Beschäftigung in Deutschland. Dabei gehen sowohl die direkten als auch die indirekten Effekte entlang der gesamten Wertschöpfungskette in die Analyse ein. Die Produktionsverluste infolge der Sanktionen liegen kumuliert über die Jahre 2014 bis 2016 bei mehreren Milliarden. Bezogen auf die Bruttowertschöpfung entsprechen die Verluste aber »nur« 0,15 Prozent des Bruttoinlandsprodukts. Starke Verluste erleiden jedoch die Hersteller unmittelbar sanktionierter Warengruppen und deren Zulieferer, insbesondere der Fahrzeugbau, der Maschinenbau und die Erzeuger von Eisen und Stahl.

\section{Wirtschaftssanktionen gegen Russland}

Als Reaktion auf die Eskalation des Konflikts zwischen Russland und der Ukraine verhängten die EU und andere westliche Länder in der zweiten Hälfte des Jahres 2014 Wirtschaftssanktionen gegen Russland, auf die Russland wiederum mit Gegensanktionen rea- gierte. Neben der Beschränkung von Finanztransaktionen setzte die EU vor allem Ausfuhrverbote für Waffen und sogenannte »Dual-Use-Güter«, die für militärische Zwecke verwendet werden können, sowie für Maschinen und Zubehör zur Öl- und Gasförderung in Kraft. Die russischen Gegensanktionen betreffen insbeson- 
dere Einfuhrverbote für landwirtschaftliche Erzeugnisse und Lebensmittel. Das Handelsembargo verstärkte die bereits abwärts gerichtete Tendenz bei Lieferungen aus Deutschland nach Russland, die der krisenhaften Gesamtsituation in Russland geschuldet ist. Im vorliegenden Beitrag werden die Effekte der Sanktionspolitik im Bereich der Realwirtschaft auf die Produktion und Beschäftigung in der deutschen Wirtschaft abgeschätzt.

\section{Deutsche Exporte nach Russland seit 2013 auf Talfahrt}

Im Vergleich zu anderen Ländern der EU pflegt Deutschland intensive Handelsbeziehungen zu Russland. Im Jahre 2013 entfielen beispielsweise rund 30 Prozent aller Exporte der EU nach Russland auf Deutschland. Die relativ schnelle wirtschaftliche Erholung nach der Finanzkrise brachte die deutschen Exporte nach Russland im Jahr 2012 auf ein Rekordniveau von fast 37 Milliarden Euro. Der Rückgang im Jahr 2013 resultierte u. a. aus die schleppenden Entwicklung der russischen Wirtschaft im Gefolge der Abwertung des Rubel und der sinkenden Einnahmen aus dem Öl- und Gasgeschäft. Nach der Einführung bilateraler Sanktionen in der Mitte des Jahres 2014 brachen die deutschen Ausfuhren nach Russland zusätzlich ein (Grafik 20). So gingen die Exporte im Jahr 2014 insgesamt um 6,5 Milliarden Euro und im Jahr 2015 um 7,5 Milliarden Euro zurück.

Grafik 20: Deutsche Exporte weltweit und nach Russland 2000 bis 2015 (Index $2000=$ 100)

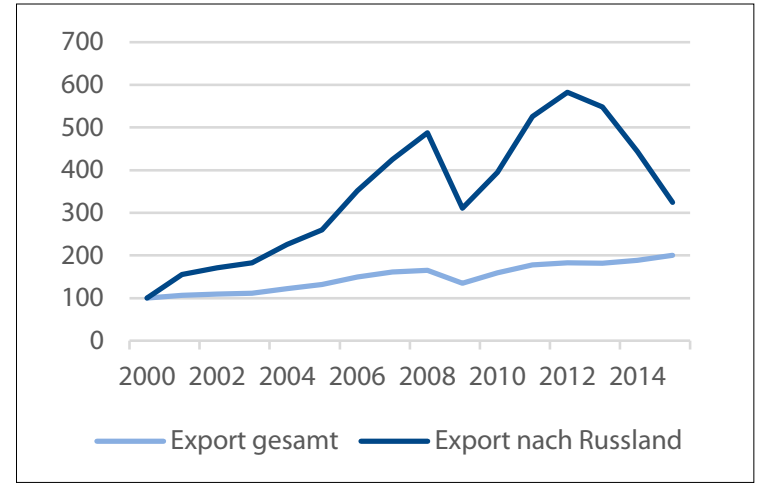

Quelle: Eurostat, eigene Berechnungen.

Betrachtet man die deutschen Exporte weltweit, rangierte Russland den Angaben des Statistischen Bundesamtes zufolge im Jahr 2015 als Absatzmarkt für Deutschland erst an 16. Stelle. Im Jahr 2014 stiegen die deutschen Exporte insgesamt um fast 40 Milliarden Euro (+ 3,4 Prozent gegenüber dem Vorjahr) und im Jahr 2015 nochmals um fast 74 Milliarden Euro (+ 6,6 Prozent). Im gleichen Zeitraum sanken die deut- schen Exporte nach Russland, so dass sich der Anteil seit 2013 kontinuierlich verringerte und 2015 bei weniger als 2 Prozent lag.

Auch wenn Russland als Absatzmarkt für die deutsche Wirtschaft an Bedeutung verloren hat, zieht der Exportrückgang spürbare Folgen für Produktion und Beschäftigung nach sich. Diese betreffen nicht nur die von den Exporteinbrüchen unmittelbar betroffenen Sektoren wie z. B. die im Russlandgeschäft aktiven Hersteller von Kraftfahrzeugen und Kfz-Teilen, deren Anteil am Export sich um 4 Prozentpunkte 2015 gegenüber 2013 verringerte, sondern auch deren Zulieferer, also die gesamte Wertschöpfungskette. Um die realwirtschaftlichen Verluste umfassender abzuschätzen, müssen diese Lieferverflechtungen mit in die Analyse eingehen.

Die Liste der sanktionierten Produkte ist zwar überschaubar, den Akteuren wird aber ein großer Ermessungsspielraum gelassen. Die Modellberechnungen beschränken sich deshalb nicht allein auf die ausgewählten, von der EU und von Russland namentlich sanktionierten einzelnen Gütergruppen. Da außerdem der Absatz der mit den sanktionierten Gütergruppen eng verbundenen nicht-sanktionierten Güter infolge der Sanktionspolitik Einbußen erleidet, werden in den Berechnungen alle Produktionsbereiche mit ihren jeweiligen Verlusten in den Blick genommen. Eine ausschließliche Betrachtung der sanktionierten Sektoren griffe nicht nur aufgrund der Kettenreaktionen zu kurz. Deshalb wird bei der Berechnung der Sanktionseffekte von einem breiteren als dem direkt sanktionierten Güterspektrum ausgegangen.

\section{Analyseansatz: Offenes, statisches Leontief-Modell}

Um die Verluste aus den realwirtschaftlichen Sanktionen des EU-Russland-Konfliktes für die deutsche Volkswirtschaft zu quantifizieren, werden zunächst (i) die Auswirkungen aus dem Exportrückgang nach Russland (2014-15) insgesamt betrachtet. Der Exportrückgang umfasst sanktionsbedingte und nicht-sanktionsbedingte Einbußen. Anschließend werden (ii) die auf die Sanktionen zurückzuführenden Exportverluste (201415) analysiert. Dabei gilt es, gestützt auf Erfahrungswerte aus »Nicht-Sanktionszeiten", die gesamten Exportverluste um die sanktionsbedingten Verluste statistisch zu bereinigen. Danach gehen (iii) die für das Jahr 2016 zu erwartenden Exporteinbußen in die Berechnungen ein. Für (ii) und (iii) sind Schätzungen (Simulationen) erforderlich. Als Grundlage für die Schätzung dienen Trendfortschreibungen auf Basis der quartalweisen Entwicklung der Exporte nach Warengruppen im Jahr 2013 und in der 1. Hälfte des Jahres 2014, d. h. während des Zeitraums vor den Sanktionen. Damit kann der Export 
für die 2. Hälfte des Jahres 2014 und das Jahr 2015, d. h. den Zeitraum mit Sanktionen, aber unter Ausschluss der Sanktionen abgeleitet werden. Da auch für das Jahr 2016 die Sanktionen nicht aufgehoben worden sind, wird für die Abschätzung der Sanktionseffekte von zwei alternativen Annahmen ausgegangen: (a) die Talsohle der Effekte ist erreicht und es kommt nicht zu zusätzlichen negativen Effekten der Sanktionen; (b) der Exportrückgang setzt sich in gleicher Höhe wie im Vorjahr fort (Exportrückgang 2016 = Exportrückgang 2015 $=-7,5 \mathrm{Mrd}$. Euro). Für die Berechnungen der für das Jahr 2016 zu erwartenden Effekte wird hier von einem mittleren Weg ausgegangen (-4,9 Mrd. Euro).

Der auf die Sanktionen zurückzuführende Exportrückgang (ii) betrug 353 Millionen Euro im Jahr 2014 und 4 Milliarden im Jahr 2015. Nach unserer Modellrechnung werden die Verluste im Jahr 2016 (iii) 2,6 Milliarden Euro betragen. Um die Effekte dieses »negativen Impulses" auf die Produktion in Deutschland zu ermitteln, wird ein offenes, statisches Leontief-Modell verwendet (s. Kasten 1). Diese Herangehensweise erlaubt sowohl die direkten als auch die indirekten Effekte entlang der Wertschöpfungsketten zu analysieren. Bereits vorliegende, ähnliche Analysen weisen darauf hin, dass die indirekten Effekte stärker sein können als die direkten.

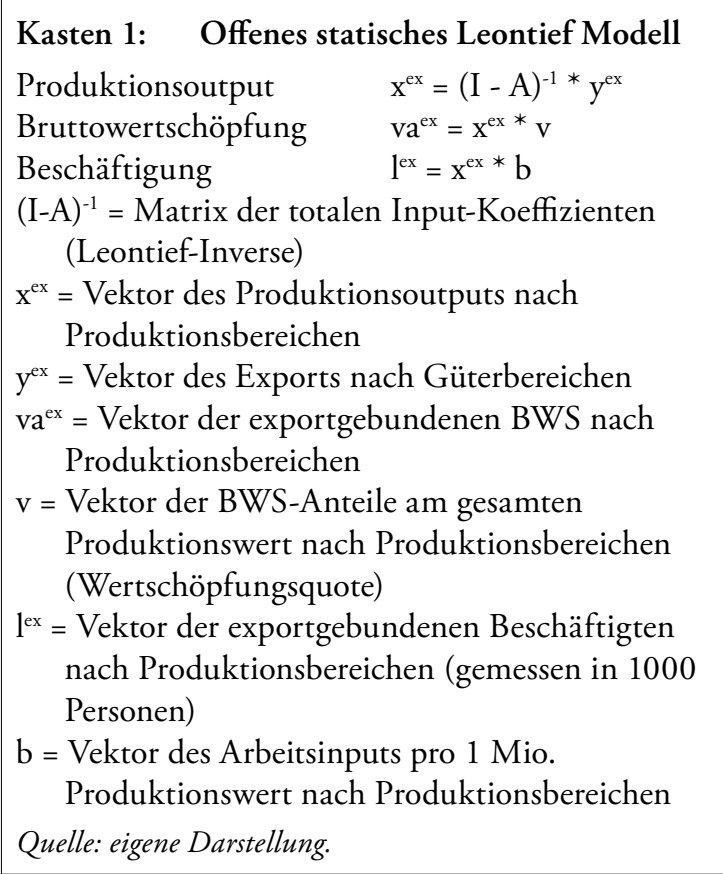

\section{Realwirtschaftlicher Einfluss der Sanktions- politik auf die deutsche Wirtschaft}

Die Berechnungen für Deutschland unter Verwendung der neuesten Input-Output-Tabelle für das Jahr 2012 weisen auf einen Verlust an inländischer Produktion in Folge des gesamten Exportrückgangs nach Russland in den Jahren 2014 und 2015 in Höhe von fast 26 bzw. 8,7 Milliarden Euro (sanktionsbedingter Produktionsrückgang) hin. Die abgeleiteten Beschäftigungseffekte entsprechen einem Verlust an Arbeitsplätzen für fast 40.000 Personen. Bei 43,32 Millionen Beschäftigten (Dezember 2015, Inlandskonzept) entspricht dieser Rückgang ca. 0,09 Prozent aller Erwerbstätigen in Deutschland (s. Tabelle 2 auf S. 24).

Zudem wirken die Exportverluste der sanktionierten Gütergruppen wegen der intensiveren Produktionsverflechtungen stärker über die Wertschöpfungsketten auf die Gesamtwirtschaft durch als die Exporte nach Russland im Schnitt. Der Produktions- bzw. Beschäftigungsmultiplikator ist deutlich größer.

Nach dem Mittelweg-Szenario für das Jahr 2016 kann der Produktionsverlust knapp über 5 Milliarden Euro erreichen und die Einbußen an Bruttowertschöpfung betragen 1,8 Milliarden Euro, was einem BIP-Verlust von ca. 0,06 Prozent entspricht. Der kumulierte BIP-Verlust über den gesamten Betrachtungszeitraum (2014-2016) beläuft sich auf bis 0,15 Prozent.

\section{Sektorale Effekte}

Die Berechnungen zeigen, dass die exportorientierten Sektoren mit starken sektoralen Verflechtungen wie bspw. die Automobilindustrie, der Maschinenbau sowie die Elektrotechnik- und Elektronikindustrie besonders betroffen sind. So verloren die Hersteller von Kraftwagen und Kraftwagenteilen (Sektor 29 lt. CPA) im ersten Sanktionsjahr 2014 Produktion in Höhe von ca. 816 Millionen Euro, die sonstigen Fahrzeugbauer (Sektor 30), deren Güterpalette unmittelbar von den Sanktionen betroffene "schwimmende, tauchende Bohr-/Förderplattformen und Feuerlöschschiffe, Schwimmkrane u. a." enthält, sogar ca. 865 Millionen Euro. Im zweiten Sanktionsjahr erleiden der sonstige Fahrzeugbau mit 1.529 Millionen Euro, der Maschinenbau (Sektor 28) mit 1.437 Millionen Euro, und die Hersteller von Eisen und Stahl (Sektor 24.1-24.3) mit 646 Millionen Euro die stärksten Verluste. Im dritten Sanktionsjahr verlieren Hersteller von sonstigen Fahrzeugen 926 Millionen Euro am Output, die Maschinenbauer etwas über 728 Millionen Euro und die Hersteller von Eisen und Stahl 435 Millionen Euro. Der Nahrungsmittelsektor weist zwar einen erheblichen Exportrückgang in Höhe von über 30 Prozent im Jahr 2014 auf, der Produktionsverlust (28 Mio. Euro) kann aber im Vergleich zu den oben genannten Sektoren als moderat eingestuft werden.

\section{Fazit: Nachhaltiges Schadenspotential durch Sanktionen}

Der wirtschaftliche Schaden der realwirtschaftlichen Sanktionen ist für Deutschland weitaus größer als das 
allein die Exportrückgänge nach Russland ausdrücken. Die indirekten Effekte auf die Beschäftigung sind durchweg höher als die direkten Effekte. Dabei sind die Multiplikatoren der auf die Sanktionen zurückzuführenden Effekte deutlich größer als im Durchschnitt. Das hängt damit zusammen, dass stärker verflochtene Sektoren (z. B. Automobilindustrie, Maschinenbau, Metallbranche) von der Sanktionspolitik in höherem Maße betroffen sind.

Mit der Dauer der Sanktionen steigen die Belastungen. So konnten 2014 7,7 Prozent des Output-Verlusts infolge des Exportrückgangs nach Russland auf die Sanktionen zurückgeführt werden, währenddessen der
Anteil im Jahr 2015 bereits 55 Prozent erreichte. 2016 kann dieser Anteil 50 Prozent überschreiten. Auch wenn einige Annahmen getroffen werden mussten, um solche Berechnungen zu ermöglichen, und die Ergebnisse in der Realität in der einen oder anderen Richtung abweichen können, unterstreichen sie doch den Schaden für die deutsche Wirtschaft. Außerdem bergen anhaltende Sanktionen das Risiko, Märkte an die Konkurrenz auf lange Zeit zu verlieren und auch die nicht-sanktionierten Bereiche sowie die Energieversorgungs- und die Direktinvestitionsbeziehungen mit Russland zu belasten.

Eine frühere Version dieses Beitrags erschien in: "Wirtschaftsdienst - Zeitschrift für Wirtschaftspolitik", Heft 7/Juli 2016, S. 524-526. Für die Neuveröffentlichung wurden die Berechnungen auf Basis der im August 2016 veröffentlichten InputOutput-Tabellen für Deutschland aktualisiert.

\section{Über die Autoren}

Jutta Günther: Seit 2014 hat Jutta Günther die Professur für Volkswirtschaftslehre, insbesondere Innovations- und Strukturökonomik, an der Universität Bremen inne. Zuvor war sie mehrere Jahre in leitenden Positionen am Leibniz Institut für Wirtschaftsforschung in Halle (IWH) tätig. Ihre Forschungsinteressen gelten der Systemtransformation, dem Strukturwandel und Innovationsprozessen. Ihre neuesten Publikationen: J._Günther, M. Kristalova: No risk no fun? Foreign Direct Investment in Central and Eastern Europe, in: Intereconomics - Review of European Economic Policy, 51.2016, Nr. 2, S. 95-99. B. Jindra, S. Hassan, J. Günther, U. Cantner: European integration and outward FDI from Central and East Europe Is there evidence of knowledge-seeking? In: Journal of Common Market Studies, 53.2015, Nr. 6, S. 1248-1267.

Maria Kristalova: Seit 2015 ist Maria Kristalova wissenschaftliche Mitarbeiterin im Fachbereich Wirtschaftswissenschaft der Universität Bremen. Ihre Forschung beschäftigt sich mit empirischen Analysen des Strukturwandels und seiner internationalen Dimension. Ihre neueste Publikation: J. Günther, M. Kristalova: No risk no fun? Foreign Direct Investment in Central and Eastern Europe, in: Intereconomics - Review of European Economic Policy, 51.2016, Nr. 2, S. 95-99. Udo Ludwig: Seit 2005 ist Udo Ludwig Professor für Empirische Wirtschaftsforschung an der Universität Leipzig. Er war von 1992 bis Mitte 2009 Abteilungsleiter für »Konjunktur und Wachstum« am IWH (Halle Institute for Economic Research). Seine Forschungsinteressen liegen auf dem Gebiet der Konjunktur- und Strukturanalyse. Seine neueste Publikation: H.-U. Brautzsch, J. Günther, B. Loose, U. Ludwig, N. Nulsch: Can R\&D subsidies counteract the economic crisis? - Macroeconomic effects in Germany, in: Research Policy, 44.2014, S. 623-633.

\section{Lesetipps}

- $\quad$ Einen guten Überblick über die EU-Sanktionen gegen Russland gibt die Website der GTAI Germany Trade \& Invest: <http://www.gtai.de/GTAI/Navigation/DE/Trade/Maerkte/Dossiers/russland-sanktionen.html>.

Weitere Quellen:

- E. Christen, O. Fritz, G. Streicher: Effects of the EU-Russia Economic Sanctions on Value Added and Employment in the European Union and Switzerland. Austrian Institute of Economic Research, Wien 2015.

- Dreger, Christian; Konstantin Kholodilin: Der Rubel zwischen Hammer und Amboss. Der Einfluss von Ölpreisen und Wirtschaftssanktionen, in: DIW-Wochenbericht, 2015, Nr. 44, S. 1051-1057.

- International Crisis Group: The Eurasian Economic Union: Power, Politics and Trade [= Europe and Central Asia Report $\mathrm{N}^{\circ} 240$ ], July 2016; <http://www.crisisgroup.org/-/media/Files/europe/central-asia/240-the-eurasian-economicunion-power-politics-and-trade. pdf>.

- Kholodilin, Konstantin A.; Aleksei Netšunajev: Crimea and Punishment. The Impact of Sanctions on Russian and European Economies [= Deutsches Institut für Wirtschaftsforschung. Discussion Papers 1569], Berlin: DIW 11.4. 2016; <http://www.diw.de/documents/publikationen/73/diw01.c.530645.de/dp1569.pdf>.

- G. Kolev: Strukturelle Schwäche der russischen Wirtschaft, in: Wirtschaftsdienst, 96. 2016, Nr. 5, S. $357-363$.

- Oxenstierna, Susanne; Per Olsson: The Economic Sanctions against Russia - Impact and Prospect of Success, Stockholm: FOI September 2015; <http://www.foi.se/templates/Pages/DownloadReport.aspx?FileName=e9be8972-4bff-9643-b7afdc239946.pdf>. 
- Schrader, Klaus; Laaser, Claus-Friedrich: Der deutsch-russische Außenhandel: Eine Bestandsaufnahme [=ifw Policy Brief Nr. 73], April 2015; <https://www.ifw-kiel.de/wirtschaftspolitik/politikberatung/kiel-policy-brief/ kpb-2014/KPB73.pdf $>$ ).

- Secrieru, Stanislav: Russia under sanctions: assessing the damage, scrutinising adaptation and evasion, Warsaw: PISM November 2015; <https://www.pism.pl/publications/PISM_Reports_ Russia-under-Sanctions-Assessing-the-Damage-Scrutinising-Adaptation-and-Evasion>

- Antwort der Bundesregierung auf die Kleine Anfrage der Abgeordneten Thomas Lutze, Klaus Ernst, Wolfgang Gehrcke, weiterer Abgeordneter und der Fraktion DIE LINKE. - Drucksache 18/6483 - Auswirkungen der Sanktionen der Europäischen Union gegen die Russische Föderation. Deutscher Bundestag 18. Wahlperiode, 16.11. 2015; <http://dip21.bundestag.de/dip21/btd/18/067/1806715.pdf>.

Tabelle 2: Effekte des gesamten (i) und des sanktionsbedingten (ii) Exportrückgangs nach Russland für den Zeitraum 2014 bis 2015

\begin{tabular}{|c|c|c|c|c|}
\hline & & (i) & (ii) & $\begin{array}{c}\text { \% der gesamten } \\
\text { Verluste }\end{array}$ \\
\hline Direkter Produktionseffekt & \multirow{3}{*}{ Mio. EUR } & -14.058 & -4.416 & \\
\hline Indirekter Produktionseffekt & & -12.392 & -4.310 & \\
\hline Insgesamt & & -26.450 & -8.726 & $33,0 \%$ \\
\hline Direkter Beschäftigungseffekt & \multirow{3}{*}{$\begin{array}{c}1.000 \\
\text { Beschäftigte }\end{array}$} & $-51,2$ & $-13,2$ & \\
\hline Indirekter Beschäftigungseffekt & & $-81,3$ & $-26,0$ & \\
\hline Insgesamt & & $-132,5$ & $-39,2$ & $29,6 \%$ \\
\hline \multicolumn{5}{|c|}{ Multiplikatoren (Verhältnis Gesamteffekt zu direktem Effekt) } \\
\hline Produktion & & 1,88 & 1,98 & \\
\hline Beschäftigung & & 2,59 & 2,98 & \\
\hline
\end{tabular}

Quelle: eigene Berechnungen.

Tabelle 3: Effekte des simulierten Exportrückgangs nach Russland insgesamt und aufgrund der Sanktionen (2016 bzw. 2014-2016)

\begin{tabular}{|c|c|c|c|c|c|}
\hline & & $\begin{array}{c}2016 \\
\text { (gesamt) }\end{array}$ & $\begin{array}{c}2016 \\
\text { (sanktions- } \\
\text { bedingt) }\end{array}$ & $\begin{array}{l}2014-16 \\
\text { (gesamt) }\end{array}$ & $\begin{array}{c}2014-16 \\
\text { (sanktions- } \\
\text { bedingt) }\end{array}$ \\
\hline Direkter Produktionseffekt & \multirow{3}{*}{ Mio. EUR } & -4.891 & -2.641 & -18.949 & -7.057 \\
\hline Indirekter Produktionseffekt & & -4.147 & -2.452 & -16.539 & -6.762 \\
\hline Insgesamt & & -9.038 & -5.093 & -35.488 & -13.819 \\
\hline Direkter Beschäftigungseffekt & \multirow{3}{*}{$\begin{array}{l}1000 \mathrm{Be}- \\
\text { schäftigte }\end{array}$} & $-19,2$ & $-9,4$ & $-70,4$ & $-22,6$ \\
\hline Indirekter Beschäftigungseffekt & & $-27,4$ & $-15,5$ & $-108,7$ & $-41,5$ \\
\hline Insgesamt & & $-46,6$ & $-24,9$ & $-179,1$ & $-64,1$ \\
\hline \multicolumn{6}{|c|}{ Multiplikatoren (Verhältnis Gesamteffekt zu direktem Effekt) } \\
\hline Produktion & & 1,85 & 1,93 & 1,87 & 1,96 \\
\hline Beschäftigung & & 2,43 & 2,64 & 2,55 & 2,84 \\
\hline
\end{tabular}

Quelle: eigene Berechnungen. 


\section{Wahrnehmung der Wirtschaftskrise und ihrer Auswirkungen}

Grafik 21: Stimmen Sie zu oder nicht zu, dass derzeit in Russland eine Wirtschaftskrise herrscht?

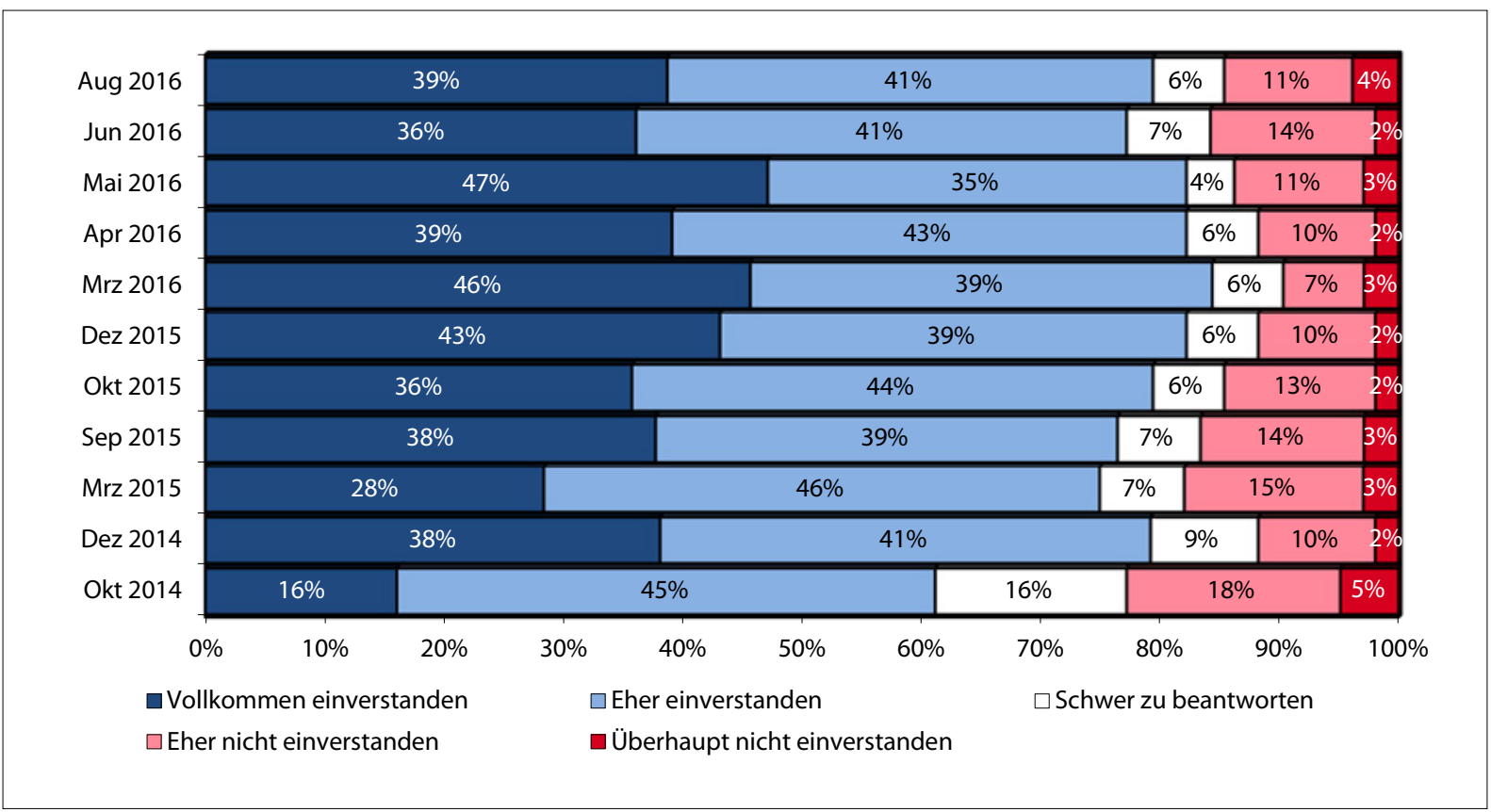

Quelle: Umfragen des Lewada-Instituts vom 26.-29. August 2016, <http://www.levada.ru/2016/09/26/krizis-i-ozhidaniya-uvolnenij/>, 28. September 2016

Grafik 22: Erwarten Sie oder Ihre Familienmitglieder Gehaltskürzungen?

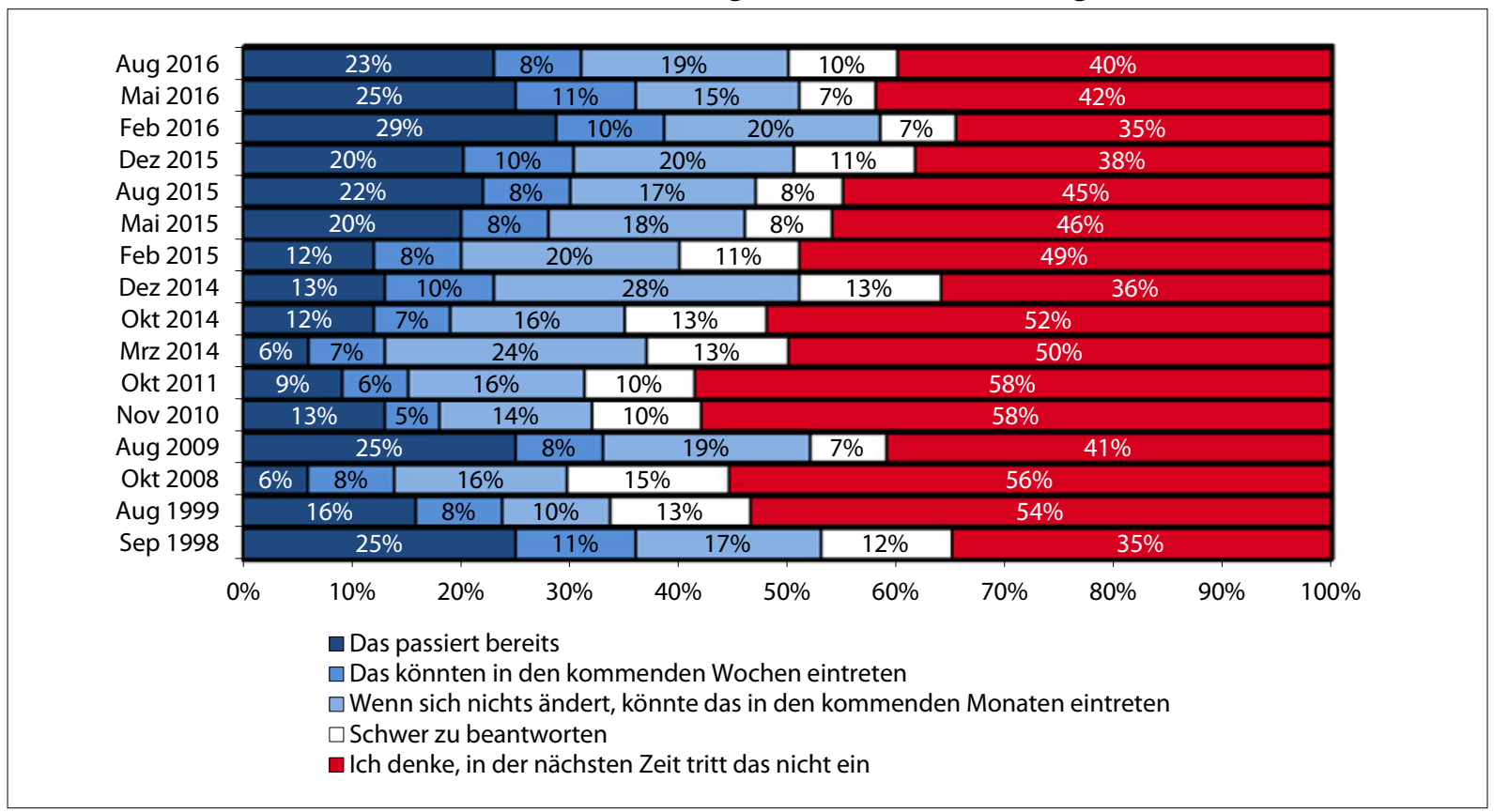

Quelle: Umfragen des Lewada-Instituts vom 26.-29. August 2016, <http://www.levada.ru/2016/09/26/krizis-i-ozhidaniya-uvolnenij/>, 28. September 2016 


\section{Einschätzung des Einflusses der Sanktionen auf die Wirtschaftskrise}

Grafik 23: Denken Sie, dass die Sanktionen seitens anderer Länder die Wirtschaft unseres Landes beeinflusst oder nicht beeinflusst?

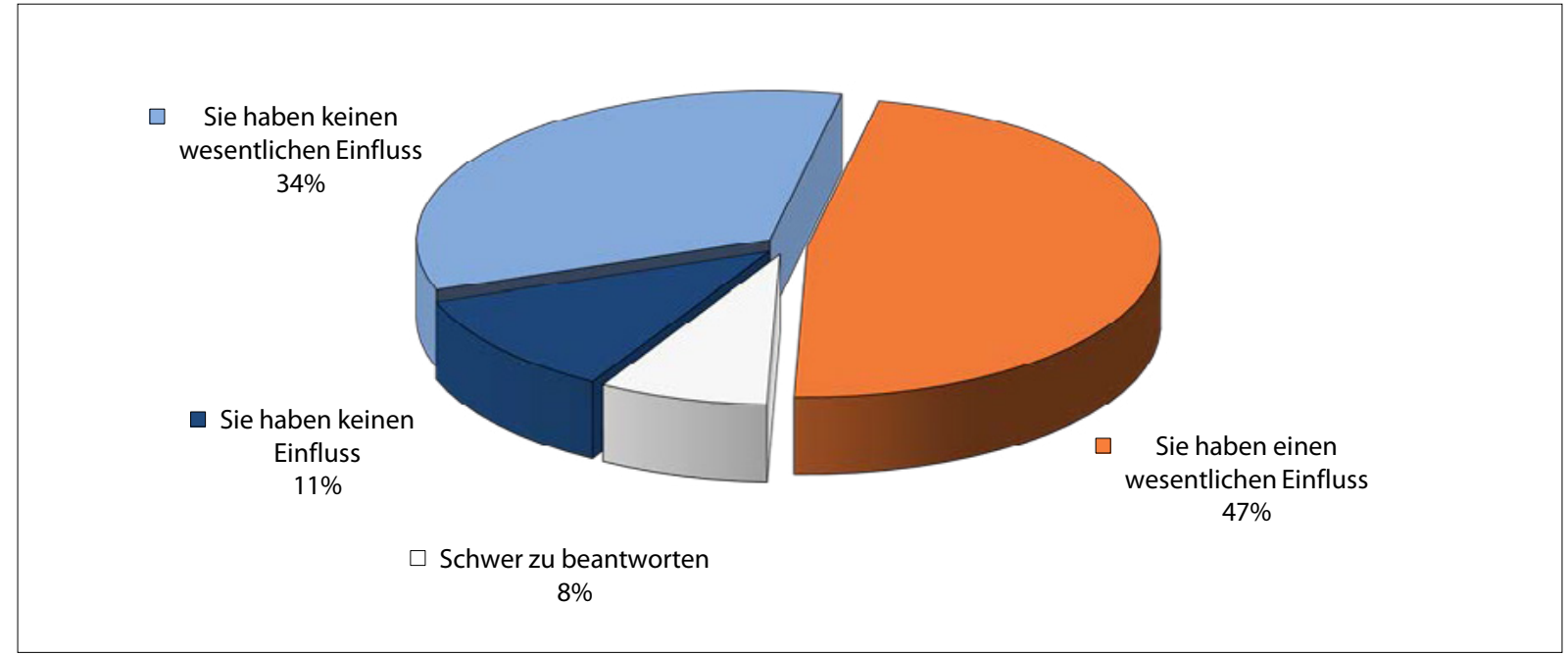

Quelle: Umfragen des FOM vom 25.-26. Juni 2016, <http://fom.ru/Ekonomika/12740>, 11. Juli 2016

Grafik 24: Was denken Sie, haben die durch Russland verhängten Einfuhrverbote die Wirtschaft unseres Landes beeinflusst oder nicht beeinflusst?

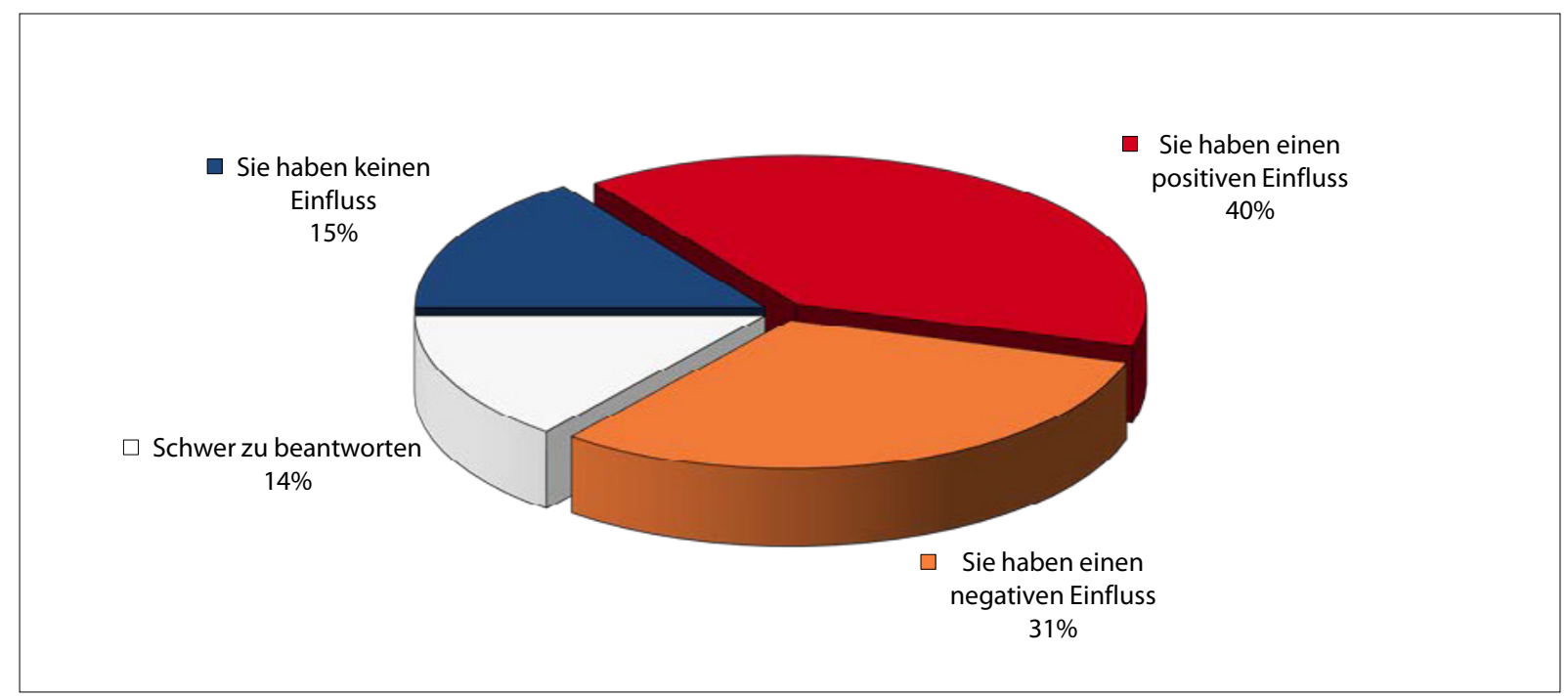

Quelle: Umfragen des FOM vom 25.-26. Juni 2016, <http://fom.ru/Ekonomika/12740>, 11. Juli 2016 


\title{
Ein Trumpolin für neue Beziehungen zwischen den USA und Russland?
}

\author{
Sergey Medvedev, Berlin/Moskau
}

Der Wahlsieg von Donald Trump hat die ganze Welt überrascht. Die Wahlergebnisse waren für viele Deutsche am frühen Morgen am 9. November ein Schock. In Russland wurde auf den Wahlausgang mit Jubel und Hoffnung reagiert. Wladimir Putin gratulierte Trump per Telegramm und äußerte den Wunsch, mit der neuen Administration in Washington die Beziehung beider Länder aus der Krise zu führen. Nach der Verkündung der Wahlergebnisse während der Vormittagssitzung in der Duma klatschten die Abgeordneten spontan Beifall. Wladimir Schirinowskij, der Vorsitzende der rechtspopulistischen LDPR, den Beobachter angesichts seiner Rhetorik und Weltansichten oft mit Trump verglichen haben, lud seine Kollegen und Journalisten während der Mittagspause zum Sektempfang ein und bat alle "auf Donald Trump, auf den Sieg« zu trinken. Der Sieg Trumps lässt Experten nachdenken, ob es nach dem Wechsel in der Präsidialadministration einen Neuanfang in der Beziehung zwischen den USA und Russland geben könnte.

\section{Ich hoffe auf Entspannungspolitik}

Wadim Wolkow, Soziologe, Europäische Universität St. Petersburg

"Geht die rechte Revanche der werktätigen »echten Männer « weiter? Die Medien-Eliten lieferten anstatt von Prognosen Projektionen ihrer Wünsche. Die gebildete Mittelschicht hat aus Arroganz die lower middle class und die Arbeiter als politische Kraft nicht beachtet. Die zwei globalisierten Küsten haben lange nicht in die kontinentale Peripherie hineingeschaut. Die Soziologen wollten nichts anderes machen außer sampling und polling... Und dann kam es irgendwie unerwartet. [...] Nun müssen die Vorstellungen über die Weltordnung korrigiert werden. Mit Clinton zusammen räumen politische Korrektheit, Toleranz und vielleicht sogar Globalisierung ihre Positionen. Ich persönlich hoffe auf eine Lockerung der internationalen Spannungen und darauf, dass man unser Land nicht mehr auf einen Krieg vorbereiten wird." Wadim Wolkow am 9. November 2016 auf Facebook; <https://www.facebook.com/vadim.volkov.169/ posts/1081714738613059>.

\section{Warum wird uns auch jetzt niemand mögen?}

\section{Viktor Schenderowitsch, Publizist}

"[...] Der Sieg eines konservativen Populisten in Ungarn oder der Türkei ist ein Ärgernis; der Sieg eines konservativen Populisten im mächtigsten Staat der Welt (vor dem Hintergrund des fast völlig gestörten Gleichgewichts bei internationalen Verhandlungen und Mechanismen) ist natürlich sehr gefährlich. Es bleibt nur, auf die Stärke des amerikanischen politischen Systems zu hoffen, das sogar einen Ultrapopulisten ausbalancieren kann. Vom heutigem Tag an beginnt nämlich eine gründliche Überprüfung dieses Systems.

Aber immerhin: Das amerikanische Volk hat seine Wahl getroffen, und keine OMON [Sondereinheit der Polizei], keine Nationalgarde, keine Interpreten der Verfassung haben je auch nur daran gedacht, auf diese rechtmäßige Wahl Einfluss zu nehmen. Sowohl Obama als auch Hillary geben friedlich die Macht ab, ohne irgendwelche Konsequenzen für die eigene Freiheit oder Gesundheit.

Wie heißt es so schön: Finden sie zehn Unterschiede.

Was in dieser Situation die Sicht auf unsere Gefilde angeht, sieht hier alles unerwartet interessant aus.

Acht Jahre war Obama an allem schuld. Wir haben Trump, könnte man sagen, selbst gewählt. (Wenn der Herr einen Menschen bestrafen will, erfüllt er dessen Wünsche, lautet eine arabische Redewendung). Und was jetzt, fragt man sich? Wer wird schuld an unserer Isolation sein? Warum wird uns auch jetzt niemand mögen? [...]

Ich sehe schon vor meinem inneren Auge das Brainstorming am Alten Platz [in der Präsidialverwaltung, d. Red.] und in Ostankino [beim russisches Fernsehen; d. Red.]. Seit dem frühen Morgen braucht Russland einen neuen globalen Feind - Right now! möchte man sagen. Einen Feind, der von uns eine volle Konsolidierung rund um den unsterblichen Anführer erfordert, dieses alte Pferd am ewigen Übergang; einen hinterhältigen und starken Feind, der kaputte Straßen entschuldigt, Inflation, die Notwendigkeit, den Gürtel enger zu schnallen, der das fehlende Wasser in der Leitung erklärt... Oder werden wir das Rad nicht neuerfinden und überlassen Amerika diesen Platz? Dann sollten sie wissen, dass Trump sehr bald Russland verraten wird, das ihm so geholfen hat, die großzügige offene Seele...

Also, schalten Sie die Sendung ,Westi ein!«

Viktor Schenderowitsch am 9. November 2016 aufFacebook; <https://www.facebook.com/permalink.php?story_fbid=11 86509774751097\&id $=100001762579664>$. 


\section{Verloren hat nicht nur Clinton, sondern auch Obama}

Konstantin von Eggert, Journalist, Fernsehmoderator bei Doschd

„Unabhängig von der Haltung gegenüber Trump - erkennt denn irgendjemand von den Verehrern des Professors aus Chicago an, dass Obama eine Katastrophe für seine Partei wie auch für sein ideologisches Programm und für das Land bedeutet hat? Wo sind all die unzähligen Anhänger des linken Kurses, die Amerika für immer umwandeln wollten? Wie ich schon sagte, ist [Obama] eine narzisstische Person, deren Auftritte, worum es auch immer gehen mag, einem Thema gewidmet waren - seiner eigenen Großartigkeit und Selbstgerechtigkeit. Verloren hat nicht nur Clinton, sondern auch Obama."

Konstantin von Eggert am 10. November 2016 auf Facebook; <https:/www.facebook.com/konstantin.voneggert/ posts/10153866762680780>.

\section{Kein Zweifel, wir werden uns mit Trump einigen}

"Dieselben Propagandisten, die buchstäblich gerade eben noch erzählt haben, dass Trump nie und nimmer und unter keinen Umständen die Wahlen in den USA gewinnen wird, haben schon ein neues Lied angestimmt. Nun erklären sie - wieder im Chor -, Trump habe zwar gewonnen, doch sollte man sich nicht darüber freuen. Russland habe keine Chance, mit der neuen Administration der USA Absprachen zu treffen. Die neuen würden noch schlimmer als die alten.

Und wieder versuchen sie, sich selbst zu täuschen. Chancen, sich zu einigen, die gibt es natürlich. Die Argumente sind Folgende:

Erstens, die Psychologie. Nach der Erfahrung mit Berlusconi wissen wir, dass es Putin leichtfällt, mit einem extrovertierten Menschen und Showman wie Trump umzugehen. Das ehemalige Team von Obama war schwierig, weil es aus arroganten, geschlossenen, eher stur und formalistisch gestimmten Leuten bestand - jetzt gibt es einen großen Spielraum für Improvisation.

[...] Ich wiederhole, Trump ist ein Showman, er liebt Aufmerksamkeit. [...] Und wenn er nach Europa reist, erwarten ihn zwangsläufig Spucke, Pfiffe und Schimpfkanonaden linker Aktivisten und die Kälte der Eliten dort. Dafür wird er in Russland empfangen werden wie einst John Kennedy in West-Berlin. Diese Haltung, diese zweifellos aufrichtige Zustimmung, wird er als Schauspieler mit Gespür für Applaus sofort wahrnehmen.

Auf die Politik wirken solche Dinge - die scheinbar nicht seriös, persönlich sind -, viel stärker, als sich das viele vorstellen.

Nun zur Politik.

Trump hätte in der Tat Schwierigkeiten, sich mit Russland zu einigen, falls das heutige Russland - so schreit es die Propaganda, vor allem »deren« aber teilweise auch unsere - den Anspruch hätte, ein Rivale Amerikas zu sein, eine Weltmacht, oder den Anspruch auf Wiedererrichtung des Imperiums in dieser oder jener Form.

Dann hätten wir zwangsläufig eine direkte Kollision, nichts würde da mehr helfen.

Diese Ambitionen gibt es aber nicht.

In Wirklichkeit ist unsere Regierung moderat und kompromissbereit gestimmt. Manchmal hat sie mehr Kompromissbereitschaft, als man sich wünschte. Der ganze Konflikt mit der westlichen Welt erfolgte ja nicht, wie viele Verrückte das schreiben, weil wir diese erobern und jene unterwerfen wollen. Sondern deshalb, weil sich in den USA und sogar auch in Europa die Haltung durchsetzte, dass man keine Kompromisse braucht. Gar keine.

Assad muss gehen. Punkt. Ukraine ist ein Flaggschiff der Demokratie. Punkt. Wir dürfen das, ihr dürft das nicht. Punkt. Und so weiter auf der Liste.

Die andere Seite sollte nur für einen Moment annehmen, dass man mit Russland feilschen kann, dass tatsächlich bestimmte versöhnliche und Zwischenpositionen möglich sind, dann stellte sich sofort heraus, dass es eine Million Varianten gibt, sich zu vertragen.

Und Trump ist jener Mensch, der ganz einsam betont hat, dass wir einen solchen Kompromiss brauchen. [...] Russland wird sich mit Trump einigen. Nicht aber mit den Propagandisten. Im Unterschied zu Vampiren und Alien sind die nämlich völlig uneinsichtig."

Dmitrij Olschanskij am 11. November 2016 auf kp.ru; <http://www.kp.ru/daily/26605/3622198/>.

\section{TRUMPolin in eine neue Zukunft?}

Konstantin Kossatschow, Mitglied des Föderationsrats

"[...] Uns interessiert selbstverständlich vor allem, was insgesamt aus der Außenpolitik der USA wird, und aus den russisch-amerikanischen Beziehungen im Besonderem. Und es scheint eine klare Nachfrage nach Erneuerung zu geben. Ich denke, [dafür gibt es] auch ein bestimmtes Mandat der Wähler. Es gibt aber auch Nuancen: 
1. Trump kennt sich in der Außenpolitik nicht aus. Deswegen sind die Posten des Leiters des State Department und der außenpolitische Berater wichtig.

2. Er wird es mit einem antirussischen überparteilichem Konsens im Kongress zu tun haben, und das ist ein deutlicher Bremsfaktor.

3. Es wird Druck geben, von außen durch die Verbündeten der USA, vor allem in Europa, wo jetzt die Stimmung zwischen Panik und Enttäuschung liegt.

[...]

Ich denke, dass Russland entsprechende Signale senden sollte, damit das neue Oberhaupt Amerikas versteht: Hier gibt es keinen genetischen oder künstlich gezüchteten Antiamerikanismus, von dem einige Experten - hier wie dort - so gerne reden. Wie es auch keinen Wunsch gibt, den Kalten Krieg oder irgendein Imperium wiederzubeleben, das die USA unbedingt herausfordern will. Wir sind sehr wohl für einen Dialog; und was wir uns in den letzten 25 Jahren wünschten, ist: Gehör zu finden. Dort, wo man nicht auf uns gehört hat (Ukraine, Raketenabwehr der USA usw.) gab es unvermeidlich Probleme. Die hätte man vermeiden können, wenn man vorher miteinander gesprochen hätte.

Es wird bestimmt keinen "Reset" geben. Es ist aber etwas viel Bedeutsameres geschehen - ein "Reset" von Amerika selbst. Ich kann diesem ohne Zweifel großen Land, das seine Fähigkeit zur Erneuerung bewiesen hat, nur gratulieren - wie natürlich auch Donald Trump, dem 45. Präsidenten der Vereinigten Staaten Amerikas." Konstantin Kossatschow am 9. November 2016 bei izvestia.ru; <http://izvestia.ru/news/643844\#ixzz4PzKQIedP>.

\section{Präsident Trump: Gut oder schlecht für Russland?}

Alexej Nawalnyj, Politiker und Antikorruptionsblogger

„Was für mich in der russischen Diskussion über die amerikanischen Wahlen am unerklärlichsten ist, ist die Frage, warum die Putinschen Medien und Bürokraten so überzeugt sind, dass ein Präsident Trump ein Geschenk für sie bedeutet. [...]

Ja, es wird höchstwahrscheinlich in den Beziehungen zwischen den USA und Russland keine Beimischung persönlicher Abneigung zwischen den Oberhäuptern geben. Hillary hat gegen Ende ihres Wahlkampfes so viel über Putin gesprochen, dass so etwas zweifellos entstanden wäre, nun wird es das aber nicht geben.

Woran sonst können wir einen prorussischen oder gar putinfreundlichen Charakter Trumps erkennen?

Schauen wir uns das < Programm von Trump> und seine (meiner Meinung nach) < wichtigste Wahlkampfrede> an und analysieren.

1. Die Politik Trumps wird wahrscheinlich zu einem Fall der Erdölpreise führen (die sind bereits nach der Nachricht über seinen Sieg <gefallen>) [...]

Die USA verfügen über riesige Erdölvorräte. Ihre Förderung und Export wurden künstlich zurückgehalten. Ein volles grünes Licht für die Öl-Leute wird zum Anstieg des Angebots führen und die Preise nach unten drücken. Klar, wird es sich auf den russischen Haushalt auswirken.

2. Anerkennung der Krim, Aufhebung der Sanktionen. Ja, Trump hat gesagt, dass er die Anerkennung der Krim in Betracht ziehen werde, das war aber im Jahr 2014. Er hat gesagt, Putin sei cool und besser als Obama, aber das ist schon lange her. Vor weniger als einem Monat sprach er aber von Bombardements in Aleppo und sagte, er revidiere seine Meinung über Putin und wisse nicht, wie die Beziehungen aussehen werden, räumte dabei aber ein, dass sie "furchtbar" werden könnten.

3. Rüstungswettlauf. [...] für die Einhaltung des Gleichgewichts werden wir nach wie vor Unmengen Geld ausgeben müssen und dabei unseren Haushalt aufzehren. Das empfindlichste Rüstungsthema für uns ist die Raketenabwehr PRO; hier tritt der neue Vizepräsident Pence als sehr viel heftigerer Falke auf als alle Administrationen vor ihm. [...]

4. Putin und Trump sind Politiker mit prinzipiell entgegengesetzten Ansichten. Ganz gleich, bei welcher Frage:

- Migration. Trump: Mauer. Putin: gegen Visapflicht für die Länder Zentralasiens.

- Staat in der Wirtschaft: Trump: Rückzug. Putin: Staatskapitalismus und Anstieg der Anzahl der Staatsbediensteten.

- Waffen an Bürger. Trump: dafür. Putin: ausdrückliches Nein.

- Islamisierung. Trump: wir werden Migration aus problemhaften islamischen Ländern verbieten. Putin: schwachsinnige Zitate darüber, dass die Orthodoxie dem Islam näher steht.

- Korruption. Trump hat seine Kampagne auf Erklärungen über deren Bekämpfung aufgebaut. Das sind seine zentralen Versprechungen. Putin hat die Korruption zur Grundlage seines Regimes gemacht.

Und so weiter, und so fort. Nach allen Punkten.

Der wichtigste Grund, warum ich denke, dass die Wahl Trumps nichts ändern wird: Es wird uns weder besser, noch schlechter gehen. 
Die amerikanische Außenpolitik ist kein Rennwagen, der von einer Person gesteuert wird. Bei uns ist das möglich, ja - innerhalb von zwei Monaten sind die Türken erst unsere Verbündeten, dann ärgste Feinde, und dann wieder beste Freunde.

In einem Land, wo es Institutionen der Staatsmacht gibt, funktioniert das anders. Da ist das eher wie ein beladener Tanker. Selbst wenn man unbedingt will, dass er abbiegt, wird er aus Trägheit noch lange Zeit weiter auf seinem Kurs durchs Meer ziehen. [...]《 Alexej Nawalnyj am 9. November 2016 bei navalny.com; <https://navalny.com/p/5124/>

Ausgewählt und eingeleitet von Sergey Medvedev, Berlin (Die Blogs, auf die verwiesen wird, sind in russischer Sprache verfasst)

\section{Lebt in Russland ein »russländisches Volk«?}

Jens Siegert, Moskau

A uch in Russland geht, jedenfalls laut Verfassung, alle Macht vom Volke aus. Allerdings ist es weit schwieriger, dieses Volk näher zu beschreiben als in den meisten klassischen Nationalstaaten. In Deutschland zum Beispiel ist der Souverän "das deutsche Volk». Nun gibt es zwar auch ein "russisches Volk» (russisch: »russkij narod«). Dieser Begriff bezeichnet aber nur die ethnischen Russen. Alle anderen Ethnien oder Völker, von denen viele sogar eigene "Republiken«, "autonome Bezirke" oder "autonome Kreise" haben, dort meist schon viel länger sind als die ethnischen Russen (die sie irgendwann kolonisiert haben), gehören also in diesem engen Sinn nicht zum "russischen Volk«. Die aktuelle Verfassung, angenommen im Dezember 1993 und in den grundlegenden Teilen bis heute unverändert, erlaubt sich daher einen Kunstgriff, um das Staatsvolk zu definieren, und spricht zweimal, in der Präambel und im dritten Artikel, vom »multinationalen Volk« Russlands. Wörtlich heißt es in Artikel 3, Absatz 1: »Träger der Souveränität und einzige Quelle der Macht in der Russländischen Föderation ist ihr multinationales Volk« (die russische Verfassung auf Deutsch gibt es hier: <http:// www.constitution.ru/de/index.htm>).

Nun ist es mit Kunstgriffen so ein Ding. Oft helfen sie, meist aber nur zeitweise, selbst wenn diese Zeit mitunter durchaus lange dauern kann. Ich habe schon mehrfach auf die daraus entstanden und weiter bestehenden Probleme hingewiesen (zum Beispiel, aus aktuellem Anlass, im Frühherbst 2010 in Bezug auf immer mal wieder aufflackernde, auch gewalttätige Auseinandersetzungen zwischen unterschiedlichen ethnischen Gruppen hier: <http://russland.boellblog. org/2010/12/19/nationalistische-demonstrationenund-strassenschlachten-russland-brennt-unddie-zuendteufel-fluestern-feuer/>). Der Begriff vom "multinationalen Volk» konnte und kann aber nicht das tiefere, dahinter liegende Problem verdecken, wie in aus einer Gesellschaft, in der vorwiegenden in bioethnischen Kategorien gedacht wird, ein funktionierenden und zusammen haltender Nationalstaat werden kann.

Seit der Annexion der Krim wird die Entwicklung Russlands wieder vermehrt mit den Begriffen »Imperium" oder "Imperialismus" beschrieben. Mir scheint das nicht zutreffend zum sein. Selbstverständlich hat die russische Politik gegenüber seinen unmittelbaren Nachbarn einen stark imperialistischen Einschlag. Ihr Treiber, so kommt es mir vor, ist aber weniger das Bestreben der (Wieder-)Herstellung eines "russischen Imperiums« (zuletzt im Übrigen die Selbstbezeichnung Russlands vor der Oktoberrevolution 1917), als vielmehr die Notwendigkeit, sich nach dessen Ende (in der Form der Sowjetunion) als Nationalstaat neu erfinden zu müssen (siehe dazu auch hier: <http://russland.boellblog. org/2014/04/10/vom-imperium-zur-nation-und-niewieder-zurueck/>). Damit ist Russland ein Nachzügler unter den Sowjetunionnachfolgestaaten. Was allerdings kaum verwundern kann, denn alle anderen Sowjetrepubliken haben ihre Nationalstaaten in dezidierter Abgrenzung zur ehemaligen Kolonialmacht Russland und auf der Basis einer dominierenden Ethnie entwickelt. Da sich Russland schlecht von sich selbst abgrenzen kann, muss anderer fester Grund gefunden werden.

Versuche dazu hat es in den vergangenen 25 Jahren, also seit dem Ende der Sowjetunion, immer wieder gege- 
ben. Meist sind sie nach kurzer Zeit im Sande verlaufen. In den 1990er Jahren dominierte die Diskussion über eine »russische Idee«. Später verdeckten die Tschetschenienkriege alle Möglichkeiten eines zukunftsgerichteten Diskurses. Die Erfahrungen mit dem Auseinanderbrechen der Sowjetunion und den zentrifugalen Tendenzen in der Russischen Föderation unter Präsident Jelzin wirken heute weit mehr als Trauma weiter, denn als Möglichkeit, daraus etwas zu lernen. Entsprechend wenig Interesse an einer Öffnung dieser Pandorabüchse gibt es im Kreml. Oder besser: Gab es bisher im Kreml, denn das scheint sich gerade zu ändern.

Ende Oktober nun hat Wjatscheslaw Michailow, Professor der Russischen Präsidialen Akademie für Nationalwirtschaft und Öffentliche Verwaltung und von 1995 bis 2000 Nationalitätenminister, auf einer Sitzung des präsidialen Rats für Nationalitätenangelegenheiten vorgeschlagen, ein Gesetz über eine »russländische Nation« zu verabschieden. Der bei der Sitzung anwesende Präsident Putin reagierte sofort und positiv: Das sei sehr richtig und müsse gemacht werden. Man müsse konkret darüber nachdenken »und ganz praktisch zu arbeiten beginnen."Worum geht es?

In einem Anfang November erschienenen programmatischen Text führte Michajlow, gemeinsam mit dem Oberhaupt der Teilrepublik Dagestan Ramasam Abdulatipow, seine Idee dann näher aus (<https://life.ru/t/ мнения/925148/rossiiskaia_natsiia_--_eto_tsiel>). Der unklare Begriffs des »multinationalen Volkes« versuche den falschen Gegensatz von »ethnischer und bürgerlicher Nation« zu überwinden, schaffe das aber nicht. Dagegen setzen die Autoren den Begriff einer »russländischen Nation« (russisch: »rossijskaja nazija«).

Hier ist zunächst ein kleiner sprachlicher Einschub nötig. Das russische Wort »russkij«/»russisch» bezeichnet eng das kulturelle und ethnische Russischsein. Tataren oder Tschetschenen zum Beispiel, deren Republiken Teil der Russischen Föderation und deren Bewohner damit russische Staatsbürger sind, sind keine »Russen« im Sinn dieses Wortes. Dagegen wird in Bezug auf die russische Staatlichkeit das Wort "rossijskij» benutzt, dass im Alltag ebenfalls mit »russisch«ins Deutsche übersetzt wird (auch die Russlandanalysen gehen so vor). Wissenschaftlich dagegen hat sich zur besseren Unterscheidung hierfür die Übersetzung "russländisch" durchgesetzt. Ich werde diese Unterscheidung im Folgenden auch machen.

Michailow und Apdulatipow postulieren also eine »russländische Nation«. Dabei bestehen sie darauf, dass das keine ausschließlich staatsbürgerliche Konstruktion sein, sondern ein ethnischer Begriff. Durch die lange, enge und besondere Verflechtung zwischen den ethnischen Russen und den anderen in Russland lebenden Völkern, zu der die (im Gegensatz zu den anderen euro- päischen Kolonialmächten) inklusive russische Kolonialpolitik geführt habe, sei es zu einer Verschmelzung dieser Ethnien unter Führung des russischen Volkes gekommen und so sei ein neues Volk entstanden, eben das »russländische«.

Diese ganze Initiative erinnert bis in die Wortwahl sehr an die Versuche, in der Sowjetunion ebenfalls ein homogenes Staatsvolk zu generieren, eben das »sowjetische«. Begonnen hatte das unter Stalin, der im Krieg die Russen zu den "älteren Brüdern" der anderen in Russland lebenden Völker bestimmt hatte. Daraus wurde das "sowjetische Volk». Sonderlich nachhaltig waren diese Versuche eine supraethnische Gemeinschaft $\mathrm{zu}$ formen allerdings nicht. Das dürfte auch den Strategen im Kreml nicht verborgen geblieben sein. Warum bekommt dann aber einen Wiederauflage in neuem Gewand die Unterstützung von Wladimir Putin? (Das ganze Setting - Michajlow leitete jahrelang eine Arbeitsgruppe des Nationalitätenrats zu diesem Thema; dazu die öffentliche Präsentation in Putins Anwesenheit - schaut nicht so aus als ob das eine spontane Aktion war, von der sich Putin hat überrumpeln lassen). Mir fallen auf diese Frage drei mögliche Antworten ein.

Zum Einen haben wir es mit einem tatsächlichen Problem zu tun, das zudem mit einem kollektiven Trauma belastet ist. Die Sowjetunion ist entlang der institutionell bestehenden, ethnisch-national definierten Trennlinien auseinander gebrochen. Die Angst, Russland könne das Gleiche passieren, sitzt vom Anfang des neuen Russlands an fest im Nacken nicht nur der jeweiligen Machthaber, sondern auch einer großen Mehrheit der Bevölkerung. Nicht zuletzt deshalb hat es immer wieder Versuche gegeben, die ein wenig taschenspielertrickartige Formel vom »multinationalen Volk« mit etwas mehr Leben zu versehen. Allerdings sind alle, zumindest bisher, daran gescheitert, dass sie (fast notwendiger Weise) zu einer Stärkung eines spezifisch russischen Nationalismus geführt haben anstatt ein russländisches Gemeinschaftsgefühl zu stärken. Im Gegenzug verstärken sich gleichzeitig immer untergründige und gegenläufige tatarische, tschetschenische oder andere nationalistische Tendenzen. Überdeckt wurden diese Probleme in der 2000 Jahren durch das hohe wirtschaftliche Wachstum und seit 2014 durch die patriotische Mobilisierung in Folge von Krimannexion, Krieg in der Ostukraine und vermeintlichem neuen Kalten Krieg mit dem "Westen«. Doch die Wirkung der Krimannexion auf die Zustimmungszahlen für Putin Herrschaft ebbt seit einiger Zeit schon wieder ab, zwar langsam aber stetig. Es könnte also sein, dass durch die Diskussion über ein russländisches Volk nun versucht wird dem entgegen zu steuern. 
Zum Zweiten haben die Euphorie nach der Krimannexion und auch die in den Anfängen des Kriegs in der Ostukraine sprießenden Phantasien über die Schaffung eines Novorossija an der Schwarzmeerküste vom Donbas bis nach Odessa, einem genuinen, wenn auch vulgären, vor allem aber vom Kreml weit schwieriger zu kontrollierenden Nationalismus in die Hände gespielt. Ein solcher Nationalismus mit überzeugten (und damit auch in großen Teilen der Bevölkerung überzeugenden) Akteuren hätte mit der Zeit zu einer echten Gefahr für die Putinsche Herrschaft werden können. Das wurde offenbar auch im Kreml gemerkt und recht schnell wieder einzufangen versucht. Die meisten der noch 2014 in Russland als »Helden« gefeierten »Kämpfer» in der Ostukraine sind inzwischen abgesetzt, weggelobt oder tot. Doch die nationalpatriotische Wende verlangt danach die dadurch entstandenen Leerstellen zu besetzen. Auch hierhin könnte die Michailow-Initiative zielen.

Die dritte mögliche Antwort, die mir in den Kopf kommt, ist etwas komplizierter und zugegebenermaßen ein wenig kremnologisch. Das von Michajlow und Abdulatipow vorgeschlagene Gesetz hätte, würde es angenommen und von Putin unterzeichnet, einen entscheidenden Nachteil. Es würde in die Verfassung eingreifen, ohne die Verfassung zu ändern. Mehr noch: Es würde nicht einfach nur allgemein in die Verfassung eingreifen, sondern in einen ihrer noch einmal besonders gegen willkürliche Änderungen geschützten Abschnitte. Wollte man den Begriff der russländischen Nation tatsächlich in der Verfassung verankern, reichte die bei einfachen Verfassungsänderungen notwendige 60-prozentige Mehrheit der Abgeordneten von Staatsduma und Föderationsrat nicht aus. Vielmehr müsste dann, so fordert es Artikel 135, Absatz 2, zusätzlich eine Verfassungsversammlung einberufen werden und zustimmen. An dieser Stelle wird es noch komplizierter, denn der gleiche Absatz verweist auf ein Verfassungsgesetz, das Näheres regeln soll. Dieses Verfassungsgesetz aber gibt es auch 23 Jahre nach Annahme der Verfassung im Dezember 1993 immer noch nicht.

Die russländische Nation in die Verfassung zu bringen, könnte also ein guter, von kaum jemandem ernsthaft in Frage gestellter Vorwand sein, dieses Gesetz endlich zu verabschieden. Und wer weiß schon, was sonst alles noch heraus kommt, wenn die Verfassungsversammlung erst einmal tagt.

Diesen und andere Texte finden Sie aufJens Siegerts Russlandblog < http://russland.boellblog.org/>. 


\section{3. - 17. November 2016}

\begin{tabular}{|c|c|}
\hline 016 & $\begin{array}{l}\text { Vor der russischen Botschaft in London findet eine Demonstration gegen Russlands Vorgehen im } \\
\text { Syrienkrieg statt. Die Botschaft protestiert beim britischen Außenministerium und wertet die Aktio- } \\
\text { nen als Folge des Aufrufs des britischen Außenministers Boris Johnson, vor der russischen Botschaft } \\
\text { gegen das russische militärische Vorgehen in Syrien zu protestieren. }\end{array}$ \\
\hline 16 & $\begin{array}{l}\text { Rund } 500 \text { Personen protestieren vor der Botschaft Großbritanniens in Moskau gegen die Demonstra- } \\
\text { tionen vor der russischen Botschaft in London, die am Vortag stattgefunden haben. Sie halten Plakate } \\
\text { mit den Aufschriften "Nieder mit den Doppelstandards« und »Unsere Diplomaten sind unantastbar». }\end{array}$ \\
\hline 04.11 .2016 & $\begin{array}{l}\text { Zum Feiertag der Nationalen Einheit weihen Präsident Wladimir Putin und Patriarch Kirill am Mos- } \\
\text { kauer Kreml ein Denkmal für Großfürst Wladimir ein. In der Regierungszeit Wladimirs war die Kie- } \\
\text { wer Rus, der Vorläufer des Moskauer Großfürstentums, christianisiert worden. Rund } 85.000 \text { Menschen } \\
\text { nehmen an den offiziellen Feierlichkeiten zum Tag der Nationalen Einheit teil. }\end{array}$ \\
\hline 04.11 .2016 & $\begin{array}{l}\text { Im Bezirk Ljublino am Stadtrand Moskaus versammeln sich wie in den vergangenen Jahren mehrere } \\
\text { Hundert Nationalisten und Rechtsextreme zum sogenannten »Russischen Marsch«. Sieben Personen } \\
\text { werden wegen Verstößen gegen das Versammlungsrecht festgenommen. }\end{array}$ \\
\hline 04.1 & $\begin{array}{l}\text { Im syrischen Aleppo beginnt die von der russischen und syrischen Regierung einseitig ausgerufene } \\
\text { Feuerpause. Die Gegenseite geht auf das russische Angebot nicht ein. Beim Beschuss eines russischen } \\
\text { Transporthubschraubers werden zwei russische Soldaten leicht verletzt. }\end{array}$ \\
\hline 05.11 & das Amt des Stellvertretenden Direktors des Föderalen Sicherheitsdiens \\
\hline 05.11 & $\begin{array}{l}\text { Die Organisation "Grannies4Equality« führt vor der russischen Botschaft in Dublin eine Protestaktion } \\
\text { gegen das russische Vorgehen im Syrienkrieg durch. Die Beteiligten laden in rote Farbe getränkte Pup- } \\
\text { pen ab und hängen einen Banner auf, auf dem das militärische Vorgehen in Syrien angeprangert wird. }\end{array}$ \\
\hline 05.1 & $\begin{array}{l}\text { Mitglieder der oppositionellen nichtregistrierten Partei „Anderes Russland«protestieren vor dem ukrai- } \\
\text { nischen Konsulat in St. Petersburg gegen die Politik der ukrainischen Regierung in der Ostukraine. Sie } \\
\text { werfen Rauchbomben und Tierknochen auf das Gelände. Es kommt zu einer Verhaftung. }\end{array}$ \\
\hline 06.1 & $\begin{array}{l}\text { Ministerpräsident Dmitrij Medwedew empfängt seinen chinesischen Amtskollegen Li Keqiang in } \\
\text { St. Petersburg. Zum Auftakt des zweitägigen Treffens besuchen die beiden Ministerpräsidenten die } \\
\text { Eremitage. }\end{array}$ \\
\hline 07.11 .2016 & $\begin{array}{l}\text { Ind } 1500 \text { Anhänger der Kommunistischen Partei Russlands (KPRF) feiern in Moskau mit einem } \\
\text { nzug den 99. Jahrestag der Oktoberrevolution. }\end{array}$ \\
\hline 07.11 .2016 & $\begin{array}{l}\text { Ministerpräsident Dmitrij Medwedew und sein chinesischer Amtskollege Li Keqiang verabreden bei } \\
\text { Regierungskonsultationen in St. Petersburg den Ausbau der bilateralen Handelsbeziehungen. }\end{array}$ \\
\hline 09.11 .2016 & $\begin{array}{l}\text { Präsident Wladimir Putin gratuliert Donald Trump zum Sieg bei den Präsidentschaftswahlen in den } \\
\text { USA. }\end{array}$ \\
\hline 10.11 .2016 & $\begin{array}{l}\text { Israels Ministerpräsident Benjamin Netanjahu empfängt seinen Amtskollegen Dmitrij Medwedew zu } \\
\text { Gesprächen in Israel. Thema ist unter anderem der Syrien-Konflikt und der Kampf gegen die Terror- } \\
\text { miliz Islamischer Staat. Beide Länder unterzeichnen zudem vier Abkommen in den Bereichen Land- } \\
\text { wirtschaft, Zoll, High-Tech und Wohnungsbau. }\end{array}$ \\
\hline 10.11 .2016 & $\begin{array}{l}\text { Das Moskauer Stadtgericht befindet die Sperrung des Online-Karriereportals LinkedIn in Russland für } \\
\text { rechtmäßig. Der Föderale Dienst für die Aufsicht im Bereich der Kommunikation, Informationstech- } \\
\text { nologie und Massenkommunikation (Roskomnadsor) hatte dies angeordnet, da sich LinkedIn bisher } \\
\text { geweigert hatte, personenbezogene Daten russischer Bürger auf russischem Staatsgebiet zu speichern } \\
\text { wie dies per Gesetz vorgesehen ist. }\end{array}$ \\
\hline
\end{tabular}




\begin{tabular}{|c|c|}
\hline 10.1 & $\begin{array}{l}\text { e Duma verabschiedet in dritter Lesung ein Gesetz über eine Einmalzahlung zusätzlich zur Rente } \\
\text { Höhe von } 5.000 \text { Rubel, die im Januar } 2017 \text { ausgezahlt werden soll. Die Zahlung ersetzt die reguläre } \\
\text { ntenanpassung, die die Inflation ausgleichen soll. Der Wechsel zur Einmalzahlung ist Teil der Spar- } \\
\text { litik, mit der das Haushaltsdefizit verringert werden soll. }\end{array}$ \\
\hline 10.1 & $\begin{array}{l}\text { e russische Föderale Kartellbehörde (FAS) leitet gegen das Unternehmen Microsoft ein Verfahren } \\
\text { gen Missbrauchs seiner beherrschenden Marktstellung ein. }\end{array}$ \\
\hline 11.1 & $\begin{array}{l}\text { Nach seinem Besuch in Jerusalem reist Ministerpräsident Dmitrij Medwedew für Gespräche mit dem } \\
\text { Palästinenserpräsidenten Mahmud Abbas nach Jericho. Im Rahmen der Gespräche ruft Medwedew } \\
\text { Israel und die Palästinenser zu neuen direkten Gesprächen auf und fordert eine aktivere Rolle der USA } \\
\text { im Nahost-Friedensprozess. }\end{array}$ \\
\hline 11.11 & $\begin{array}{l}\text { In mehreren Städten Russlands protestieren Fernfahrer gegen das Mautsystem »Platon«. In Chimki im } \\
\text { Moskauer Umland werden mehr als zehn Teilnehmer und ein Mitarbeiter des Fernsehsenders »Doschd» } \\
\text { sowie ein Korrespondent der Zeitung »Nowaja Gaseta» wegen Verstößen gegen das Versammlungs- } \\
\text { recht festgenommen. }\end{array}$ \\
\hline 12.1 & $\begin{array}{l}\text { Der Inlandsgeheimdienst (FSB) nimmt in Moskau und St. Petersburg zehn Personen fest, die mutmaßlich } \\
\text { in Verbindung mit der Terrormiliz »Islamischer Staat« stehen und Anschlagspläne in den beiden } \\
\text { Großstädten verfolgt haben sollen. }\end{array}$ \\
\hline 14.1 & $\begin{array}{l}\text { Nach Angaben des Kreml verständigen sich Präsident Wladimir Putin und der designierte US-Präsi- } \\
\text { dent Donald Trump in einem ersten Telefongespräch auf beidseitige Bemühungen zur Verbesserung } \\
\text { der bilateralen Beziehungen. Thema des Gesprächs war zudem der Syrien-Konflikt und der gemein- } \\
\text { same Kampf gegen den internationalen Terrorismus. }\end{array}$ \\
\hline 14.1 & $\begin{array}{l}\text { as russische Verteidigungsministerium bestätigt den Absturz eines Trägerflugzeugs vom Typ MiG-29K } \\
\text { enige Kilometer entfernt vom Flugzeugträger »Admiral Kusnezow«, der im Mittelmeer stationiert ist. } \\
\text { s Absturzursache werden technische Fehler genannt. Der Pilot konnte sich offiziellen Angabe zufolge } \\
\text { urch einen Schleudersitz retten und ist unverletzt. }\end{array}$ \\
\hline 14.11 & $\begin{array}{l}\text { äsident Wladimir Putin weist das Verteidigungsministeri } \\
\text { e über die Bildung einer gemeinsamen Streitkräftegruppe } \\
\text { Angriffen zu führen. }\end{array}$ \\
\hline 15.11 & $\begin{array}{l}\text { Präsident Wladimir Putin entlässt den Minister für wirtschaftliche Entwicklung, Aleksej Uljukajew, } \\
\text { nachdem dieser in der Nacht auf Dienstag festgenommen wurde. Nach Angaben des Strafermittlungs- } \\
\text { komitee soll Uljukajew umgerechnet 1,8 Millionen Euro Bestechungsgelder gefordert haben, um den } \\
\text { Verkauf der } 50 \text { Prozent Staatsanteile des Konzerns »Baschneft« an "Rosneft« im Oktober dieses Jahres } \\
\text { zu genehmigen. Uljukajew bestreitet die Vorwürfe und bezeichnet die Aktion der Strafverfolgungsbe- } \\
\text { hörden als Provokation. }\end{array}$ \\
\hline 15.11.2016 & $\begin{array}{l}\text { Der Inlandsgeheimdienst (FSB) nimmt fünf mutma } \\
\text { scher Staat nahestehen und Anschläge in Inguscheti }\end{array}$ \\
\hline 16.11 .2016 & $\begin{array}{l}\text { Auf Anordnung von Präsident Wladimir Putin zieht Russland seine Unterschrift unter das Statut des } \\
\text { Internationalen Strafgerichtshof (ICC) zurück. Russland hatte das sogenannte »Römische Statut« im } \\
\text { Jahr } 2000 \text { unterschrieben, der Vertrag wurde aber bislang nicht ratifiziert. Begründet wird dieser Rück- } \\
\text { zug damit, dass Russland seine nationalen Interessen wahren wolle. }\end{array}$ \\
\hline 16.11 .2016 & $\begin{array}{l}\text { Der Menschenrechtsausschuss der UN-Vollversammlung verabschiedet eine Resolution, in der er Men- } \\
\text { schenrechtsverstöße auf der von Russland annektierten Krim verurteilt. Für den Text stimmten in New } \\
\text { York } 73 \text { Länder, } 23 \text { Staaten votierten dagegen und } 76 \text { Mitgliedsländer enthielten sich. In der Resolu- } \\
\text { tion wird Russland dazu aufgerufen, die Diskriminierung zu beenden und UN-Beobachtern für ein } \\
\text { Menschenrechtsmonitoring Zutritt zur Halbinsel Krim zu gewähren. }\end{array}$ \\
\hline
\end{tabular}




\begin{tabular}{|l|l|}
\hline 16.11 .2016 & $\begin{array}{l}\text { Das oberste Gericht Russlands hebt das Urteil gegen den Oppositionspolitiker Alexej Nawalnyj im Fall } \\
\text { »Kirowles« auf, mit dem er } 2013 \text { zunächst zu fünf Jahren Haft und später zu einer Bewährungsstrafe } \\
\text { verurteilt wurde. Es soll nun eine Wiederaufnahme des Betrugsverfahrens erfolgen. Die Entscheidung } \\
\text { des Gerichts geht aus einer Prüfung des Urteils des Europäischen Gerichtshofs für Menschenrechte } \\
\text { hervor, der die Einstellung des Verfahrens gefordert hatte. }\end{array}$ \\
\hline 17.11 .2016 & $\begin{array}{l}\text { Der Föderale Dienst für die Aufsicht im Bereich der Kommunikation, Informationstechnologie und } \\
\text { Massenkommunikation (Roskomnadsor) sperrt das Online-Karriereportal LinkedIn in Russland. Zuvor } \\
\text { hatte das Moskauer Stadtgericht eine Sperrung wegen Verletzung des Gesetzes über personenbezogene } \\
\text { Daten für rechtmäßig befunden. }\end{array}$ \\
\hline
\end{tabular}

Sie können die gesamte Chronik seit 1964 auch auf <http://www.laender-analysen.de/russland/> unter dem Link »Chronik»lesen.

Die Russland-Analysen werden von Mangold Consulting GmbH unterstützt.

\section{MANGOLD}

C o n s u l t i n g

Herausgeber: Forschungsstelle Osteuropa an der Universität Bremen, Zentrum für Osteuropa- und internationale Studien und Deutsche Gesellschaft für Osteuropakunde Die Meinungen, die in den Russland-Analysen geäußert werden, geben ausschließlich die Auffassung der Autoren wieder. Abdruck und sonstige publizistische Nutzung sind nach Rücksprache mit der Redaktion gestattet. Redaktion: Hans-Henning Schröder (verantwortlich), Julia Glathe Sprachredaktion: Hartmut Schröder

$$
\text { Satz: Matthias Neumann }
$$

Russland-Analysen-Layout: Cengiz Kibaroglu, Matthias Neumann und Michael Clemens Alle Ausgaben der Russland-Analysen sind mit Themen- und Autorenindex archiviert unter www.laender-analysen.de

Die Russland-Analysen werden im Rahmen eines Lizenzvertrages in das Internetangebot der Bundeszentrale für politische Bildung (www.bpb.de) aufgenommen. Die Russland-Analysen werden im Rahmen der Datenbank World Affairs Online (WAO) ausgewertet und sind im Portal IREON www.ireon-portal.de recherchierbar. ISSN 1613-3390 @ 2016 by Forschungsstelle Osteuropa, Bremen

Forschungsstelle Osteuropa • Länder-Analysen • Klagenfurter Str. 8 • 28359 Bremen • Telefon: + 49 421-218-69600 • Telefax: + 49 421-218-69607 e-mail: laender-analysen@uni-bremen.de•Internet-Adresse: http://www.laender-analysen.de/russland/ 

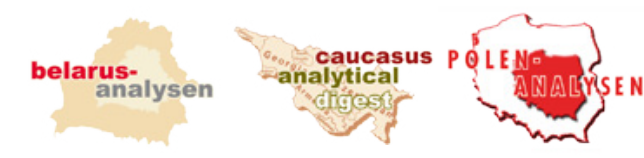

\section{Kostenlose E-Mail-Dienste der Forschungsstelle Osteuropa und ihrer Partner auf www.laender-analysen.de}

Die Länder-Analysen bieten regelmäßig im kostenlosen Abonnement kompetente Einschätzungen aktueller politischer, wirtschaftlicher, sozialer und kultureller Entwicklungen in Ostmitteleuropa und der GUS. Sie machen das Wissen, über das die wissenschaftliche Forschung in reichem Maße verfügt, für Politik, Wirtschaft, Medien und die interessierte Öffentlichkeit verfügbar. Autoren sind internationale Fachwissenschaftler und Experten. Die Redaktionen der Länder-Analysen bestehen aus Wissenschaftlern mit langjähriger Forschungserfahrung.

Die einzelnen Länder-Analysen werden von der Forschungsstelle Osteuropa an der Universität Bremen und der Deutschen Gesellschaft für Osteuropakunde herausgegeben. Partner der deutschsprachigen Analysen zur postsowjetischen Region ist das Zentrum für Osteuropa- und internationale Studien, Partner der Polen-Analysen ist das Deutsche Polen-Institut. Partner der englischsprachigen Analysen ist die ETH Zürich.

Die Länder-Analysen bieten regelmäßig Kurzanalysen zu aktuellen Themen, ergänzt um Grafiken und Tabellen sowie Dokumentationen. Zusätzlich gibt es eine Chronik aktueller Ereignisse. Alle Länder-Analysen sind auch mit Archiv und Indizes online verfügbar unter $<$ www.laender-analysen.de $>$.

\section{Belarus-Analysen}

Erscheinungsweise: zweimonatlich

Abonnement unter: <http://www.laender-analysen.de/belarus/>

\section{Caucasus Analytical Digest}

In englischer Sprache. Erscheinungsweise: monatlich

Abonnement unter: <http://www.css.ethz.ch/en/publications/cad.html>

\section{Polen-Analysen}

Erscheinungsweise: zweimal monatlich

Abonnement unter: <http://www.deutsches-polen-institut.de/newsletter/polen-analysen/>

Auch als App für Android ${ }^{\mathrm{TM}}$ (ab Januar 2016) kostenlos auf Google Play ${ }^{\mathrm{TM}}$.

\section{Russland-Analysen}

Erscheinungsweise: zweiwöchentlich

Abonnement unter: <http://www.laender-analysen.de/russland/>

Auch als App für Android (ab Januar 2016) kostenlos auf Google Play.

\section{Russian Analytical Digest}

In englischer Sprache. Erscheinungsweise: zweimal monatlich

Abonnement unter: <http://www.css.ethz.ch/en/publications/rad.html>

\section{Ukraine-Analysen}

Erscheinungsweise: zweimal monatlich

Abonnement unter: <http://www.laender-analysen.de/ukraine/>

Auch als App für Android (ab Januar 2016) kostenlos auf Google Play.

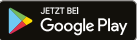

\section{Zentralasien-Analysen}

Erscheinungsweise: monatlich

Abonnement unter: <http://www.laender-analysen.de/zentralasien/>

Auch als App für Android (ab Januar 2016) kostenlos auf Google Play.

\section{Bibliographische Dienste}

Die Bibliographien informieren über englisch- und deutschsprachige wissenschaftliche Neuerscheinungen zu Belarus, Russland, Ukraine sowie zu den zentralasiatischen und kaukasischen Staaten. Erfasst werden jeweils die Themenbereiche Politik, Außenpolitik, Wirtschaft und Soziales.

Erscheinungsweise: viermal jährlich

Abonnement unter: <http://www.laender-analysen.de/bibliographies $>$ 